Metal doped hybrid silica for hydrothermally stable hydrogen separation membranes 


\section{METAL DOPED HYBRID SILICA FOR}

HYDROTHERMALLY STABLE HYDROGEN SEPARATION MEMBRANES

Marcel ten Hove 


\section{Promotiecommissie:}

Prof.dr.ir. J.W.M. Hilgenkamp (Voorzitter)

Prof.dr.ir. A. Nijmeijer (Promotor)

Prof.dr. A.J.A. Winnubst (Promotor)

Prof.dr.ir. M. van Sint Annaland

Prof.dr. F Kapteijn

Prof.dr.ir. J.E. ten Elshof

Prof.dr. G. Mul

Prof.dr. W.A. Meulenberg

\section{Universiteit Twente}

Universiteit Twente

Universiteit Twente

Technische Universiteit Eindhoven

Technische Universiteit Delft

Universiteit Twente

Universiteit Twente

Universiteit Twente

The research described in this thesis was carried out in the Inorganic Membrane group and the MESA+ Institute for Nanotechnology at the University of Twente, Enschede, the Netherlands. This project was financially supported by ADEM, A Green Deal in Energy Materials of the Ministry of Economic Affairs of The Netherlands(www.adem-innovationlab.nl).

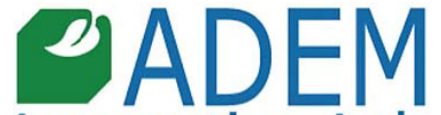
Innovation Lab

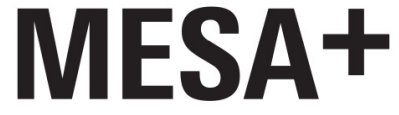

INSTITUTE FOR NANOTECHNOLOGY

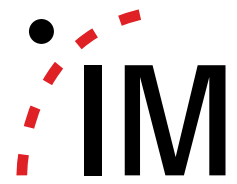

Metal doped hybrid silica for hydrothermally stable hydrogen separation membranes ISBN: 978-90-365-4226-5

DOI: $10.3990 / 1.9789036542265$

Copyright (C) 2016 by Marcel ten Hove

Printed by: Gildeprint Drukkerijen

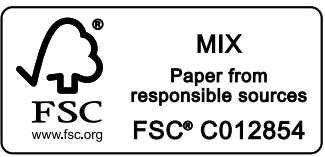




\title{
METAL DOPED HYBRID SILICA FOR HYDROTHERMALLY STABLE HYDROGEN SEPARATION MEMBRANES
}

\author{
PROEFSCHRIFT
}

ter verkriijging van

de graad van doctor aan de Universiteit Twente, op gezag van de rector magnificus, prof. dr. H. Brinksma, volgens besluit van het College voor Promoties in het openbaar te verdedigen op woensdag 23 november om 14:45 uur

door

Marcel ten Hove geboren op 28 april 1984 te Beekbergen 
Dit proefschrift is goedgekeurd door:

Promotor: prof.dr.ir. A. Nijmeijer

Promotor: prof.dr. A.J.A. Winnubst 


\section{Table of Contents}

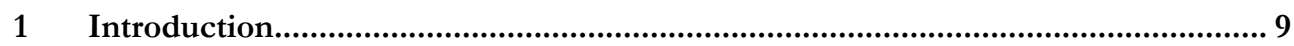

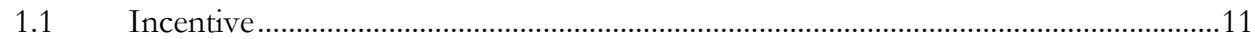

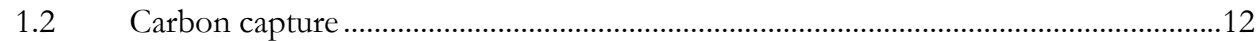

1.3 Membranes for the water gas shift-membrane reactor .............................................15

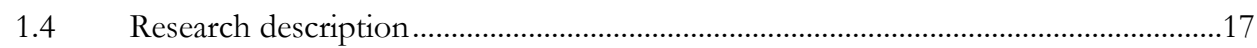

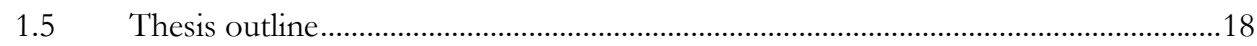

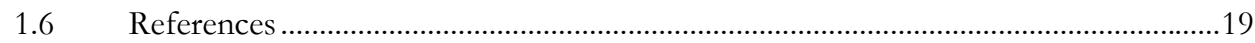

2 Theoretical background and experimental methods .........................................21

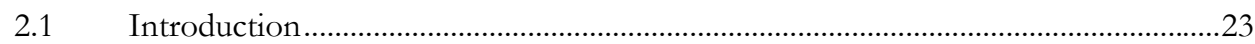

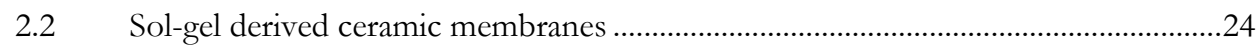

2.3 Membrane fabrication and characterization ........................................................29

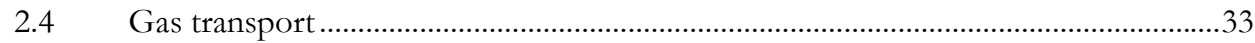

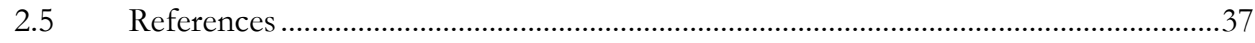

3 Facile synthesis of zirconia doped hybrid organic inorganic silica membranes.....39

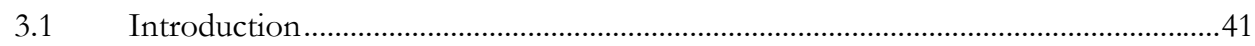

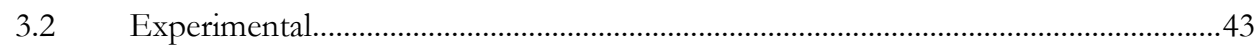

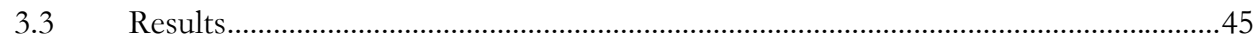

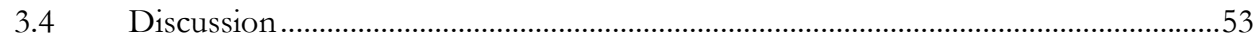

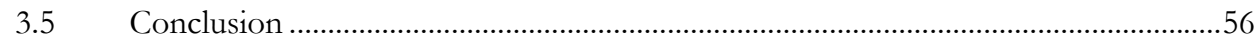

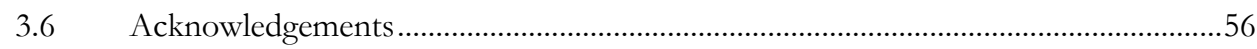

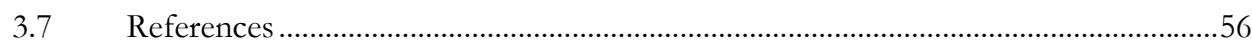

4 Impact of metal doping on the performance of hybrid organic-inorganic silica

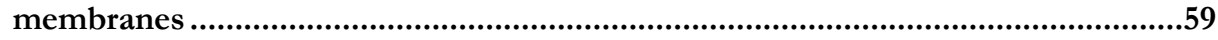

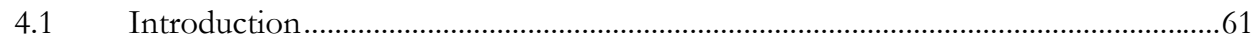

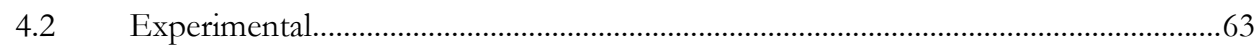

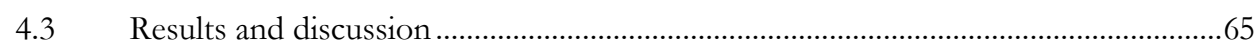

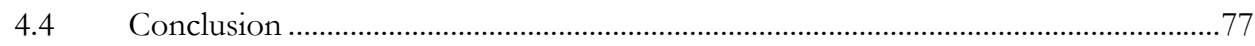

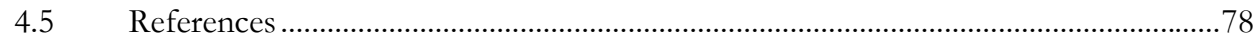


5 Influence of the intermediate layer on the hydrothermal stability of sol-gel derived

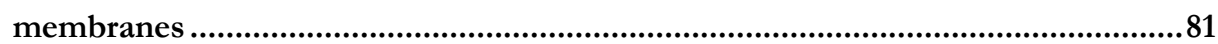

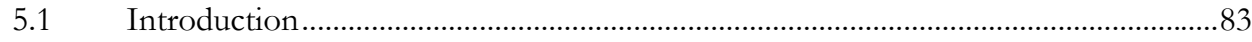

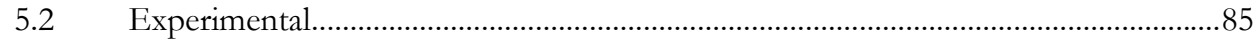

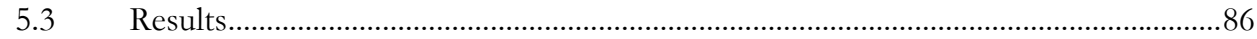

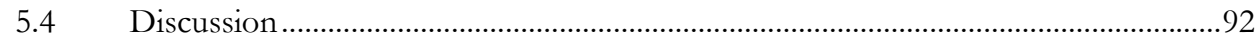

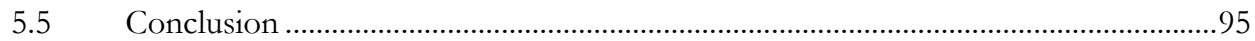

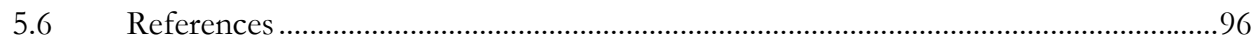

6 Hydrothermal stability of TEOS, BTESE and Zr-BTESE derived membranes ...99

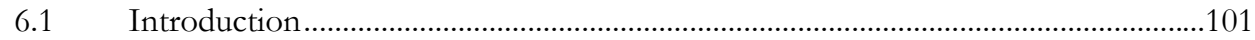

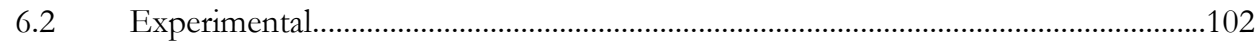

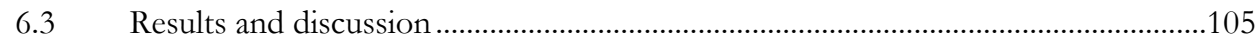

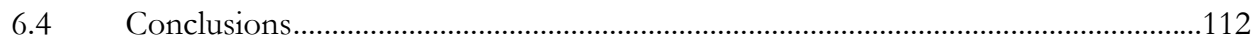

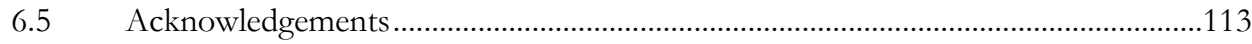

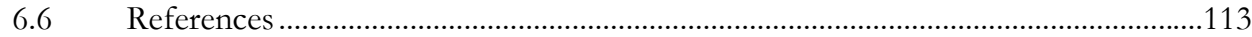

7 Sol gel silica derived microporous membranes for $\mathrm{H}_{2} / \mathrm{CO}_{2}$ separation: current status, limitations and perspectives ..................................................................... 115

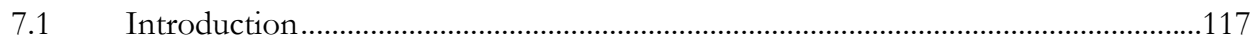

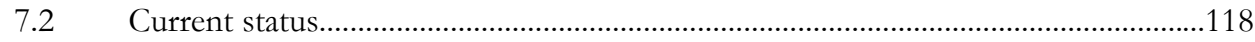

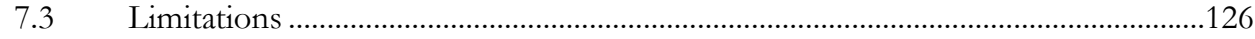

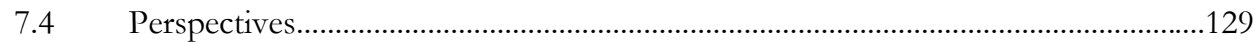

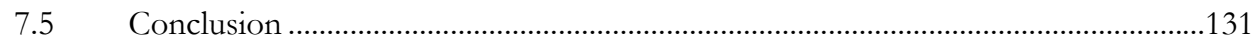

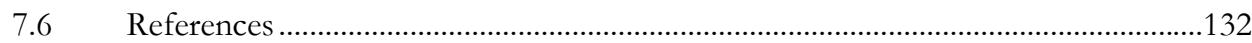

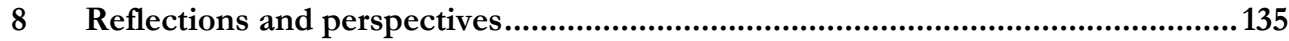

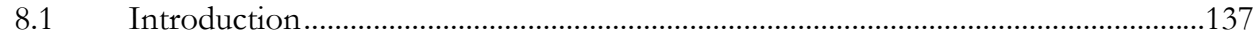

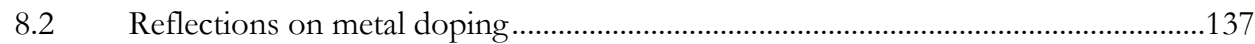

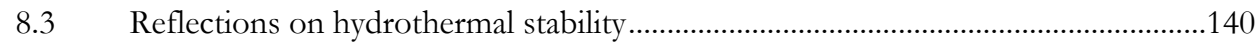

$8.4 \quad$ Reflections on measurement techniques...................................................................141

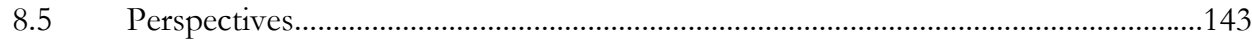

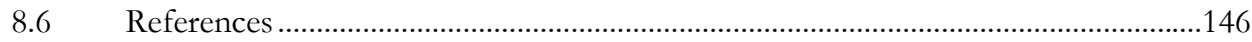




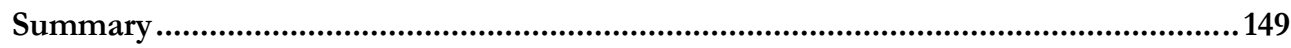

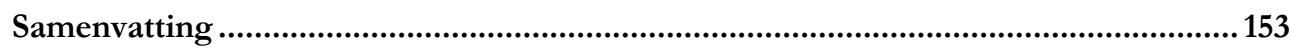

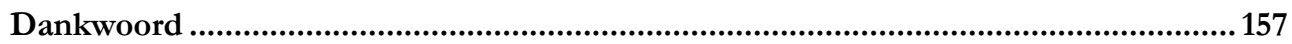





\section{Introduction}


Chapter 1 


\subsection{Incentive}

The world energy demand will continue to rise due to the increasing world population and the increased welfare levels. Therefore it is expected that the electricity production will increase by 93\% from 2010 to 2040 [1]. In Figure 1.1 the electricity generation by fuel type is shown for the period of 2010 to 2040. The expected growth of renewables is $130 \%$ from 2010 to 2040, with as main contributors hydroelectric and wind energy. However, the use of coal and natural gas will continue to increase as well, with a growth of $70 \%$ and $109 \%$ respectively.

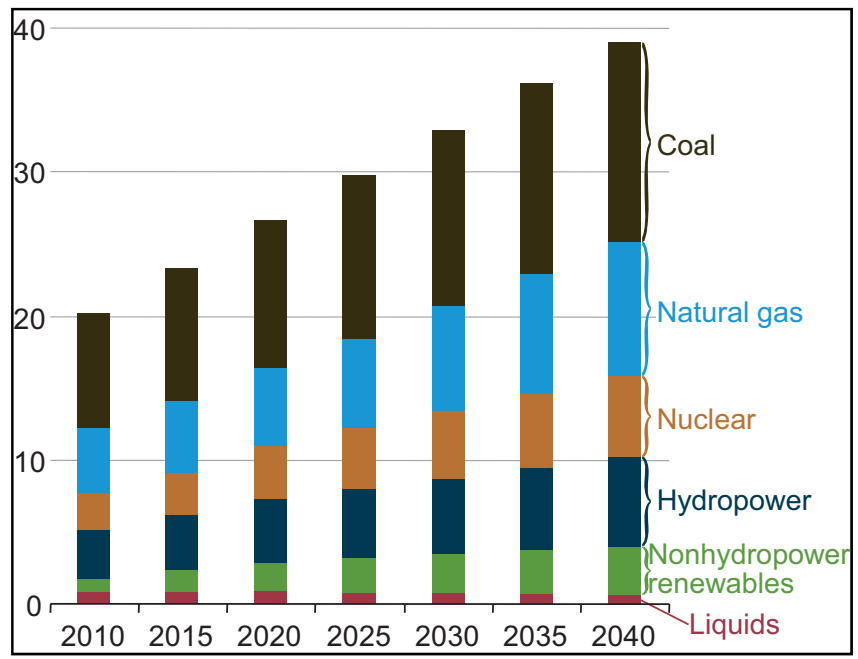

Figure 1.1: World net electricity generation by fuel type, 2010-2040 $\left(10^{12} \mathrm{kWh}\right)$ [1]

The use of coal and natural gas for electricity generation is one of the main sources for $\mathrm{CO}_{2}$ emission, together with liquid fuels that are mostly used for transportation. In Figure 1.2 the projections for $\mathrm{CO}_{2}$ emissions for the three types of fuel are shown. The increase in energy demand clearly leads to an increase in $\mathrm{CO}_{2}$ emissions.

In order to reverse the increase in $\mathrm{CO}_{2}$ emissions, a full transition to renewable energy sources is necessary. However, there are two major technical challenges to overcome before such a transition becomes viable; transport and storage. 


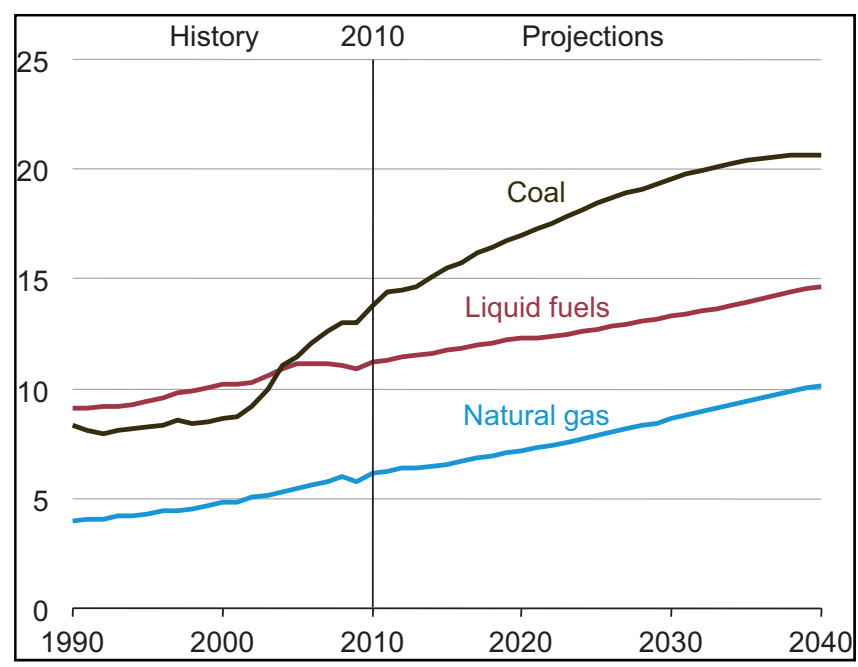

Figure 1.2: World energy-related carbon dioxide emissions by fuel type, $1990-2040\left(10^{12} \mathrm{~kg}\right)[1]$

Electricity from renewable sources are in general not generated at a location that is close to the demand. Wind energy for example is generated most efficiently offshore, which implies that long transport lines are needed. The longer these transport lines are, the more energy losses occur. Besides, the generation from renewable sources is not determined by the actual demand of electricity. For example, the generation of electricity from wind depends on the actual wind power, which can fluctuate heavily and is often not in accordance with electricity demand. Therefore, it is necessary to have local electricity storage.

In order to achieve a reduction in carbon dioxide emissions on a shorter timescale, carbon capture and storage strategies can be used on fossil fuel based power plants. These strategies can also be implemented in other processes that emit carbon dioxide. In such a way carbon emissions can be reduced while a full transition to renewables is being developed.

\subsection{Carbon capture}

There are three different strategies that can be used for carbon capture in the production of electricity: post-combustion, oxyfuel and pre-combustion [2]. An overview of these strategies is given in Figure 1.3. 


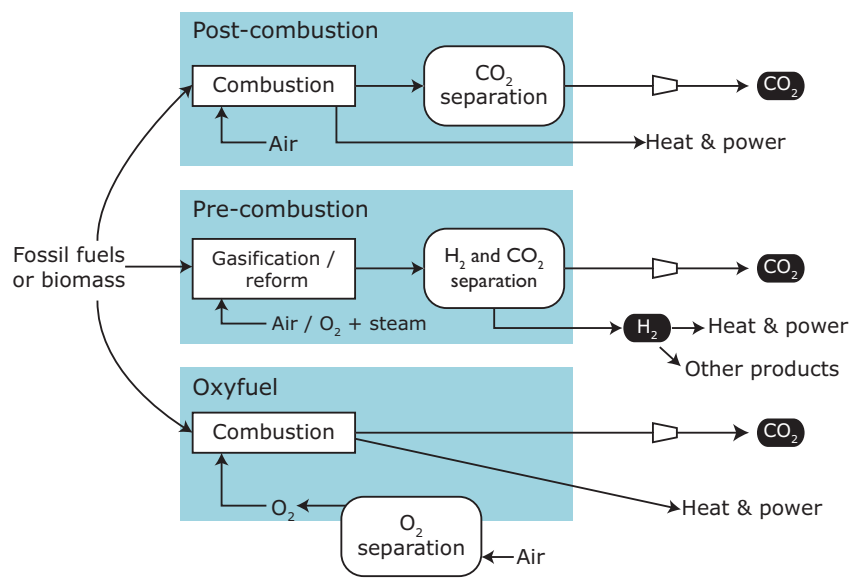

Figure 1.3: Block diagram with the different routes of carbon capture. Illustration adapted from [2]

\subsubsection{Post-combustion}

In post-combustion carbon capture the carbon dioxide is removed from the flue gas that is emitted from the combustion process. The flue gas typically contains a low concentration of carbon dioxide and has a high volumetric flow rate and low pressure. Conventional techniques for $\mathrm{CO}_{2}$ removal are scrubbing with amine solutions like monoethanolamine (MEA) [3]. For membrane separation typically polymeric membranes like polyimides and polyether oxides are used which are selective towards carbon dioxide [4]. Due to the low concentration of carbon dioxide and low pressure the driving force for carbon dioxide removal by membranes is low. Therefore, it is more efficient to use a solvent scrubbing process. Although the energy requirements for $\mathrm{CO}_{2}$ removal are relatively high in post-combustion carbon capture, the process can be retrofitted to existing power plants and is therefore an approach that can be implemented on short term.

\subsubsection{Oxy-fuel}

In the oxyfuel strategy the fuel is burned in a mixture of pure oxygen and carbon dioxide, which is recycled back into the burner to prevent a too high temperature. The flue gas consists of mainly carbon dioxide and water, which can be separated from each other with relative ease [2]. The current commercially available technique to separate oxygen from air is by means of cryogenic distillation. A membrane based option is the use of dense ceramic ion transport 
membranes, which are mainly of the perovskite type [5, 6]. Oxygen transport membranes suffer considerably from a tradeoff between oxygen permeability and carbon dioxide stability, i.e. the higher the oxygen permeability, the lower the stability in carbon dioxide containing atmospheres. Therefore it is important to understand the behavior of those membranes in a carbon dioxide environment and how to improve such membranes [5].

\subsubsection{Pre-combustion}

In pre-combustion carbon capture the fuel is decarbonized before combustion. This is achieved by converting the fuel into hydrogen and carbon dioxide, which are then separated from each other. For a methane based fuel a two-step approach is used; first of all the methane and steam is converted to syngas, which is a mixture of hydrogen and carbon monoxide, by methane steam reforming (MSR) (1). The carbon monoxide in the syngas and steam are converted in to carbon dioxide and additional hydrogen by means of the water gas shift reaction (WGS) (2) [7].

$$
\begin{array}{ll}
\mathrm{CH}_{4}+\mathrm{H}_{2} \mathrm{O} \rightleftharpoons 3 \mathrm{H}_{2}+\mathrm{CO} & \Delta \mathrm{H}=206 \mathrm{~kJ} / \mathrm{mol} \\
\mathrm{CO}+\mathrm{H}_{2} \mathrm{O} \rightleftharpoons \mathrm{CO}_{2}+\mathrm{H}_{2} & \Delta \mathrm{H}=-41 \mathrm{~kJ} / \mathrm{mol}
\end{array}
$$

A product stream of carbon dioxide and hydrogen is left, from which the carbon dioxide has to be removed for storage. The hydrogen can be used as a fuel with water as the combustion product. The conventional method of separating carbon dioxide from hydrogen is by means of a physical absorption process. In this process the carbon dioxide is selectively dissolved in the absorption fluid. Typical solvents that are used are methanol (Rectisol), N-methyl-2-pyrrolidone (Purisol) and polyethylene glycol dimethyl ether (Selexol) [3, 8]. In order to efficiently absorb the carbon dioxide, this absorption process is operated at low temperatures, between $0{ }^{\circ} \mathrm{C}$ and $40{ }^{\circ} \mathrm{C}$. Therefore the product stream that is coming from the WGS, which is typically between $180{ }^{\circ} \mathrm{C}$ and $270{ }^{\circ} \mathrm{C}$ for a low temperature WGS reactor [8], has to be cooled. For a membrane based approach a hydrogen selective membrane like a microporous ceramic membranes or palladium membranes can be used [9]. The advantages of these membranes are that they can be operated at higher temperatures, thus eliminating the need for extensive cooling of the WGS product stream. Another advantage of a membrane for hydrogen/carbon dioxide separation is that such a membrane can also be used integrated in a membrane reactor, where reaction and separation 
takes place in the same unit. A schematic representation of such a water gas shift membrane reactor (WGS-MR) is depicted in Figure 1.4. The use of a WGS-MR has the benefit that the equilibrium of the reaction can be shifted towards the product side due to hydrogen removal, resulting in a higher carbon monoxide conversion [10].

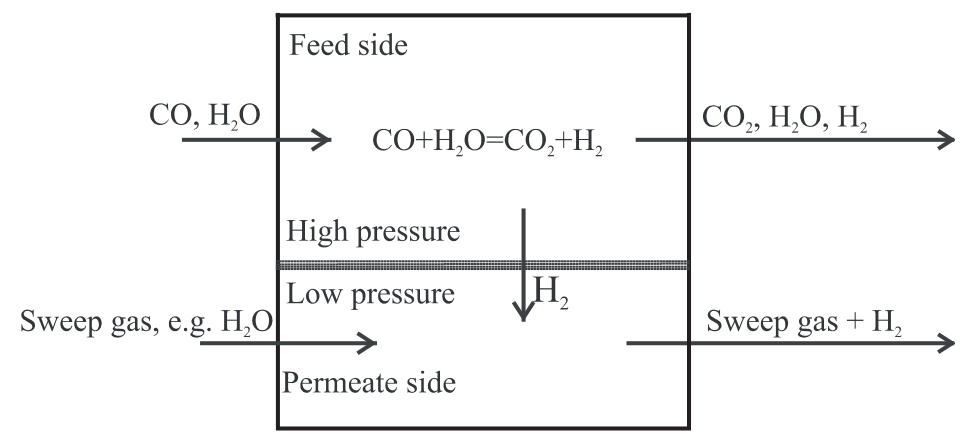

Figure 1.4: Schematic representation of a water gas shift membrane reactor

\subsection{Membranes for the water gas shift-membrane reactor}

In order to successfully operate a water gas shift membrane reactor, the membrane must possess a number of characteristics. First of all, the membrane should have a high hydrogen permeance in order to remove hydrogen from the reactor to facilitate the equilibrium shift. Secondly, the membrane should be hydrogen selective, in order to retain most of the carbon dioxide. Finally, the membrane should be stable under operating conditions, which implies for the water gas shift reaction a temperature range of $250-500{ }^{\circ} \mathrm{C}$, pressures up till 40 bar and stability towards water vapor and impurities like sulfur.

Based on the criteria as given above a number of materials are suitable to be used as a hydrogen selective membrane. The classes of membranes that are of most interest are microporous ceramic or dense metallic membranes. The other classes of hydrogen selective membranes like polymeric and ceramic proton conductors can also be of interest if only separation is needed, but are not interesting for use in a WGS-MR due to temperature constraints. Most polymeric membranes cannot withstand the temperatures as present in a WGS-MR, while for proton conducting membranes temperatures of over $800{ }^{\circ} \mathrm{C}$ are necessary for obtaining a sufficient flux [9]. A number of reviews are written on hydrogen selective membranes in the past few years 
which address the different kinds of membranes and their strengths and limitations [6, 9, 11-16]. Here a brief overview of the most important findings will be given.

Dense metallic membranes based on palladium are interesting based on their high flux and in theory infinite selectivity of hydrogen over other gases. The mechanism of hydrogen permeation is a complex process, which involves dissociation of hydrogen molecules on the surface of feed side the membrane, transport of protons and electrons in the membrane material itself and regeneration of hydrogen molecules on the permeate side [6]. Palladium membranes were produced in the past by rolling a palladium foil around a support. Nowadays plating methods are used to get thin membranes to increase the hydrogen flux. The main issues with palladium based membranes are phase transformations, which can lead to pinholes and cracking, as well as poising by e.g. $\mathrm{H}_{2} \mathrm{~S}$ and $\mathrm{CO}$. Another point that is of concern is coke formation on the membrane when used in a catalytic reactive environment [14].

Microporous ceramic membranes have a drawback over metallic membranes that separation is based on the size of the gas molecules, which leads to a lower selectivity of hydrogen over other gases, especially over $\mathrm{CO}_{2}$. However, they do not suffer from phase transformations and are in general less susceptible to poisoning. Microporous ceramic membranes can basically be divided in two classes: zeolites and amorphous silica based.

Zeolites have a high thermal stability and well defined pore sizes, which allow them to very selectively permeate gases [17]. One of the most used zeolite for gas separation membranes is the MFI type, which includes silicalite-1 and ZSM-5, due to their relative ease of preparation [12, 15]. For the fabrication of these membranes in general two synthesis methods are used; in-situ synthesis, where the zeolites are grown directly onto a support, and a secondary growth method, where zeolite seed particles are deposited onto a support by a coating method, after which the seeds are grown. Although the MFI type is used often for membranes, it is not suitable for separation of smaller gases due to the relative large pore size of $0.56 \mathrm{~nm}$. There are very little zeolites that have a sufficient small pore size for $\mathrm{H}_{2} / \mathrm{CO}_{2}$ separation. However, separation in zeolites is not only based on molecular sieving, but also depends on an adsorption/diffusion mechanism, which can enhance the selectivity as compared to only molecular sieving [11]. With zeolite membranes the biggest challenge is to avoid defects and inter crystalline pores during growth. Zeolite membranes are therefore quite thick $(>1 \mu \mathrm{m})$, especially in comparison to 
amorphous silica membranes $(<200 \mathrm{~nm})$. Therefore the hydrogen permeance of zeolite membranes is relatively low [11].

There are generally two techniques for the preparing amorphous silica based membranes: chemical vapor deposition (CVD) and sol-gel. CVD silica membranes often have a high selectivity, but generally have low fluxes as the resulting membrane has a very dense structure $[18,19]$. Sol-gel derived silica in general membranes have a lower selectivity, but show on the other hand higher fluxes. One of the most used precursors for sol-gel derived silica is tetraethylorthosilicate (TEOS) which can produce membranes with excellent gas separation properties [20]. The main drawback of these type of membranes is their poor hydrothermal stability [21]. On the other hand bridged silsesquioxanes are used to prepare a hybrid organicinorganic silica network that has a high hydrothermal stability [22]. Membranes based on these silsesquioxanes do however show a poor $\mathrm{H}_{2} / \mathrm{CO}_{2}$ selectivity due to the larger pore size if compared from sol gel TEOS-derived membranes [23].

\subsection{Research description}

The research, as described in this thesis, is carried out in the cluster "Catalysis, Membranes and Separations" (CMS) of ADEM (A green Deal in Energy Materials), which is funded by the Dutch ministry of economic affairs. The ADEM program aims to materialize innovations in energy technologies in close collaboration with industry. In the CMS cluster the focus is on material development for technologies that can mitigate the effects of carbon dioxide. By understanding the structure-property relationship of the materials it is possible to gain insight in the performance of such materials under processing conditions.

The focus of this thesis is on the development of a hydrothermally stable microporous membrane that can be used in a WGS-membrane reactor concept. In order to make this reactor concept economically viable, the membrane in this reactor should be able to selectively separate $\mathrm{H}_{2}$ from $\mathrm{CO}_{2}$ and should be stable under operating conditions. For a successful implementation of a hydrogen selective membrane in a power plant with pre-combustion capture technology the membrane should meet the following demands: operating temperatures of $200-450{ }^{\circ} \mathrm{C}$, pressures of 3-4 MPa, a hydrogen permeance of $1.5 \times 10^{-6} \mathrm{~mol} \mathrm{~m}^{-2} \mathrm{~Pa}^{-1} \mathrm{~s}^{-1}$ and $\mathrm{H}_{2} / \mathrm{CO}_{2}$ selectivity of over 60. Furthermore, the membrane should be stable under these conditions in the presence of steam. 
To achieve the above goal a hybrid organic inorganic silica membrane material is used as a platform for further development. Membranes based on 1,2-bis(triethoxysilyl)ethane (BTESE) have already been proven to be hydrothermally stable under pervaporation conditions [24]. However, the $\mathrm{H}_{2} / \mathrm{CO}_{2}$ selectivity of such a membrane is around 4 [25].

\subsection{Thesis outline}

The aim of the work as described in this thesis is the fabrication and characterization of a suitable membrane that can be used in a WGS-MR. This work can be divided into three objectives. The first objective is to understand how metal doping can be utilized to alter the pore structure of a BTESE membrane. The second objective is to understand how the hydrothermal stability of such membranes can be assessed by using simple screening tools. The third objective to critically assess the characterization methods that are used for the determination of membrane performance.

In chapter 2 backgrounds on membrane fabrication and characterization are presented. Furthermore, the experimental techniques used throughout this thesis are discussed.

In chapter 3 a one-step synthesis approach is described for the fabrication of zirconium doped BTESE membranes by using zirconyl nitrate as the zirconium precursor. It is shown that by using this method a fourfold increase in $\mathrm{H}_{2} / \mathrm{CO}_{2}$ selectivity can be obtained in comparison to undoped BTESE membranes.

In chapter 4 a systematic investigation on the influence of doping of several metals to BTESE on gas separation is presented. The influence of metal type, precursor type and dopant concentration is investigated and compared with literature data. This reveals that the synthesis method has a big impact on the gas permeation properties.

In chapter 5 a simple hydrothermal screening test is presented and utilized to analyze the complete membrane system with regard to hydrothermal stability. Especially the effect of a hydrothermal stable BTESE membrane on a hydrothermally unstable $\gamma$-alumina intermediate layer is investigated. Furthermore the effect of phosphorus doping in $\gamma$-alumina on the hydrothermal stability is investigated.

In chapter 6 a hydrothermal testing setup is used to assess the hydrothermal stability of BTESE and zirconium doped BTESE under conditions that more closely resemble the conditions of a 18 
water gas shift reactor. Hydrothermal testing of zirconium doped BTESE led to an increase in $\mathrm{H}_{2} / \mathrm{CO}_{2}$ selectivity, which is further investigated by in-line hydrothermal stability measurements.

In chapter 7 a review is presented on the current status of sol-gel derived microporous membranes, especially with respect to $\mathrm{H}_{2} / \mathrm{CO}_{2}$ separation. The major challenges are identified that are needed to be resolved in order to pursue industrial acceptance.

In chapter 8 reflections on the obtained results in this thesis are made and are used as a basis for recommendations for further research.

\subsection{References}

[1] Energy Information Administration, International Energy Outlook 2013 With Projections to 2040, U.S. Government Printing Office, 2013.

[2] Intergovernmental Panel on Climate Change., Carbon Dioxide Capture and Storage: Special Report of the Intergovernmental Panel on Climate Change, Cambridge University Press, 2005.

[3] J. Black, Cost and Performance Baseline for Fossil Energy Plants: Volume 1: Bituminous Coal and Natural Gas to Electricity, in, 2010.

[4] A. Brunetti, F. Scura, G. Barbieri, E. Drioli, Membrane technologies for CO2 separation, Journal of Membrane Science, 359 (2010) 115-125.

[5] D.W. Chen, Oxygen Transport Membranes: A Material Science and Process Engineering Approach, in, Enschede, 2014, pp. 147.

[6] R. Bredesen, K. Jordal, O. Bolland, High-temperature membranes in power generation with CO2 capture, Chemical Engineering and Processing, 43 (2004) 1129-1158.

[7] P. Häussinger, R. Lohmüller, A.M. Watson, Hydrogen, in: Ullmann's Encyclopedia of Industrial Chemistry, Wiley-VCH Verlag GmbH \& Co. KGaA, 2000.

[8] H. Hiller, R. Reimert, F. Marschner, H.-J. Renner, W. Boll, E. Supp, M. Brejc, W. Liebner, G. Schaub, G. Hochgesand, C. Higman, P. Kalteier, W.-D. Müller, M. Kriebel, H. Schlichting, H. Tanz, H.-M. Stönner, H. Klein, W. Hilsebein, V. Gronemann, U. Zwiefelhofer, J. Albrecht, C.J. Cowper, H.E. Driesen, Gas Production, Wiley-VCH Verlag GmbH \& Co. KGaA, 2000.

[9] F. Gallucci, E. Fernandez, P. Corengia, M.V. Annaland, Recent advances on membranes and membrane reactors for hydrogen production, Chemical Engineering Science, 92 (2013) 40-66.

[10] J. Franz, P. Maas, V. Scherer, Economic evaluation of pre-combustion CO2-capture in IGCC power plants by porous ceramic membranes, Applied Energy, (2014).

[11] J. Caro, M. Noack, P. Kölsch, R. Schäfer, Zeolite membranes - state of their development and perspective, Microporous and Mesoporous Materials, 38 (2000) 3-24.

[12] N.W. Ockwig, T.M. Nenoff, Membranes for Hydrogen Separation, Chemical Reviews, 107 (2007) 4078-4110.

[13] M.-B. Hägg, Membranes in Gas Separation, in: Handbook of Membrane Separations, CRC Press, 2008, pp. 65-106.

[14] G.Q. Lu, J.C. Diniz da Costa, M. Duke, S. Giessler, R. Socolow, R.H. Williams, T. Kreutz, Inorganic membranes for hydrogen production and purification: A critical review and perspective, Journal of Colloid and Interface Science, 314 (2007) 589-603.

[15] M. Pera-Titus, Porous inorganic membranes for CO2 capture: present and prospects, Chem Rev, 114 (2014) 1413-1492.

[16] H. Verweij, Y.S. Lin, J. Dong, Microporous Silica and Zeolite Membranes for Hydrogen Purification, MRS Bulletin, 31 (2006) 756-764.

[17] E.E. McLeary, J.C. Jansen, F. Kapteijn, Zeolite based films, membranes and membrane reactors: Progress and prospects, Microporous and Mesoporous Materials, 90 (2006) 198-220. 
[18] S.-i. Nakao, T. Suzuki, T. Sugawara, T. Tsuru, S. Kimura, Preparation of microporous membranes by TEOS/O3 CVD in the opposing reactants geometry, Microporous and Mesoporous Materials, 37 (2000) $145-152$.

[19] K. Akamatsu, M. Nakane, T. Sugawara, S. Nakao, Performance Under Thermal and Hydrothermal Condition of Amorphous Silica Membrane Prepared by Chemical Vapor Deposition, Aiche Journal, 55 (2009) 2197-2200.

[20] R.M. de Vos, H. Verweij, High-selectivity, high-flux silica membranes for gas separation, Science, 279 (1998) 1710-1711.

[21] M.C. Duke, J.C.D. da Costa, D.D. Do, P.G. Gray, G.Q. Lu, Hydrothermally robust molecular sieve silica for wet gas separation, Advanced Functional Materials, 16 (2006) 1215-1220.

[22] H.L. Castricum, A. Sah, R. Kreiter, D.H.A. Blank, J.F. Vente, J.E. ten Elshof, Hydrothermally stable molecular separation membranes from organically linked silica, Journal of Materials Chemistry, 18 (2008) 2150-2158.

[23] M. Kanezashi, M. Kawano, T. Yoshioka, T. Tsuru, Organic-Inorganic Hybrid Silica Membranes with Controlled Silica Network Size for Propylene/Propane Separation, Industrial \& Engineering Chemistry Research, 51 (2011) 944-953.

[24] H.L. Castricum, A. Sah, R. Kreiter, D.H. Blank, J.F. Vente, J.E. ten Elshof, Hybrid ceramic nanosieves: stabilizing nanopores with organic links, Chem Commun (Camb), (2008) 1103-1105.

[25] H.F. Qureshi, A. Nijmeijer, L. Winnubst, Influence of sol-gel process parameters on the microstructure and performance of hybrid silica membranes, Journal of Membrane Science, 446 (2013) 19-25. 
2 Theoretical background and experimental methods 
Chapter 2 


\subsection{Introduction}

Ceramic gas separation membranes are often multilayered structures. A typical membrane consists of the following layers; a macroporous support, a mesoporous intermediate layer and a microporous separation layer. According to IUPAC the following classification for pore sizes in a material is used [1]:

- Pores larger than $50 \mathrm{~nm}$ are considered macropores

- Pores between 2 and $50 \mathrm{~nm}$ are considered mesopores

- Pores smaller than $2 \mathrm{~nm}$ are considered micropores

The macroporous support is used to provide mechanical strength to the membrane. The pores are larger than $50 \mathrm{~nm}$ to accommodate large gas flows, while still keeping mechanical strength [2]. Typical materials that are used are $\alpha$-alumina, mullite and kaolin. For research purposes often disc shaped membranes are used that have a very well defined surface [3]. These discs can e.g. be made via slip casting, tape casting or extrusion [4]. For upscaling tubular, multi-channel or monolithic membranes are used, which can be made by extrusion [4] or dry-wet spinning [5]. Tubular membranes with a high surface quality can also be made on a lab scale by centrifugal casting [6].

The mesoporous intermediate layer is used to lower the pore size in order to accommodate the coating of the separation layer. The pore size of this intermediate layer (which can actually be made by multiple coatings) is typically between 2 and $10 \mathrm{~nm}$. Typical materials that are used are $\gamma$-alumina [7], zirconia [8], silica-zirconia [9] or titania. One or more intermediate layers can be applied with different pore-sizes and made of different materials. The intermediate layers are often prepared by dip-coating [7].

The microporous separation layer performs the actual separation and can be as thin as $60 \mathrm{~nm}$ on a well-defined support [10]. Also here multiple coatings can be used in order to construct a defect free separation layer and various layers can be applied in the same or different materials The pore size of such layers are in the same range as the kinetic diameters of the gases that need to be separated, i.e. in the range of 0.3 to $0.5 \mathrm{~nm}$. In case of sol-gel derived membranes these microporous separation layers are often prepared by dip-coating of the sol, although alternative techniques such as hot cloth coating are used as well [11-13]. However, such microporous 
separation layers can also be prepared by other deposition techniques such as chemical vapor deposition (CVD) [14, 15].

\subsection{Sol-gel derived ceramic membranes}

The mesoporous intermediate layer as well as the various microporous separation layers, as discussed in this thesis are made by sol-gel processing. The basic steps of this process are depicted in Figure 2.1. A metal-organic precursor is polymerized or precipitated to either form a polymer or colloid, which is called the sol. The sol is then coated onto a substrate and converted into a gel by solvent evaporation. To convert the gel into an inorganic membrane a calcination step is needed to remove the organics and to consolidate the structure [4].

A colloidal sol leads to a more open network due to the maximum packing density of a particle. Therefore membranes prepared from a colloidal sol are often used for the formation of mesoporous structures like the $\gamma$-alumina intermediate layers used in the work as described in this thesis. A polymeric sol forms a random network that is much denser than a colloidal sol, although this depends on the degree of branching of the polymer [16]. For the fabrication of a microporous membrane the polymeric route with a low degree of branching is preferred [17].

\subsubsection{Sol synthesis}

The polymeric route is used for the silica-based sols, treated in this thesis. First of all, a silicon alkoxide precursor is hydrolyzed by water to form an silicon hydroxide. Subsequently the silicon hydroxide will undergo a condensation reaction with either a silicon alkoxide (alcohol condensation) or silicon hydroxide (water condensation). Both reaction can be catalyzed by either an acid or a base [18].

$$
\begin{gathered}
\equiv \mathrm{Si}-\mathrm{OR}+\mathrm{H}_{2} \mathrm{O} \rightleftharpoons \equiv \mathrm{Si}-\mathrm{OH}+\mathrm{ROH} \\
\equiv \mathrm{Si}-\mathrm{OH}+\equiv \mathrm{Si}-\mathrm{OR} \rightleftharpoons \equiv \mathrm{Si}-\mathrm{O}-\mathrm{Si} \equiv+\mathrm{ROH} \\
\equiv \mathrm{Si}-\mathrm{OH}+\equiv \mathrm{Si}-\mathrm{OH} \rightleftharpoons \equiv \mathrm{Si}-\mathrm{O}-\mathrm{Si} \equiv+\mathrm{H}_{2} \mathrm{O}
\end{gathered}
$$

There are a number of parameters that are of importance for the sol synthesis. These parameters can be divided into two groups; parameters that control the structure of the sol and parameters that control the kinetics of the reaction. The parameters which control the structure of the sol are the amount of acid (acid ratio) and the amount of water (hydrolysis ratio) relative to the 24 
precursor concentration. The parameters which control the kinetics of the reaction are temperature and concentration of precursor, acid and water. In order to obtain a sol that is suitable for membrane formation the most important parameters are the acid ratio and hydrolysis ratio, as these govern the structure of the polymeric sol and ultimately the structure of the membrane. In general, an acid catalyzed reaction with a low hydrolysis ratio leads to a weakly branched polymeric structure due to the retardation of the condensation reaction. Base catalysis or a high hydrolysis ratio leads to an increased condensation, which leads to a more branched or colloidal structure $[18,19]$.

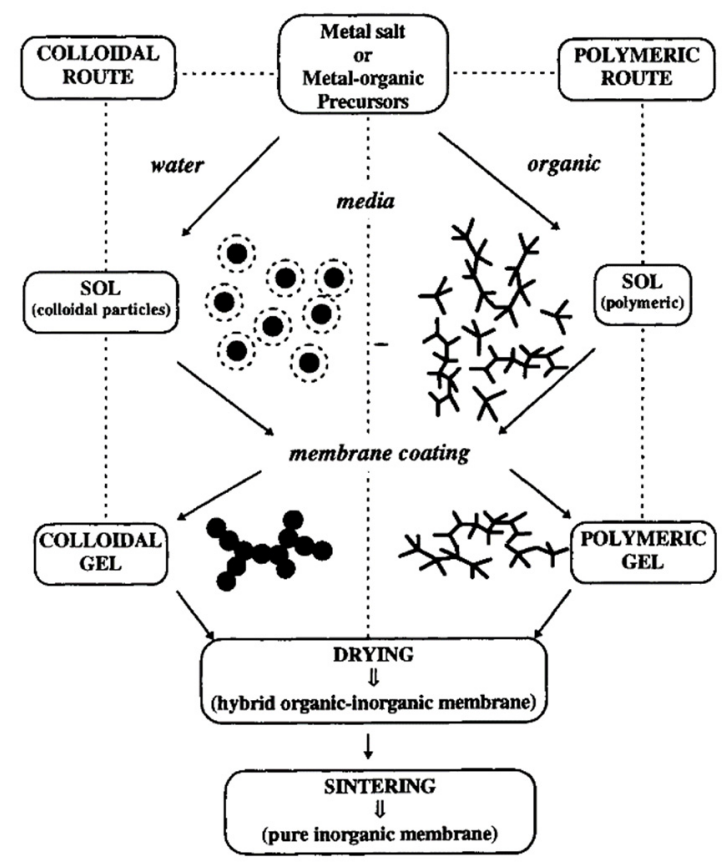

Figure 2.1: The two sol-gel routes that are used in sol-gel processing for membranes fabrication [17]

\subsubsection{Particle size analysis}

Dynamic light scattering (DLS) is a very convenient tool to assess the particle size of a produced sol. In order to make a good membrane the sol size has to be in a certain range, which is depending on the support and the desired layer thickness. Foremost the particle size of the sol should be larger than the pore size of the support to prevent infiltration. Furthermore, the sol 
particle size should not be too large, otherwise defects are likely to occur during drying and subsequent calcination [20].

In DLS a sample is illuminated by a laser. The scattering of the light, caused by Rayleigh scattering is collected by a photomultiplier, which forms a speckle pattern. Due to the Brownian motion the particles move through the solution, causing the speckle pattern to fluctuate due to interference. The speckle pattern is recorded at small time intervals and analyzed by an autocorrelator, which compares the intensity over time. The correlation is high at short timespans due to the fact that particles did not have a chance to move a great distance. At higher time spans the correlation decays, which can be translated into a diffusion coefficient (D). The diffusion coefficient is used to calculate the radius ( $r$ ) by using the Stokes-Einstein equation [21].

$$
D=\frac{k_{B} T}{6 \pi \eta r}
$$

Where $\mathrm{k}_{\mathrm{B}}$ is the Boltzmann constant and $\eta$ the viscosity of the medium.

From dynamic light scattering an intensity weighed size distribution is obtained, where bigger particles will give a higher intensity as compared to smaller particles. In order to convert the intensity weighed distribution to a number weighed distribution the refractive index of the particle and the particle shape should be known [22]. Since the particles in a polymeric sol are highly irregular of shape and polydisperse it is therefore advised to use an intensity distribution as characteristic of the sol particle size.

\subsubsection{Surface area and pore volume of unsupported sol-gel layers.}

By drying the produced sol under ambient conditions flakes are obtained that can be calcined and ground to a powder. These powders can then be used to perform further analysis. Although it is not certain that these powders have the same structure as the actual membrane layer, the advantage of powders is that these can easily be made and multiple characterizations can be performed on them. One of these characterizations is nitrogen adsorption. With nitrogen adsorption information can be obtained about the pore size, surface area and micropore volume of the membrane material.

In a nitrogen adsorption experiment the sample is introduced in a sample tube and fully outgassed under vacuum to eliminate all volatiles and moisture from the sample. After careful weighing of the outgassed sample the tube is put under vacuum and cooled down to $77 \mathrm{~K}$, which 26 
is the temperature of liquid nitrogen. The pressure inside the sample tube is carefully monitored while small doses of nitrogen are being introduced to the sample tube. In this way an isotherm is being recorded, which displays the adsorbed volume as a function of partial (or relative) pressure of nitrogen. The shape of this isotherm is based on the type of material. In general six classifications for the shape of the isotherm are described by IUPAC [1]. The classifications that are of interest for membrane applications are type I for microporous materials, which resembles Langmuir type adsorption, and type IV for mesoporous materials [23].

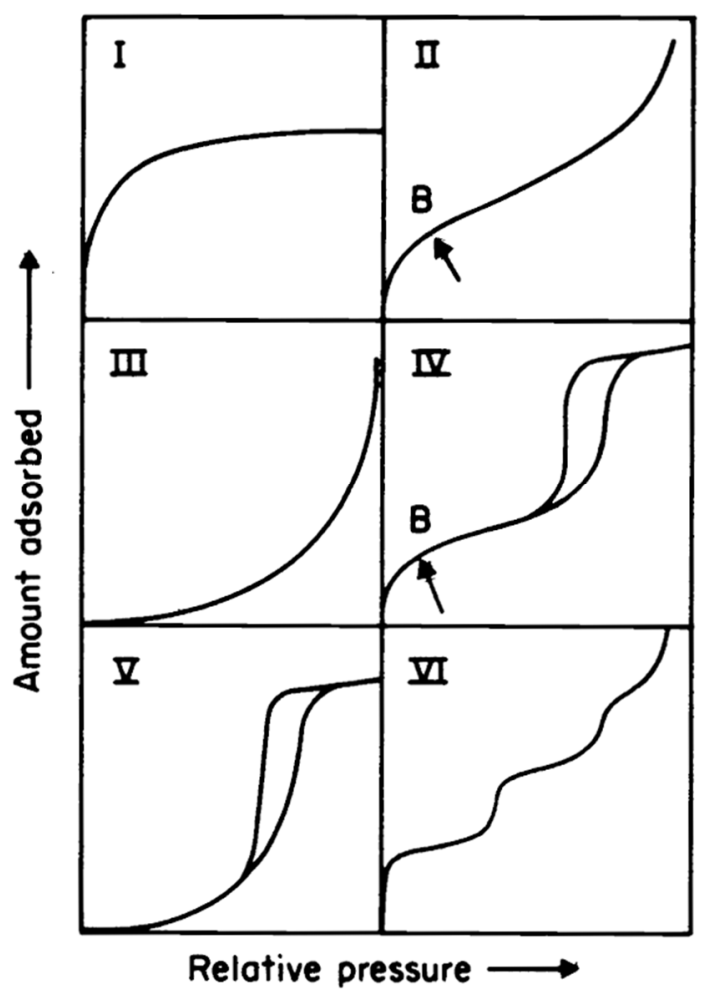

Figure 2.2: The six types of isotherms classified by IUPAC [1]

The most widely used method for determination of the surface area is by a theory, developed by Brunauer, Emmett and Teller [24]. It is based on a multilayer adsorption model, where multilayer adsorption can take place before complete coverage of a monolayer. BET is applicable for both mesoporous and microporous materials. However, for microporous materials where a large 
specific interaction or pore filling can take place the use of the BET method is less accurate [25]. However, in this case it can still be used for a qualitative comparison.

A common method to determine the micropore volume is by using the t-plot, where the adsorbed volume is plotted against the thickness of the t-layer. The t-layer thickness is determined from a standard reference [25]. The micropore volume as discussed in this thesis is determined by the method of Dubinin and Radushkevich [26]. This empirical method is developed in order to take into account that an adsorption layer as used in the t-plot method is not necessarily valid for pores that are marginally bigger than the size of the adsorbed molecules. The method makes use of an adsorption potential, which is proportional to the logarithm of the partial pressure. The equation has the form of:

$$
\ln W=\ln W_{0}-\left(\frac{R T}{\beta E_{0}}\right)^{2}\left(\ln ^{2} \frac{P}{P_{0}}\right)
$$

Where $\mathrm{W}$ is the quantity of adsorbed nitrogen at relative pressure $\mathrm{P} / \mathrm{P}_{0}, \beta$ the affinity coefficient and $\mathrm{E}_{0}$ the characteristic energy of adsorption. By plotting $\ln \mathrm{W}$ against $\ln ^{2} \mathrm{P} / \mathrm{P}_{0}$ the limiting micropore volume $\mathrm{W}_{0}$ can be obtained. The method was originally developed for benzene adsorption and is therefore less applicable for nitrogen adsorption, as the affinity and energy of adsorption are largely different. Also not always a straight line is obtained, which can make it difficult to interpret the results.

Nitrogen adsorption alone can only give qualitative data and to obtain fully representable values a number of probe molecules should be used [23]. Furthermore, in the case that the pore size is in the range of the kinetic diameter of nitrogen the measured pore volume is only the accessible pore volume and not the true pore volume. In materials used for gas separation this can lead to big differences, especially for membranes that block nitrogen like the silica membranes developed by de Vos et al. [10].

Furthermore, great care should be taken when correlating nitrogen adsorption data with gas permeation experiments in the case of sol-gel derived microporous membranes. It is impossible to directly correlate surface area and micropore volume from nitrogen adsorption measurements on a powder to permeance and selectivity from gas permeation measurements on a thin membrane layer. The differences in gelation behavior between bulk and a thin membrane layer are large. During membrane dip coating a small layer is formed, from which the solvent 
evaporates relatively fast, thereby "freezing" the gel structure in a dried state. During powder preparation from a sol a larger volume of solvent needs to be evaporated, which gives the sol particles more time to further grow and to form a denser gel. A comparison between surface area and micropore volume from nitrogen adsorption and permeance and selectivity from gas permeation can only be made in a qualitative way by comparing trends in the separate measurements.

\subsection{Membrane fabrication and characterization}

\subsubsection{Coating}

In the work as described in this thesis dip-coating is used for deposition of the intermediate and gas separation layers. As depicted in Figure 2.3, batch-wise dipcoating happens in five stages: immersion, startup, deposition, drainage and evaporation [18].

The thickness of the coating is governed by the ratio of viscous drag and the entrainment of liquid due to gravitational forces. The thickness can be calculated by the following equation:

$$
h=\frac{0.94(\eta U)^{2 / 3}}{\gamma_{l v}^{1 / 6}(\rho g)^{1 / 2}}
$$

Where $\mathrm{h}$ is the film thickness, $\eta$ the viscosity, $\mathrm{U}$ the withdrawal speed, $\gamma_{\mathrm{l}}$ the liquid/vapor interfacial tension, $\varrho$ the density and $g$ the gravitational constant. From this equation it can be noticed that the main parameters for film thickness are the viscosity and withdrawal speed. The membranes as discussed in this thesis are coated by a rotational dip-coater as shown in Figure 2.4. In this way only one side of the support is coated, so no masking methods are needed. The rotational speed used is $0.06 \mathrm{rad} \cdot \mathrm{s}^{-1}$, which corresponds to a contact time between the support and the dip-sol of approximate 2 seconds. 


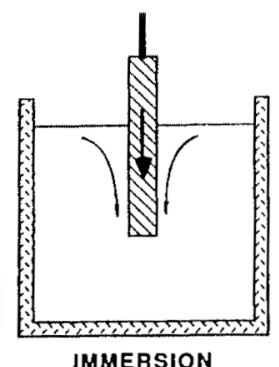

(a)

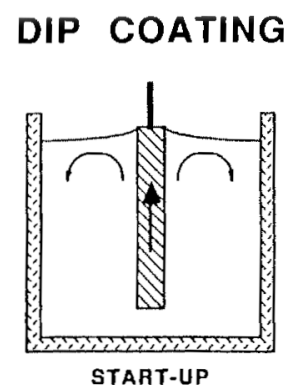

(b)

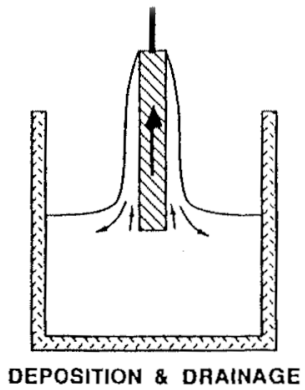

(c)

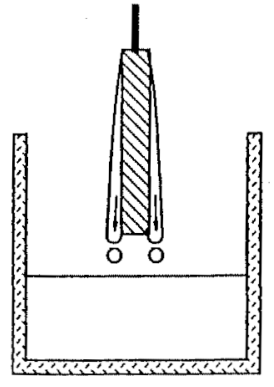

DRAINAGE

(d)

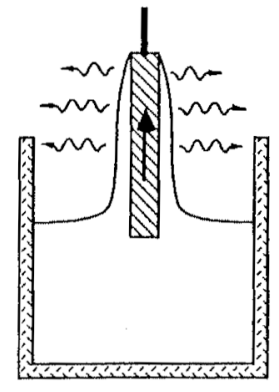

EVAPORATION

(e)

Figure 2.3: the five stages of dip-coating [17]

The thickness of the separation layer is typically below $300 \mathrm{~nm}$, while a dust particle has a size in the range of $1-100 \mu \mathrm{m}$ [27]. Therefore it is of great importance that dust is avoided at all times. It was demonstrated by de Vos et al. [10] that by using class 100 cleanroom conditions membranes without defects could be prepared that were impermeable for methane. The membranes as discussed in this thesis were prepared under class 100 cleanroom conditions as described by Wolf [28] and Qureshi [29] in order to minimize defects. 


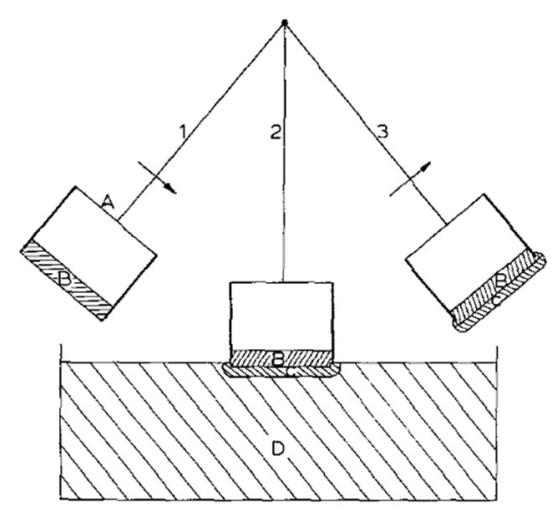

Figure 2.4: Dip-coater with the three stages of dipping: 1. A ceramic support (B) is placed in a holder (A), 2. The support is put in contact with a dip-sol (D) and infiltration can result in an initial membrane layer (C), 3. The holder exits the dip-sol and a membrane layer is formed by film-coating [30]

\subsubsection{Pore size distribution}

The pore size of the intermediate layer should be known to determine the minimum particle size of the sol for the separation layer. One of the most suitable methods to do so is permporometry. The method is based on controlled blocking of pores by capillary condensation, while monitoring a gas diffusional flux. With this method only the "active" pores, i.e. pores that contribute to the permeation are measured instead of all open pores, including "dead-end" pores, that are measured by nitrogen adsorption [31].

The permporometry measurements as discussed in this thesis were performed with nitrogen as a carrier gas, oxygen for measuring the diffusional flux and cyclohexane as a condensable vapor. Cyclohexane is used as it is considered a Van der Waals gas, which implies that the molecules in the gas phase act as a non-interacting hard sphere [31]. By starting with a fully saturated cyclohexane flow the membrane pores are filled with cyclohexane. The partial pressure of cyclohexane is step-wise reduced, which leads to an opening of the pores. By using a desorption mode, the Kelvin equation which relates partial pressure of the condensable phase to a pore size can be simplified as:

$$
\ln p_{r}=\frac{-2 \gamma v}{R T r_{k}}
$$


Where $\mathrm{p}_{\mathrm{r}}$ is the relative pressure of the condensable gas, $\gamma$ the interfacial tension, $\nu$ the molar volume, $\mathrm{R}$ the gas constant and $\mathrm{r}_{\mathrm{k}}$ the Kelvin radius. The Kelvin radius is the radius of curvature in the pore, which is the pore radius minus the t-layer. The t-layer is the adsorption layer of the condensate. So the pore radius $r_{p}$ is calculated by:

$$
r_{p}=r_{k}+t
$$

So in order to accurately measure the pore radius the thickness of the t-layer is needed. This t-layer can be determined by an adsorption measurement on a non-porous, flat surface of the same material. Since it is often difficult to prepare such a sample for adsorption measurements an estimation of the t-layer is done by the following method. The oxygen flux through the membrane increases after all the pores are opened, which is ascribed to the removal of the t-layer. Therefore, the t-layer can be estimated by the following equation:

$$
\frac{F_{X}}{r_{k}^{3}}=\frac{F_{0}}{\left(r_{k}+t\right)^{3}}
$$

Where $\mathrm{F}_{\mathrm{X}}$ is the oxygen flux at the partial pressure $\mathrm{X}$, which is the point where all pores have opened and $\mathrm{F}_{0}$ the oxygen flux in dry conditions, i.e. no t-layer present [32]. The transition point between pore opening and removal of the t-layer is not always trivial, which can make it very difficult to estimate the t-layer and hence the true pore radius. This is more prone to happen at low pore radii, i.e. below $1 \mathrm{~nm}$.

When conducting a permporometry measurement great care should be taken to have equal total pressure on the feed and permeate side of the membrane to prevent incorrect determination of the Kelvin radius and to prevent convective flow of oxygen.

\subsubsection{Thickness of the separation layer}

The gas transport through a membrane is influenced by the thickness of the membrane. In order to be able to make a good comparison between membranes the thickness of the membrane separation layer should be taken into account. Scanning electron microscopy (SEM) is a very useful tool that can help to determine the thickness of such membranes. SEM uses an electron beam to scan the sample in a grid-like pattern. Secondary electrons are detected and used to reconstruct an image. 
To measure the thickness of a membrane a cross section is needed, therefore this method is a destructive technique. Due to the electrically isolating nature of the ceramic materials used, a charge will build up in samples when it is exposed to an electron beam, which will lead to artifacts in the imaging. There are two ways to prevent charge buildup in the sample. The first method is to sputter coat a layer of a conductive metal on the specimen, while the latter is to use a low accelerating voltage $(<1 \mathrm{kV})$ for the electron beam [33]. The sputter coating is often used to prevent the charge buildup, but it is very difficult to get a monolayer of metal on the specimen. Therefore, it is possible that details of the specimen are lost due to the coating process. In this work a low voltage was used to obtain the images, however a low voltage is only possible when the electron beam is produced by a field emission gun due to the coherence and small diameter of the electron beam, which can be more easily achieved by a field emission electron gun than by a conventional tungsten filament.

\subsection{Gas transport}

\subsubsection{Transport models}

For the complete multilayer membrane system, comprising of a macroporous support, a mesoporous intermediate layer and a microporous separation layer, three types of gas transport modes are of interest: viscous flow, Knudsen diffusion and activated diffusion or molecular sieving.

For a macroporous support with large pores $(>50 \mathrm{~nm})$ the dominant transport mechanism is viscous flow. This mechanism results in very small difference in permeance values between several gases and is therefore not interesting for gas separation application. As the pore size is entering the mesoporous region $(2<50 \mathrm{~nm})$, more interactions of a gas molecule with the pore wall will occur, which can be explained as Knudsen diffusion. The gas selectivity of Knudsen diffusion is determined by the square root of the molecular mass ratio: $\left(\mathrm{M}_{2} / \mathrm{M}_{1}\right)^{0.5}$, where $\mathrm{M}$ is the molecular mass of the two different gases. When there is a strong affinity between the gas and the pore capillary condensation can occur, although this is only the case in low-temperature applications. 

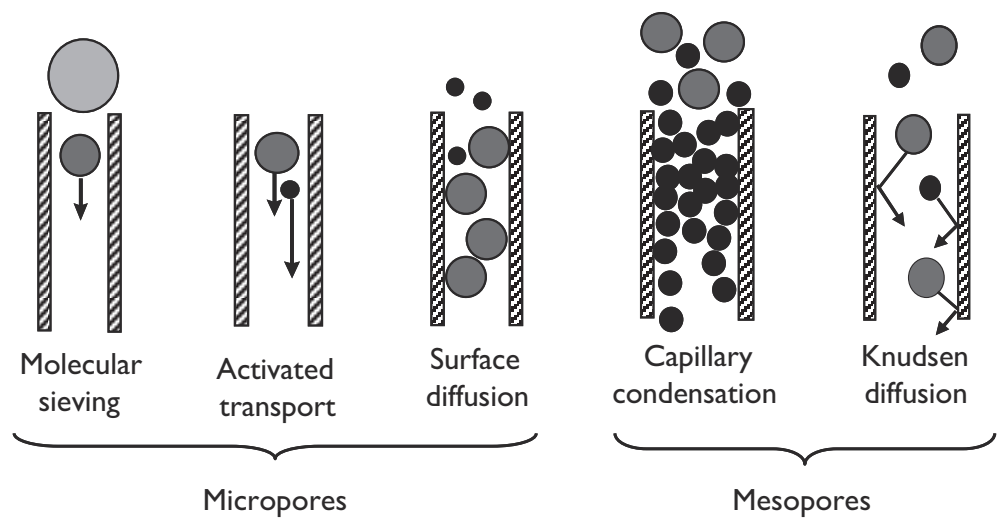

Figure 2.5: Different transport modes in micropores and mesopores

In micropores membranes (pore size $<1 \mathrm{~nm}$ ) a number of transport methods can occur. First of all, molecular sieving can occur, which is purely based on size exclusion. For slightly larger pores the transport is based on activated transport, where the molecules need to overcome a diffusional barrier caused by the pore wall. With strongly interacting gases surface diffusion can occur as well. Due to a broad pore size distribution in amorphous sol-gel derived membranes a combination of all the microporous transport modes will occur. However, activated transport is often assumed to be the most prevalent transport mode present in sol-gel derived microporous membranes.

\subsubsection{Analysis of gas transport and gas separation}

The most often used method to assess the separation performance of a membrane is by means of single gas permeation. In Figure 2.6 a schematic is depicted of the gas permeation setup as used in this work. The stainless steel measurement cell is shown in Figure 2.7. The cell has two inlets and outlets, so that the cell can be flushed with gas prior to measurements. All the gas lines are made from stainless steel to make sure that no permeation through the gas lines can occur to ensure a correct measurement. Three flow meters (FI in Figure 2.6) with different flow ranges are placed in parallel to ensure that a wide range of gas flows is measured accurately. The flow 
meters are thermal mass flow meters (Bronkhorst EL-Flow) with a maximum range of respectively $200 \mathrm{~mL} / \mathrm{min}, 10 \mathrm{~mL} / \mathrm{min}$ and $1 \mathrm{~mL} / \mathrm{min}$.

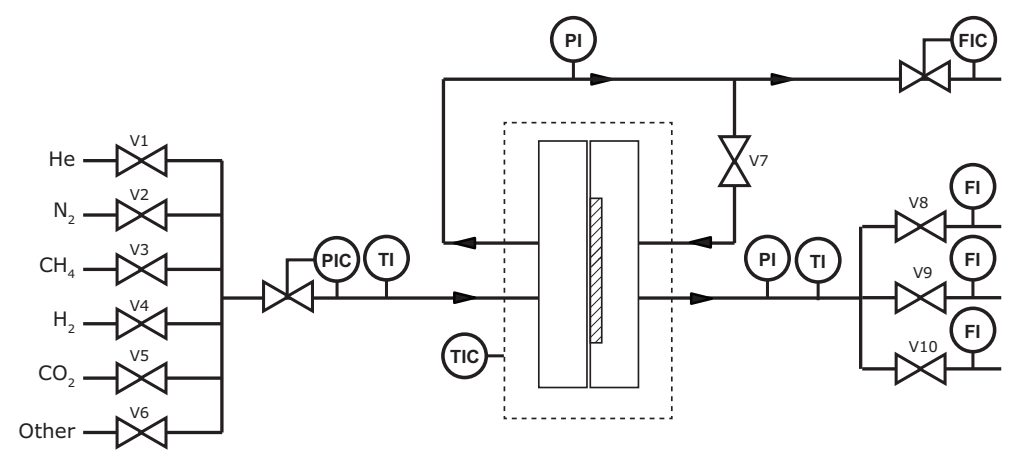

Figure 2.6: Schematic of gas permeation setup

The thermal mass flow controllers are calibrated with nitrogen. In order to obtain the flow for other gases a correction factor is used. This correction factor is based on the heat capacity and the density of the gases. The error in the mass flow meter is $2 \%$ full scale, so in the case of the flow meter with a maximum flow of $1 \mathrm{~mL} / \mathrm{min}$ the error is $0.02 \mathrm{~mL} / \mathrm{min}$ for nitrogen, which is for methane $0.015 \mathrm{~mL} / \mathrm{min}$ due to the correction factor of 0.766 . This corresponds to a permeance of $2.2 \times 10^{-10} \mathrm{~mol} \mathrm{~m}^{-2} \mathrm{~s}^{-1} \mathrm{~Pa}^{-1}$ for a transmembrane pressure of 2 bar and an active membrane area of $2.37 \times 10^{-4} \mathrm{~m}^{2}$. The practical measurement limit that is used is $5 \times 10^{-10} \mathrm{~mol}$ $\mathrm{m}^{-2} \mathrm{~s}^{-1} \mathrm{~Pa}^{-1}$, due to the error in the pressure sensor and in the membrane area. For the area measurement the center line of the o-ring is used, assuming no depression of the o-ring on the membrane surface.

A typical measurement is started with a helium leak test to ensure all connections are correctly placed. In order to do so, the system is pressurized to 2 bar. Once it reaches the pressure, all valves are closed and the pressure is monitored by PI. The leak test is passed if the pressure drop is less than $5 \%$ in 10 minutes. After leak testing the membrane is heated up till $200{ }^{\circ} \mathrm{C}$ with a heating rate of $2{ }^{\circ} \mathrm{C} / \mathrm{min}$. The heating is done under nitrogen flow to ensure that moisture is transported away from the membrane. 


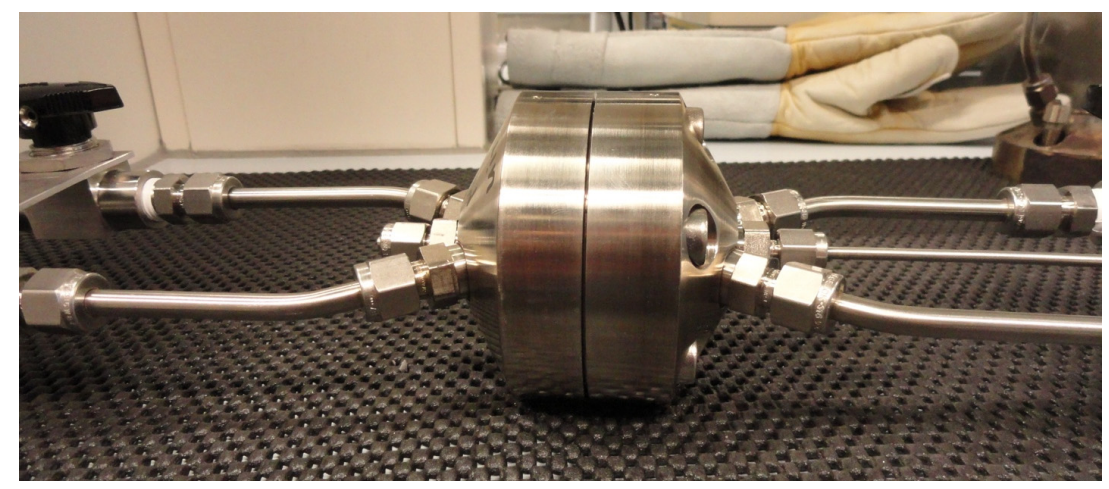

Figure 2.7: Measurement cell that is used in the setup

Prior to measuring a gas, the whole system is flushed with the gas that is to be measured for 2 minutes to ensure that no contaminants can have an influence on the measurement. Also during a measurement, a small purge flow is present on the feed side of the membrane to prevent buildup of contaminations that can be present in the feed gas. The gases are measured in the following order: $\mathrm{He}, \mathrm{N}_{2}, \mathrm{CH}_{4}, \mathrm{H}_{2}$ and $\mathrm{CO}_{2}$. This particular order has a historical reason. In the past manual measurements were done which were time consuming. In order to do measurements as efficient as possible first helium and nitrogen and methane were measured. If the selectivity of helium over nitrogen and methane was sufficient the measurements continued with hydrogen and carbon dioxide. The reason carbon dioxide is measured last is to ensure that if carbon dioxide adsorbs strongly onto the membrane that it does not influence the measurements of the other gases. With fully automatic measurements the need for this particular order is not present anymore, however this particular measurement order was retained. The reason behind this is that it is still now possible to quickly assess the performance of the membrane by looking at the helium/nitrogen selectivity. This selectivity can be used to assess whether or not it is worthwhile to continue the measurement.

Sometimes it is of interest to measure the permeance of sulfur hexafluoride $\left(\mathrm{SF}_{6}\right)$ to determine defects in the membrane. $\mathrm{SF}_{6}$ has a kinetic diameter of $0.55 \mathrm{~nm}$, which is far bigger that the gases of interest. When a membrane shows $\mathrm{SF}_{6}$ permeance it is considered not suitable as a gas separation membrane. 
When a strong interaction of gases with the membrane material is expected, or when degradation is expected it is wise to perform a second helium measurement after the other gases. Since helium is an inert gas and has the smallest kinetic diameter it is considered an as excellent probe gas for monitoring changes in the membrane structure, due to e.g. degradation or strong adsorption.

\subsection{References}

[1] K.S.W. Sing, Reporting physisorption data for gas/solid systems with special reference to the determination of surface area and porosity (Recommendations 1984), in: Pure and Applied Chemistry, 1985, pp. 603.

[2] H. Verweij, Y.S. Lin, J. Dong, Microporous Silica and Zeolite Membranes for Hydrogen Purification, MRS Bulletin, 31 (2006) 756-764.

[3] P.M. Biesheuvel, H. Verweij, Design of ceramic membrane supports: permeability, tensile strength and stress, Journal of Membrane Science, 156 (1999) 141-152.

[4] A.J. Burggraaf, L. Cot, Fundamentals of Inorganic Membrane Science and Technology, Elsevier Science, 1996.

[5] d.i.M.W.J. Luiten-Olieman, Inorganic porous hollow fiber membranes : with tunable small radial dimensions, in, Enschede, 2012, pp. 131.

[6] A. Nijmeijer, C. Huiskes, N.G.M. Sibelt, H. Kruidhof, H. Verweij, Centrifugal casting of tubular membrane supports, American Ceramic Society Bulletin, 77 (1998) 95-98.

[7] R.J.R. Uhlhorn, M.H.B.J.H.I.t. Veld, K. Keizer, A.J. Burggraaf, Synthesis of ceramic membranes, Journal of Materials Science, 27 (1992) 527-537.

[8] T. van Gestel, D. Sebold, F. Hauler, W.A. Meulenberg, H.-P. Buchkremer, Potentialities of microporous membranes for $\mathrm{H} 2 / \mathrm{CO} 2$ separation in future fossil fuel power plants: Evaluation of SiO2, $\mathrm{ZrO} 2, \mathrm{Y} 2 \mathrm{O} 3-$ $\mathrm{ZrO} 2$ and TiO2-ZrO2 sol-gel membranes, Journal of Membrane Science, 359 (2010) 64-79.

[9] M. Asaeda, Y. Sakou, J. Yang, K. Shimasaki, Stability and performance of porous silica-zirconia composite membranes for pervaporation of aqueous organic solutions, Journal of Membrane Science, 209 (2002) 163-175.

[10] R.M. de Vos, H. Verweij, High-selectivity, high-flux silica membranes for gas separation, Science, 279 (1998) 1710-1711.

[11] R. Igi, T. Yoshioka, Y.H. Ikuhara, Y. Iwamoto, T. Tsuru, Characterization of Co-Doped Silica for Improved Hydrothermal Stability and Application to Hydrogen Separation Membranes at High Temperatures, Journal of the American Ceramic Society, 91 (2008) 2975-2981.

[12] M. Kanezashi, M. Asaeda, Hydrogen permeation characteristics and stability of Ni-doped silica membranes in steam at high temperature, Journal of Membrane Science, 271 (2006) 86-93.

[13] T. Yoshioka, E. Nakanishi, T. Tsuru, M. Asaeda, Experimental studies of gas permeation through microporous silica membranes, AIChE Journal, 47 (2001) 2052-2063.

[14] S.-i. Nakao, T. Suzuki, T. Sugawara, T. Tsuru, S. Kimura, Preparation of microporous membranes by TEOS/O3 CVD in the opposing reactants geometry, Microporous and Mesoporous Materials, 37 (2000) 145-152.

[15] M. Nomura, K. Ono, S. Gopalakrishnan, T. Sugawara, S.-I. Nakao, Preparation of a stable silica membrane by a counter diffusion chemical vapor deposition method, Journal of Membrane Science, 251 (2005) 151-158.

[16] R.S.A. de Lange, J.H.A. Hekkink, K. Keizer, A.J. Burggraaf, Polymeric-silica-based sols for membrane modification applications: sol-gel synthesis and characterization with SAXS, Journal of Non-Crystalline Solids, 191 (1995) 1-16.

[17] J. Caro, M. Noack, P. Kölsch, R. Schäfer, Zeolite membranes - state of their development and perspective, Microporous and Mesoporous Materials, 38 (2000) 3-24. 
[18] C.J. Brinker, G.W. Scherer, Sol-gel Science: The Physics and Chemistry of Sol-Gel Processing, Academic Press, San Diego, 1990.

[19] A. Ayral, A. Julbe, V. Rouessac, S. Roualdes, J. Durand, Microporous Silica Membrane: Basic Principles and Recent Advances, in: M. Reyes, M. Miguel (Eds.) Membrane Science and Technology, Elsevier, 2008, pp. 33-79.

[20] H.L. Castricum, A. Sah, J.A.J. Geenevasen, R. Kreiter, D.H.A. Blank, J.F. Vente, J.E. ten Elshof, Structure of hybrid organic-inorganic sols for the preparation of hydrothermally stable membranes, Journal of Sol-Gel Science and Technology, 48 (2008) 11-17.

[21] B.J. Berne, R. Pecora, Dynamic Light Scattering: With Applications to Chemistry, Biology, and Physics, Dover Publications, 1976.

[22] M.S. Dyuzheva, O.V. Kargu, V.V. Klyubin, The Effect of Polydispersity on the Size of Colloidal Particles Determined by the Dynamic Light Scattering, Colloid Journal, 64 (2002) 33-38.

[23] K.S.W. Sing, Adsorption methods for the characterization of porous materials, Advances in Colloid and Interface Science, 76-77 (1998) 3-11.

[24] S. Brunauer, P.H. Emmett, E. Teller, Adsorption of Gases in Multimolecular Layers, Journal of the American Chemical Society, 60 (1938) 309-319.

[25] P.A. Webb, C. Orr, M.I. Corporation, Analytical methods in fine particle technology, Micromeritics Instrument Corporation, 1997.

[26] M.M. Dubinin, L.V. Radushkevich, The equation of the characteristic curve of activated charcoal, Doklady Akademii Nauk SSSR, 55 (1947) 327-329.

[27] J.G. Calvert, Glossary of atmospheric chemistry terms (Recommendations 1990), in: Pure and Applied Chemistry, 1990, pp. 2167.

[28] M.J. Wolf, Microporous membranes for gas separation : a study towards preparation and characterization of different sol-gel derived membrane materials, in, Enschede, the Netherlands, 2015, pp. 126.

[29] H.F. Qureshi, Orchestrating Pore Structure of Hybrid Silica Membranes for Molecular Separations, in, Enschede, 2014, pp. 140.

[30] A.F.M. Leenaars, A.J. Burggraaf, The preparation and characterization of alumina membranes with ultrafine pores. 2. The formation of supported membranes, Journal of Colloid and Interface Science, 105 (1985) 27-40.

[31] F.P. Cuperus, D. Bargeman, C.A. Smolders, Permporometry: the determination of the size distribution of active pores in UF membranes, Journal of Membrane Science, 71 (1992) 57-67.

[32] G.Z. Cao, J. Meijerink, H.W. Brinkman, A.J. Burggraaf, Permporometry Study on the Size Distribution of Active Pores in Porous Ceramic Membranes, Journal of Membrane Science, 83 (1993) 221-235.

[33] D.C. Joy, C.S. Joy, Low voltage scanning electron microscopy, Micron, 27 (1996) 247-263. 


\section{Facile synthesis of zirconia doped hybrid organic inorganic silica membranes}

This chapter has been published:

M. ten Hove, A. Nijmeijer, L. Winnubst, Facile synthesis of zirconia doped hybrid organic inorganic silica membranes, Separation and Purification Technology, 147 (2015) 372-378. 


\begin{abstract}
Hybrid organic inorganic silica membranes are interesting candidates for gas-separation applications due to their excellent hydrothermal stability. However, up to now these membranes lack the separation performance required to separate hydrogen from carbon dioxide. In this work a procedure for doping zirconia into the hybrid silica matrix is reported, resulting in an improved $\mathrm{H}_{2} / \mathrm{CO}_{2}$ permselective membrane compared with non-doped hybrid silica membranes. Zirconia doped 1,2-bis(triethoxysilyl)ethane (Zr-BTESE) was synthesized by solgel chemistry, using zirconyl nitrate as the zirconium source. By optimization the sol reaction conditions (i.e. reaction time and temperature) a homogenous sol was obtained. Defect-free membranes were obtained by adjusting the concentration of the dip-coating solution. The doped membranes showed a slight decrease in hydrogen permeance from $4.4 \times 10^{-7}$ to $1.8 \times 10^{-7} \mathrm{~mol}$ $\mathrm{m}^{-2} \mathrm{~s}^{-1} \mathrm{~Pa}^{-1}$ as compared to an undoped BTESE membrane, but a large increase in $\mathrm{H}_{2} / \mathrm{CO}_{2}$ (from 4 to 16 ) and $\mathrm{H}_{2} / \mathrm{N}_{2}$ (from 12 to 100 ) permselectivity was observed.
\end{abstract}




\subsection{Introduction}

The world energy demand is increasing and although the growth in energy produced by renewable sources is large, there is still a big demand for energy from coal and gas, according to the energy outlook of the EIA [1]. This demand for fossil fuels will cause a further increase in carbon dioxide emissions. According to the $4^{\text {th }}$ IPCC assessment report carbon dioxide is one of the main contributors to global warming [2]. It is therefore necessary to reduce the emissions of $\mathrm{CO}_{2}$ by means of carbon capture and storage (CCS). One of the strategies for CCS is pre-combustion carbon capture in which a fuel is converted to hydrogen and carbon dioxide that can be separated easily.

Methane steam reforming (MSR), as given in reaction (1) can be utilized to convert natural gas to hydrogen and carbon monoxide, a mixture called synthesis gas or syngas. This syngas is shifted towards hydrogen and carbon dioxide in the water gas shift reaction (WGS)(1). Due to the highly exothermic nature of the WGS reaction it is often performed in a two-stage approach to ensure full conversion of carbon monoxide to hydrogen and $\mathrm{CO}_{2}$ [3]. A typical purification step to obtain 90\% pure hydrogen for pre-combustion carbon capture is physical absorption of carbon dioxide, e.g. by using Selexol and Rectisol [4]. For applications that demand high purity hydrogen like ammonia synthesis or fuel cell applications typically pressure swing adsorption is used [3].

$$
\begin{array}{cc}
\mathrm{CH}_{4}+\mathrm{H}_{2} \mathrm{O} \rightleftharpoons 3 \mathrm{H}_{2}+\mathrm{CO} \quad \Delta \mathrm{H}=206 \mathrm{~kJ} / \mathrm{mol} \\
\mathrm{CO}+\mathrm{H}_{2} \mathrm{O} \rightleftharpoons \mathrm{CO}_{2}+\mathrm{H}_{2} \quad \Delta \mathrm{H}=-41 \mathrm{~kJ} / \mathrm{mol}
\end{array}
$$

By using a water gas shift membrane reactor (WGS-MR) instead of the conventional approach, the equilibrium of the WGS reaction (2) can be shifted to the product $\left(\mathrm{H}_{2}\right.$ and $\left.\mathrm{CO}_{2}\right)$ side by continuous removal of hydrogen. The need for extra cooling steps is eliminated by the integration of reaction and separation into one unit operation. This reduces the energy demand, resulting in a more efficient process.

Membranes that are utilized in a WGS-MR need to have a high hydrogen permeance and a high $\mathrm{H}_{2} / \mathrm{CO}_{2}$ selectivity. Palladium membranes have a high $\mathrm{H}_{2} / \mathrm{CO}_{2}$ selectivity and high hydrogen permeance, but suffer from hydrogen embrittlement and sulfur poisoning, which decreases their lifespan [5]. On the other hand sol-gel derived silica membranes are known for their excellent $\mathrm{H}_{2} / \mathrm{CO}_{2}$ selectivity, but degrade in a hydrothermal environment due to the mobility of the silanol 
groups in the material $[6,7]$. Strategies to increase the hydrothermal stability of silica are doping silica with metal oxides to stabilize the siloxane bonds [6, 8-11] or by using a hydrophobic compound to prevent water sorption onto or into the material [12-14]. The latter approach is used in hybrid silica membranes based on bridged silsesquioxanes like bis(triethoxysilyl)ethane (BTESE). It is proven that BTESE membranes are hydrothermally stable for over one year in dehydration of butanol by pervaporation at $150^{\circ} \mathrm{C}$ [15]. These BTESE derived membranes have a lower $\mathrm{H}_{2} / \mathrm{CO}_{2}$ selectivity than silica membranes. Kanezashi et al. [16] proposed that the network of BTESE is more loose due to the ethane bridge, which would lead to a larger pore size. From silica it is known that an increase in calcination temperature from $400{ }^{\circ} \mathrm{C}$ to $600{ }^{\circ} \mathrm{C}$ leads to densification of the matrix and a lower number of silanol groups, which leads to an increase in $\mathrm{H}_{2} / \mathrm{CO}_{2}$ selectivity from 7.5 to 71 [17]. Since BTESE starts to decompose above $470{ }^{\circ} \mathrm{C}$ in an inert atmosphere [12] only temperatures below this decomposition temperature can be used for calcination. Typical calcination temperatures for BTESE are $300{ }^{\circ} \mathrm{C}[12,16]$, which leads to a less condensed network and hence to a lower $\mathrm{H}_{2} / \mathrm{CO}_{2}$ selectivity if compared with silica membranes calcined at $600^{\circ} \mathrm{C}$.

In order to increase the gas separation performance of these hybrid silica systems two routes have been suggested. The first route is changing the length of the organic bridge in the silsesquioxane [18], while the second route is metal doping of the hybrid silica matrix [19]. Metal doping of silica with niobium, cobalt or nickel was used by several research groups to improve the hydrothermal stability $[9,11,20-24]$ and was only recently used on BTESE to improve the gas separation performance. Qi et al. doped BTESE with niobia to achieve a $\mathrm{H}_{2} / \mathrm{CO}_{2}$ selectivity of 200 [19]. The authors explained this improved selectivity by network densification, caused by niobia, and by a reduced affinity for $\mathrm{CO}_{2}$ due to the presence of acidic niobia groups in the niobia/BTESE network.

Zirconia doping of silica by using a zirconium-alkoxide was done by Yoshida et al. [24]. They observed that increasing the zirconia content in silica results in increased activation energy of permeation for helium and hydrogen. This increased activation energy is ascribed to network densification, which leads to smaller pore sizes. This results in lower gas permeances but also in a higher selectivity for hydrogen over carbon dioxide.

In this work a zirconia doped hybrid silica sol was produced by using zirconyl nitrate as a zirconium source. Zirconyl nitrate was chosen instead of a zirconium-alkoxide precursor due to 
the too fast hydrolysis rate of the latter. Membranes were prepared by dip coating of the sol on a porous support. The effects of sol concentration in the dip coat solution on membrane microstructure and membrane performance were investigated. The results are compared with undoped BTESE membranes fabricated in a similar way.

\subsection{Experimental}

\subsubsection{Sol-gel preparation}

All chemicals were used as received. The hybrid silica precursor, 1,2-bis(triethoxysilyl)ethane (BTESE 97\%), was obtained from ABCR. A zirconyl nitrate solution $\left(\mathrm{ZrO}\left(\mathrm{NO}_{3}\right)_{2}(99 \%\right.$, $35 \mathrm{wt} . \%$ in dilute nitric acid) was obtained from Sigma-Aldrich. Ethanol (99\%) and concentrated nitric acid (65\%) were obtained from Merck.

BTESE sols were prepared by the following procedure: $1.04 \mathrm{~mL}$ of a $1.77 \mathrm{~mol} / \mathrm{L} \mathrm{HNO}_{3}$ solution was added to $5.53 \mathrm{~mL}$ ethanol and placed in an ice bath. Subsequently $3.33 \mathrm{~mL}$ of BTESE was dropped slowly into the mixture under vigorous stirring to obtain a final ratio of BTESE:EtOH:HNO $3: \mathrm{H}_{2} \mathrm{O}$ of 1:10.8:0.2:6. The mixture was reacted at $60{ }^{\circ} \mathrm{C}$ for 90 minutes and put in an ice bath to quench the reaction. Ethanol was added to the solution to dilute the sol for dip coating to a final silicon concentration of $0.3 \mathrm{~mol} / \mathrm{L}$.

Zirconia doped BTESE sols were made by the following procedure: zirconyl nitrate $(0.802 \mathrm{~mL})$, $0.337 \mathrm{~mL} \mathrm{H} \mathrm{H}_{2} \mathrm{O}$ and $5.53 \mathrm{~mL}$ ethanol were mixed and the mixture was placed in an ice bath. BTESE $(3.33 \mathrm{~mL})$ was added drop wise to the mixture under vigorous stirring to obtain a final ratio of BTESE: $\mathrm{ZrO}\left(\mathrm{NO}_{3}\right)_{2}: \mathrm{EtOH}: \mathrm{HNO}_{3}: \mathrm{H}_{2} \mathrm{O}$ of 1:0.19:10.5:0.2:6. The mixture was reacted at $25{ }^{\circ} \mathrm{C}$ for 90 minutes and afterwards put in an ice bath to quench the reaction. Ethanol was added to the solution to dilute the sol for dip coating. Final $[\mathrm{Zr}+\mathrm{Si}]$ concentrations were $0.33 \mathrm{~mol} / \mathrm{L}, 0.2 \mathrm{~mol} / \mathrm{L}$ and $0.13 \mathrm{~mol} / \mathrm{L}$ with a Si:Zr ratio of $10: 1$. All sol solutions were stored at $-18{ }^{\circ} \mathrm{C}$ prior to further use.

\subsubsection{Characterization}

The sol particle size was determined by dynamic light scattering (DLS) using a Malvern Zetasizer Nano ZS. Diluted sols were used for the measurements and were filtered over a $0.2 \mu \mathrm{m}$ filter beforehand to remove dust-particles that could have a negative influence on the measurement. 
Unsupported membrane materials were obtained by drying the sol overnight in a petri dish. After drying, the flakes were calcined under nitrogen. Calcination was performed at $400{ }^{\circ} \mathrm{C}$ or $600{ }^{\circ} \mathrm{C}$ with a heating/cooling rate of $0.5^{\circ} \mathrm{C} / \mathrm{min}$ and a dwell of $3 \mathrm{~h}$. After calcination the flakes were ground into a powder using a mortar. Unsupported silica, prepared by the procedure as described by De Vos and Verweij [17], was used for comparison. These powders were calcined at $600{ }^{\circ} \mathrm{C}$ in air with a heating/cooling rate of $0.5^{\circ} \mathrm{C} / \mathrm{min}$ and a dwell of $3 \mathrm{~h}$.

Nitrogen adsorption experiments were performed on unsupported membrane materials with a Quantachrome Autosorb-1MP. The samples were degassed overnight at $300{ }^{\circ} \mathrm{C}$. The surface area of the samples was calculated using the BET equation and the micropore volume was calculated using the Dubinin-Radushkevich method [25]. Powder X-ray diffraction was performed on a Bruker Phaser D2. Scans were taken from $2 \theta$ of $20^{\circ}$ to $80^{\circ}$ with a step size of $0.02^{\circ}$ and a step time of $0.5 \mathrm{~s}$. Thermogravimetric analysis was performed on a Netzch STA 449 F3 Jupiter with a nitrogen flow of $70 \mathrm{~mL} \mathrm{~min}^{-1}$. Measurements were taken with a heating rate of $20^{\circ} \mathrm{C} / \mathrm{min}$ from $35^{\circ} \mathrm{C}$ to $1000{ }^{\circ} \mathrm{C}$. Pretreatment was done at $50{ }^{\circ} \mathrm{C}$ in vacuum to ensure that most of the physisorbed water is removed.

\subsubsection{Membrane preparation}

Porous $\alpha$-alumina supports (pore size $80 \mathrm{~nm}$, porosity 35\%) with a diameter of $39 \mathrm{~mm}$ and a thickness of $2 \mathrm{~mm}$ (Pervatech B.V. the Netherlands) were coated twice under cleanroom conditions with a boehmite sol and calcined at $650{ }^{\circ} \mathrm{C}$ at a heating rate of $1{ }^{\circ} \mathrm{C} / \mathrm{min}$ and a dwell of $3 \mathrm{~h}$, resulting in a $\gamma$-alumina intermediate layer with a thickness of $3 \mu \mathrm{m}$ and a pore size of $5 \mathrm{~nm}$ as reported by Uhlhorn et al. [26]. BTESE and Zr-BTESE layers were coated in one step under cleanroom conditions onto the supported $\gamma$-alumina membranes using an automatic dipcoating machine, with an angular dipping rate of $0.06 \mathrm{rad} \cdot \mathrm{s}^{-1}$. The membranes were calcined under nitrogen at $400{ }^{\circ} \mathrm{C}$ with a heating and cooling rate of $0.5^{\circ} \mathrm{C} / \mathrm{min}$ and a dwell of $3 \mathrm{~h}$. Zr-BTESE membranes were named Zr-BTESE-X in which $\mathrm{X}$ is the total $[\mathrm{Si}+\mathrm{Zr}$ ] concentration in $\mathrm{mol} / \mathrm{L}$ in the dip coating solution.

High resolution scanning electron microscopy (SEM) was performed with a Zeiss Leo 1550 FESEM on membrane cross-sections to determine the thickness of the selective layer. The cross sections were placed on a sample holder and partly covered with aluminum tape to prevent sample charging. No further pretreatment was done on the samples and images were acquired at an accelerating voltage of $1 \mathrm{kV}$.

44 


\subsubsection{Single gas permeation}

The membrane performance was characterized by means of single gas permeation. The membranes were measured in a "dead-end" mode as depicted in Figure 3.1. A feed pressure of 3 bara was applied to the membrane, while the permeate pressure was kept atmospheric. The pressure difference over the membrane was measured by a differential pressure sensor (GE Druck STX2100). The flow through the membrane was determined by a Bronkhorst EL-FLOW mass flow meter.

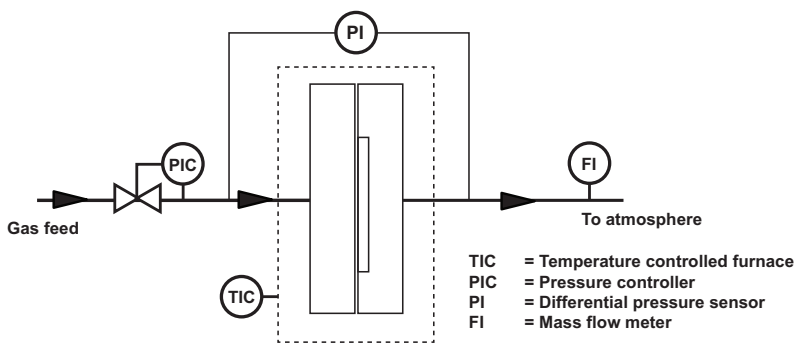

Figure 3.1: Schematic representation of the single gas permeation setup

The membranes were pretreated by heating up to $200{ }^{\circ} \mathrm{C}$ with a heating rate of $1.5^{\circ} \mathrm{C} / \mathrm{min}$ under helium flow to ensure a complete removal of water from the membranes. After this conditioning step, the following gases were measured (in order of measurement): $\mathrm{He}, \mathrm{N}_{2}, \mathrm{CH}_{4}, \mathrm{H}_{2}$, and $\mathrm{CO}_{2}$. All gases were equilibrated for at least half an hour to ensure a constant flux. Two membranes were made from each sol and gas permeation results were averaged over the two membranes. The difference between the two membranes measured was within the experimental error.

\subsection{Results}

\subsubsection{Sol characteristics}

Initially a sol synthesis of Zr-BTESE was performed at $60{ }^{\circ} \mathrm{C}$, using the same experimental conditions as for the undoped BTESE sol synthesis. These conditions resulted in gelation of the Zr-BTESE system within 10 minutes, which was caused by the high reactivity of the zirconium precursor. At a lower reaction temperature of $25^{\circ} \mathrm{C}$ the overall rate of the reaction was 
decreased, resulting in a non-gelated system with a monomodal sol particle size of $6.5 \mathrm{~nm}$ after 90 min of reaction.

In Figure 3.2 the size intensity distribution are shown from the dynamic light scattering results for silica, BTESE and Zr-BTESE sol particles. The Zr-BTESE sol synthesized at $25^{\circ} \mathrm{C}$ has a similar polydispersity as the silica sol synthesized at $60^{\circ} \mathrm{C}$, both showing a lower polydispersity compared to pure BTESE synthesized at $60^{\circ} \mathrm{C}$. The average particle size of the silica, BTESE and Zr-BTESE sols are 5.6, 10.2 and $6.5 \mathrm{~nm}$ respectively. Besides these sols a BTESE sol was synthesized at a reaction temperature of $30^{\circ} \mathrm{C}$ for 90 minutes. This sol yielded an average sol particle size of $3.6 \mathrm{~nm}$, which is smaller than the pore size of $5 \mathrm{~nm}$ of the $\gamma$-alumina substrate. Hence this BTESE sol was not suitable for coating and further membrane fabrication.

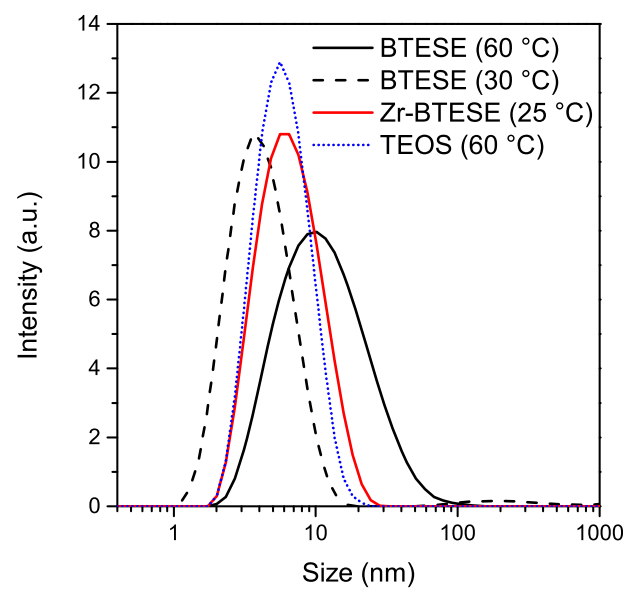

Figure 3.2: Dynamic Light Scattering intensity of the particles in the produced sols. The value in brackets is the temperature during the sol synthesis

\subsubsection{Powder characteristics}

Figure 3.3 shows the nitrogen adsorption isotherms for calcined silica, BTESE and Zr-BTESE. They have a type 1 isotherm, which corresponds to microporous materials. In Table 3.1 the calculated micropore volume and surface area of the prepared materials are given. BTESE showed a high surface area and micropore volume, $485 \mathrm{~m}^{2} / \mathrm{g}$ and $0.173 \mathrm{~cm}^{3} / \mathrm{g}$ respectively, while silica has a low surface area and micropore volume of respectively $46 \mathrm{~m}^{2} / \mathrm{g}$ and $0.022 \mathrm{~cm}^{3} / \mathrm{g}$. 46 
Zr-BTESE showed a lower surface area and micropore volume as compared to BTESE, indicating that zirconia doping indeed results in a denser structure.

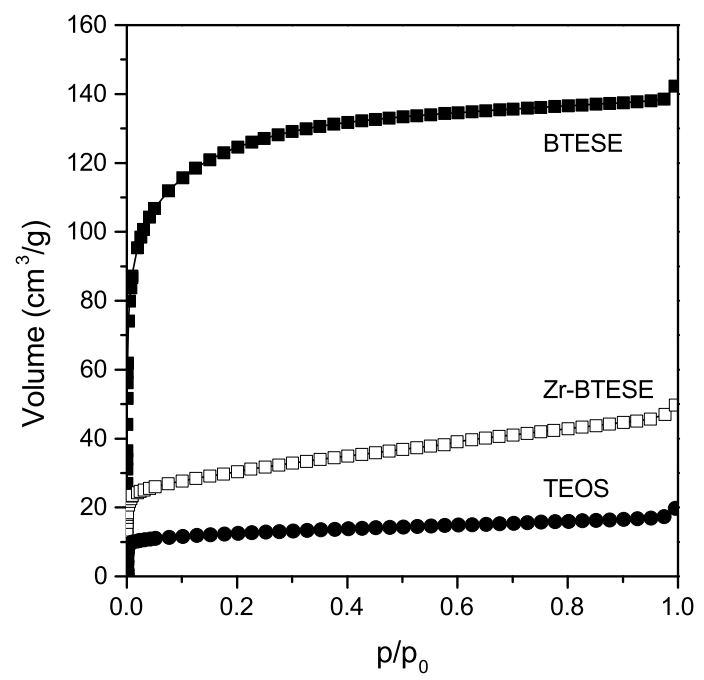

Figure 3.3: Nitrogen adsorption isotherms for unsupported membranes

Table 3.1: Micropore volume and surface area for unsupported membranes as determined by nitrogen adsorption. The temperature between brackets corresponds to the calcination temperature

\begin{tabular}{lll}
\hline & $\begin{array}{l}\text { Micropore volume } \\
\left(\mathrm{cm}^{3} / \mathrm{g}\right)\end{array}$ & $\begin{array}{l}\text { Surface area } \\
\left(\mathrm{m}^{2} / \mathrm{g}\right)\end{array}$ \\
\hline BTESE $\left(400{ }^{\circ} \mathrm{C}\right)$ & 0.173 & 485 \\
Zr-BTESE $\left(400^{\circ} \mathrm{C}\right)$ & 0.055 & 154 \\
TEOS $\left(600^{\circ} \mathrm{C}\right)$ & 0.022 & 46 \\
\hline
\end{tabular}

Figure 3.4 shows the XRD pattern of BTESE calcined at $400^{\circ} \mathrm{C}$ and Zr-BTESE calcined at $400{ }^{\circ} \mathrm{C}$ and $600^{\circ} \mathrm{C}$. The peak at $51^{\circ} 2 \theta$, as visible in all XRD patterns, can be ascribed to a small defect in the nickel shield of the apparatus. In all patterns no crystalline peaks were detected, while only broad bands are found, which are typical for randomLy-oriented amorphous systems. The patterns for BTESE and Zr-BTESE calcined at $400{ }^{\circ} \mathrm{C}$ and $600{ }^{\circ} \mathrm{C}$ are similar, which is an 
indication that the zirconia is fully incorporated and does not segregate into crystalline clusters that would be detectable by XRD.

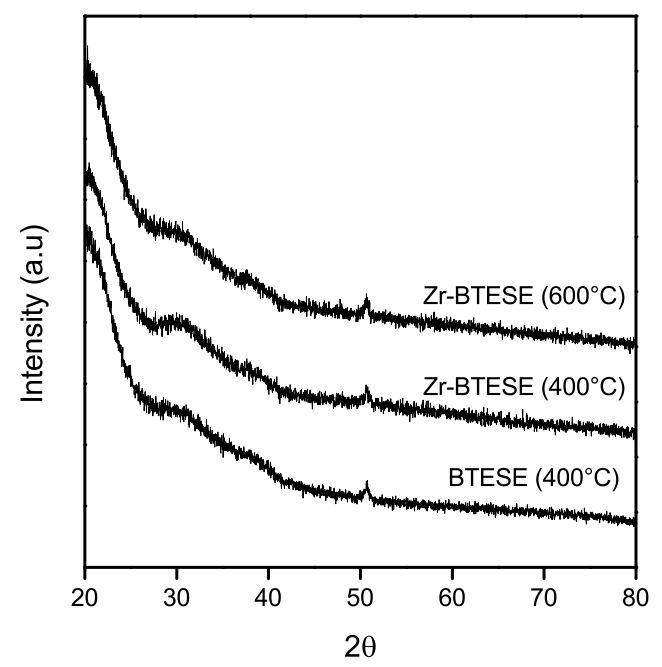

Figure 3.4: XRD patterns of BTESE calcined at $400^{\circ} \mathrm{C}$ and Zr-BTESE calcined at $400^{\circ} \mathrm{C}$ and $600^{\circ} \mathrm{C}$. The band for amorphous silica is visible at $30^{\circ} 2 \theta$. The peak at $51^{\circ} 2 \theta$ is due to an instrument error

Figure 3.5 shows the results of the thermogravimetric analysis. Due to the pretreatment of the sample no significant loss as a result of water evaporation is observed. The first part of the mass loss, up till $250{ }^{\circ} \mathrm{C}$, is the removal of strongly bound water and the decomposition of nitrates. For Zr-BTESE the weight loss is bigger in this part due to the higher amount of nitrates present from the zirconyl nitrate precursor. After this initial mass loss, both BTESE and Zr-BTESE follow the same trend. The trend found is in line with the thermogravimetric graphs of Kappert et al. [27]. 


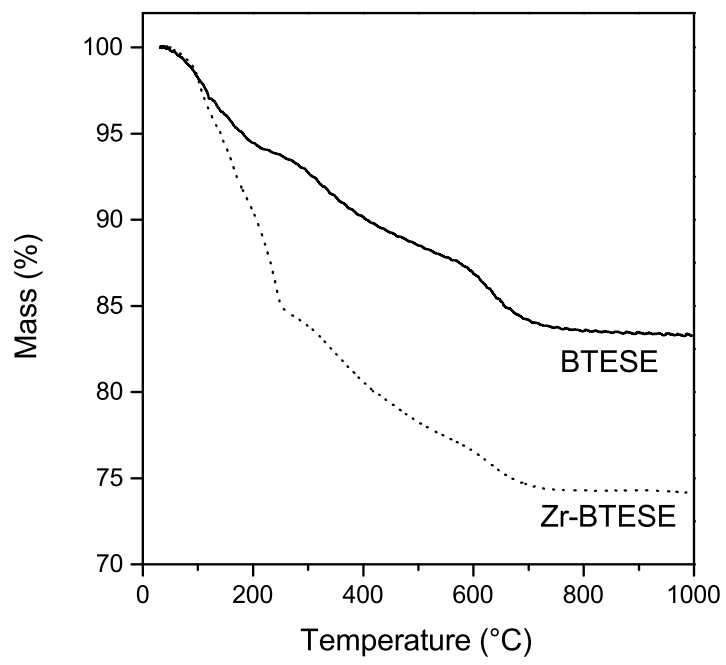

Figure 3.5: Thermogravimetric curve of BTESE and Zr-BTESE powders at a heating rate of $20^{\circ} \mathrm{C} \mathrm{min}-1$ and nitrogen flow of $70 \mathrm{~mL} \mathrm{~min}^{-1}$

\subsubsection{Membrane characteristics}

In Figure 3.6 a SEM cross-section is given of a Zr-BTESE- 0.2 membrane. The $\alpha$-alumina substrate, the $\gamma$-alumina intermediate layer and the Zr-BTESE top layer are clearly visible. No pore intrusion of the sol into the intermediate layer is observed. Table 3.2 provides the thickness of all membrane separation layers investigated, as determined from SEM images. The BTESE-0.3 and Zr-BTESE-0.33 have the same degree of dilution from the starting sol and hence have the same silicon concentration. However due to the addition of zirconium the total $[\mathrm{Si}+\mathrm{Zr}]$ concentration is increased. This increase in metal-ion concentration is reflected in the measured thickness, as the BTESE-0.3 and Zr-BTESE-0.33 have a thickness of 270 and $300 \mathrm{~nm}$ respectively. 


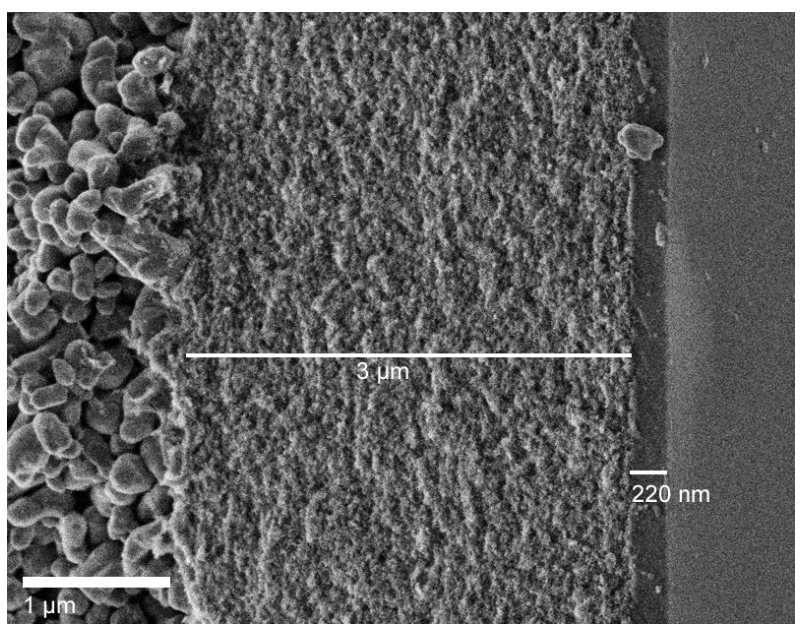

Figure 3.6: SEM picture of $\mathrm{Zr-BTESE-0.2}$ membrane. The $\alpha-\mathrm{Al}_{2} \mathrm{O}_{3}$ support layer, $\gamma-\mathrm{Al}_{2} \mathrm{O}_{3}$ intermediate layer and hybrid silica toplayer are all clearly visible

Table 3.2: Layer thickness of membranes as determined from SEM images

\begin{tabular}{ll}
\hline Membrane & Layer thickness (nm) \\
\hline BTESE-0.3 & $270 \pm 17$ \\
Zr-BTESE-0.33 & $300 \pm 20$ \\
Zr-BTESE-0.20 & $220 \pm 13$ \\
Zr-BTESE-0.13 & $148 \pm 8$ \\
\hline
\end{tabular}

Figure 3.7 shows the gas permeance measured at $200{ }^{\circ} \mathrm{C}$ at a transmembrane pressure of 2 bar as function of the kinetic diameter of the gas molecules for BTESE membranes with a dip sol concentration of $0.3 \mathrm{~mol} / \mathrm{L}$ and Zr-BTESE membranes with a dip sol concentration of $0.33 \mathrm{~mol} / \mathrm{L}, 0.2 \mathrm{~mol} / \mathrm{L}$ and $0.13 \mathrm{~mol} / \mathrm{L}$. Table 3.3 shows the hydrogen permeances of these membranes and the permselectivities $\left(\mathrm{F}_{\alpha}\right)$ of hydrogen over carbon dioxide, nitrogen and methane respectively. The hydrogen permeance for BTESE- 0.3 is $4.4 \times 10^{-7} \mathrm{~mol} \mathrm{~m}^{-2} \mathrm{~s}^{-1} \mathrm{~Pa}^{-1}$ with a $\mathrm{H}_{2} / \mathrm{N}_{2}$ selectivity of 12 , which is an indication that molecular sieving is prevailing for these membranes. These values are in accordance to results obtained in previous work [28]. The addition of zirconium to the BTESE matrix leads to a slightly lower permeance for helium and hydrogen, compared to undoped BTESE. The Zr-BTESE-0.33 membrane, which was only slightly thicker than the BTESE-0.3 membrane, showed cracks after post analysis Rhodamine staining. This proves that the observed gas transport through the Zr-BTESE-0.33 membranes 
was governed by defects in the membrane. Zr-BTESE membranes with lower dip sol concentrations and hence thinner layers show an increase in the selectivity of hydrogen over the other gases. For Zr-BTESE-0.2 the $\mathrm{H}_{2} / \mathrm{CO}_{2}$ selectivity has increased from 4 to 16 while the $\mathrm{H}_{2} / \mathrm{N}_{2}$ selectivity has increased from 12 to 100 if compared with BTESE. The Zr-BTESE-0.13 shows selectivity for $\mathrm{H}_{2} / \mathrm{CO}_{2}$ and $\mathrm{H}_{2} / \mathrm{N}_{2}$ of 7 and 44 respectively with a hydrogen permeance of $2.8 \times 10^{-7} \mathrm{~mol} \mathrm{~m}^{-2} \mathrm{~s}^{-1} \mathrm{~Pa}^{-1}$.

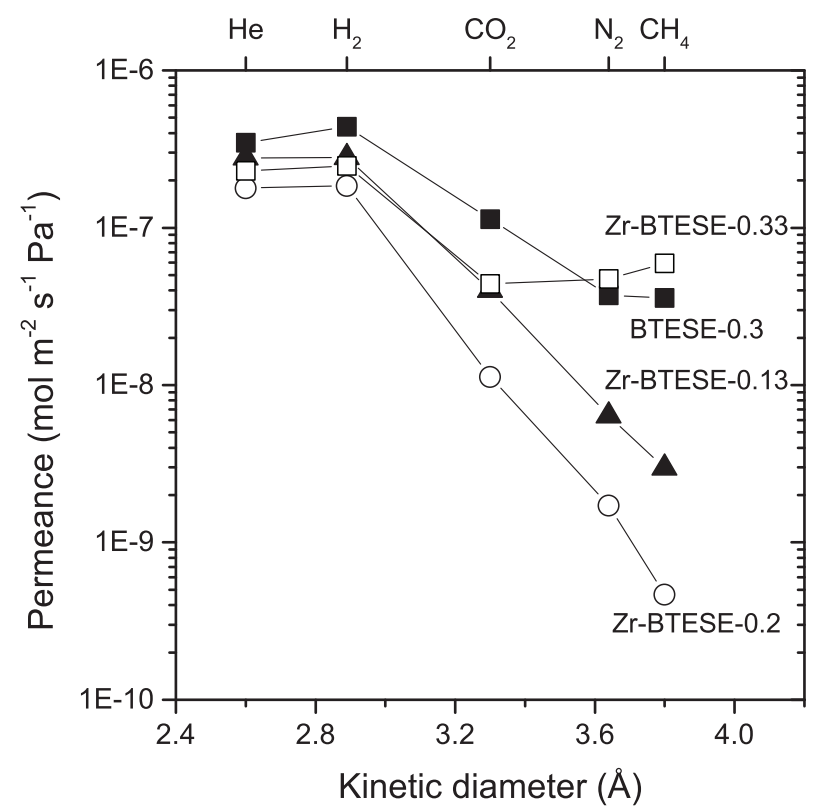

Figure 3.7: Gas permeance versus kinetic diameter for the membranes coated with a different sol dilution measured at $200^{\circ} \mathrm{C}$ with a transmembrane pressure of $2 \mathrm{bar}$

Table 3.3: Hydrogen permeance and permselectivity, $\mathrm{F}_{\alpha}$, of $\mathrm{H}_{2} / \mathrm{CO}_{2}$ and $\mathrm{H}_{2} / \mathrm{N}_{2}$ for membranes, measured at $200^{\circ} \mathrm{C}$ with a transmembrane pressure of 2 bar

\begin{tabular}{lllll}
\hline & $\begin{array}{l}\mathrm{H}_{2} \text { Permeance } \\
\left(10^{-7} \mathrm{~mol} \mathrm{~m}^{-2} \mathrm{~s}^{-1} \mathrm{~Pa}^{-1}\right)\end{array}$ & $\begin{array}{l}\mathrm{F}_{\alpha} \\
\mathrm{H}_{2} / \mathrm{CO}_{2}\end{array}$ & $\begin{array}{l}\mathrm{F}_{\alpha} \\
\mathrm{H}_{2} / \mathrm{N}_{2}\end{array}$ & $\begin{array}{l}\mathrm{F}_{\alpha} \\
\mathrm{H}_{2} / \mathrm{CH}_{4}\end{array}$ \\
\hline Knudsen & & 4.7 & 3.7 & 2.8 \\
BTESE-0.3 & 4.4 & 4 & 12 & 12 \\
Zr-BTESE-0.33 & 1.9 & 6 & 5 & 4 \\
Zr-BTESE-0.20 & 1.8 & 16 & 100 & 400 \\
Zr-BTESE-0.13 & 2.8 & 7 & 44 & 94 \\
\hline
\end{tabular}


The temperature dependency for the Zr-BTESE-0.2 membrane was measured in the temperature range of $50-200{ }^{\circ} \mathrm{C}$. In Figure 3.8 the permeance is plotted against 1000/RT. Table 3.4 shows the calculated apparent activation energy of permeation for each gas Zr-BTESE and the reported values for BTESE [18]. The apparent activation energy of permeation for hydrogen is $7.4 \mathrm{~kJ} / \mathrm{mol}$, which is almost eight times higher than reported for BTESE.

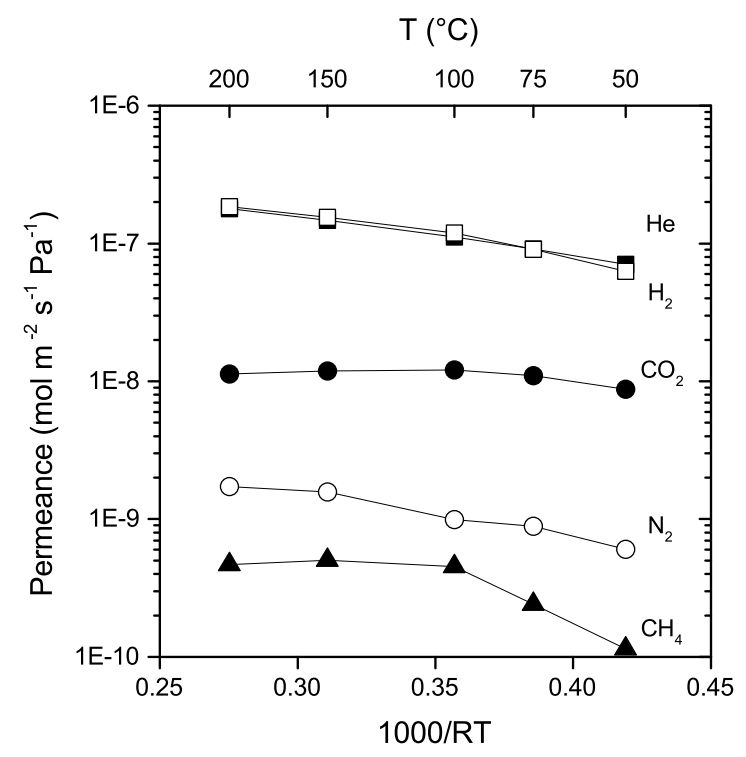

Figure 3.8: Arhenius plot for the Zr-BTESE-0.2 membrane with a transmembrane pressure of 2 bar

Table 3.4: Apparent activation energies for Zr-BTESE and BTESE

\begin{tabular}{lll}
\hline & $\mathrm{E}_{\text {app }}(\mathrm{kJ} / \mathrm{mol})$ & \\
$\mathrm{Gas}$ & Zr-BTESE-0.2 & BTESE [18] \\
\hline $\mathrm{He}$ & $6.4 \pm 0.3$ & 1.7 \\
$\mathrm{H}_{2}$ & $7.4 \pm 0.7$ & 0.9 \\
$\mathrm{CO}_{2}$ & $1.5 \pm 1.0$ & -2.4 \\
$\mathrm{~N}_{2}$ & $7.4 \pm 0.8$ & 0.6 \\
$\mathrm{CH}_{4}$ & $9.5 \pm 3.3$ & 0.5 \\
\hline
\end{tabular}




\subsection{Discussion}

Miller and Ko [29] state that for a mixed-metal oxide sol a more homogenous structure on the atomic scale can be achieved if the reaction rate of the individual metal precursors is low. This approach results in a true mixed oxide system, rather than clusters of the faster reacting species in a matrix of the slower reacting ones. The zirconyl nitrate precursor is the faster reacting component compared to BTESE, which results in fast gelation during sol synthesis at $60{ }^{\circ} \mathrm{C}$ when using a mixture of these two precursors, while a well-defined sol is obtained under the same reaction conditions when only the BTESE precursor is used. Lowering the reaction temperature for the mixed metal oxide system from $60{ }^{\circ} \mathrm{C}$ to $25^{\circ} \mathrm{C}$ results in the formation of a sol with a uniform particle size distribution instead of a gel. It is assumed that a more uniform particle size distribution results in the formation of a more homogeneous separation layer with a better separation performance.

XRD shows no crystalline domains of zirconia. This gives an indication that the zirconia is incorporated into the silica matrix or exist in (nanometer or sub-nanometer sized) domains that are smaller than the detection limit for XRD. For amorphous zirconia a broad band would be expected at $30^{\circ}$ and $50^{\circ}$ [30]. Even when the powder is calcined at $600^{\circ} \mathrm{C}$, which is above the decomposition temperature of BTESE and above the crystallization temperature from amorphous to tetragonal zirconia [31], still no crystalline peaks appear. Apart from the higher nitrate content no significant differences in the decomposition of the ethane bridge between undoped and zirconia doped BTESE is observed. Kappert et al. [27] observed after rigorous kinetic analysis that the decomposition of the ethane linker starts at $500{ }^{\circ} \mathrm{C}$, which implies that firing at $400{ }^{\circ} \mathrm{C}$ is possible without risk of degradation.

The micropore volume and surface area as analyzed from nitrogen adsorption measurements can be correlated to membrane performance. Based on the gas permeation results of de Vos et al. [17] on silica membranes, calcined at $600{ }^{\circ} \mathrm{C}$, one can conclude that the average pore size of the silica membrane is smaller than the kinetic diameter of nitrogen. Therefore only a small amount of pores can be probed by nitrogen during the nitrogen adsorption experiments, which leads to the observed small micropore volume and surface area for the silica system (see Table 1). For BTESE an almost nine-fold larger surface area and micropore volume is found than for silica. This indicates that more pores are accessible for nitrogen, which is reflected in the high nitrogen flux of BTESE. For Zr-BTESE a lower micropore volume and surface area is observed 
compared to BTESE, but not as small as for silica calcined at $600^{\circ} \mathrm{C}$. From these results it can be assumed that the addition of zirconia in BTESE leads to a (micro) porous structure, which is less accessible for nitrogen than in the case of undoped BTESE.

The Zr-BTESE-0.2 and Zr-BTESE-0.13 membranes are thinner than the undoped BTESE membrane, but have a lower permeance for helium and hydrogen in comparison with undoped BTESE. Besides, the selectivity of these gases towards $\mathrm{CO}_{2}, \mathrm{~N}_{2}$ and $\mathrm{CH}_{4}$ were largely increased. The higher permselectivity indicate that the pore size of the membrane is smaller in comparison with BTESE, which corresponds well with the sorption data on unsupported membrane material. This shows that the sorption data on unsupported membrane material can be used as an indication of the membrane performance. The activation energy of permeation is often a good measure for the pore size as it correlates to the energy of diffusion through the pores [24, 32]. The activation energies of permeation are in general much higher for Zr-BTESE-0.2 in comparison with BTESE [18], which is another indication that the pore size for Zr-BTESE is smaller in comparison with BTESE. Also for the larger gases the activation energy is much larger, which is a clear indication that the pore size becomes much smaller upon doping with zirconia. Also $\mathrm{CO}_{2}$ shows positive activation energy, while for BTESE the activation energy is negative. This negative activation energy for $\mathrm{CO}_{2}$ transport through BTESE membranes is ascribed to the fact that there is a strong affinity for $\mathrm{CO}_{2}$. Therefore $\mathrm{CO}_{2}$ transport is governed by molecular affinity rather than by size, which gives rise to $\mathrm{H}_{2} / \mathrm{CO}_{2}$ permselectivities which are lower than the Knudsen value [18].

BTESE membranes without defects and with a thickness of up to $550 \mathrm{~nm}$ have been reported $[28,33]$. However, the here prepared Zr-BTESE- 0.33 membranes with a thickness of $300 \mathrm{~nm}$ show already defects. There are a number of factors that could explain this behavior. First of all the smaller particle size of the Zr-BTESE sol can lead to higher inter-particle stresses during drying [34]. Another factor could be that the zirconia is forming small clusters in the matrix with a higher coordination number. These small clusters, with a size of around $0.4 \mathrm{~nm}$, and hence undetectable by XRD, are known to be formed under aqueous conditions [35]. These clusters can give rise to a more rigid structure, leading to higher drying stresses.

In Figure 3.9 the single gas permeance of BTESE-0.3 and Zr-BTESE-0.2 are compared with literature values for Nb-BTESE [36], TEOS-derived silica [17], Co-TEOS [37] and Zr-TEOS [24]. TEOS-derived silica outperforms all other membranes with respect to hydrogen permeance 
and $\mathrm{H}_{2} / \mathrm{CO}_{2}$ permselectivity, but is known to be unstable under steam conditions [7]. Co-TEOS has the highest $\mathrm{H}_{2} / \mathrm{CO}_{2}$ selectivity, but the hydrogen permeance is too low to be attractive for an application. Zr-BTESE shows in comparison to Zr-TEOS similar hydrogen permeance, but a much better selectivity with respect to the other gases. Although some general comparisons can be made between literature data, a true comparison is not possible, since there are differences in the used substrate, coating method and measurement method.

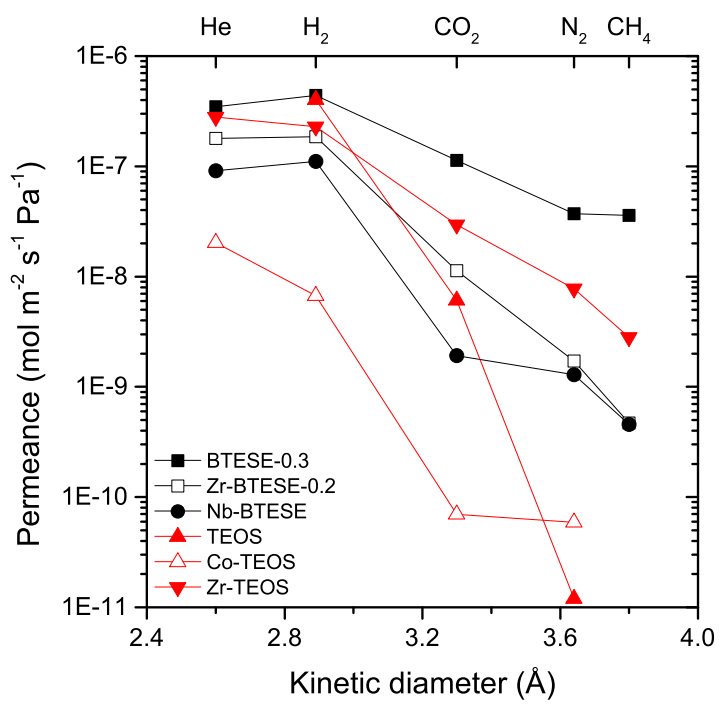

Figure 3.9: Comparison of BTESE and Zr-BTESE with Nb-BTESE [36], TEOS [17], Co-TEOS [37] and Zr-TEOS [24]

A $\mathrm{H}_{2} / \mathrm{CO}_{2}$ selectivity of 16 as achieved in this work is not sufficient for WGS-MR applications, since it would lead to a too high $\mathrm{CO}_{2}$ concentration that is emitted. However, we show that the pore size of BTESE can be tuned towards a better selectivity of $\mathrm{H}_{2} / \mathrm{CO}_{2}$ without compromising too much on hydrogen permeance. 


\subsection{Conclusion}

Zirconia doped BTESE membranes have been successfully synthesized by a sol-gel method, using zirconyl nitrate and 1,2-bis(triethoxysilyl)ethane (BTESE) as precursors. By using a reaction temperature of $25^{\circ} \mathrm{C}$ a homogenous sol has been produced that shows no crystalline zirconia in XRD-spectra after calcination at $400{ }^{\circ} \mathrm{C}$ or $600{ }^{\circ} \mathrm{C}$ in nitrogen. These $\mathrm{Zr}$-doped BTESE membranes have a slightly lower permeance for the gases $\mathrm{He}$ and $\mathrm{H}_{2}$ if compared with BTESE-derived membranes but an increase in selectivity of hydrogen over carbon dioxide, nitrogen and methane is achieved. A Zr-BTESE membrane has a hydrogen permeance of $1.8 \mathrm{x}$ $10^{-7} \mathrm{~mol} \mathrm{~m}^{-2} \mathrm{~s}^{-1} \mathrm{~Pa}^{-1}$, and $\mathrm{H}_{2} / \mathrm{CO}_{2}, \mathrm{H}_{2} / \mathrm{N}_{2}$ and $\mathrm{H}_{2} / \mathrm{CH}_{4}$ permselectivity of respectively 16,100 and 400 .

Nitrogen adsorption analysis indicates a threefold decrease in micropore volume and micropore surface area for Zr-doped BTESE with respect to undoped BTESE indicating a micropore structure for Zr-BTESE, which is less accessible for nitrogen than the micropore structure of undoped BTESE. Gas adsorption on unsupported membrane materials can give a reasonable indication of the membrane performance of such materials.

\subsection{Acknowledgements}

We acknowledge financial support for this research from ADEM, A green Deal in Energy Materials of the Ministry of Economic Affairs of The Netherlands (www.adem-innovationlab.nl).

\subsection{References}

[1] International Energy Outlook 2010, in, U.S. Energy Information Administration, 2010.

[2] S. Solomon, D. Qin, M. Manning, Z. Chen, M. Marquis, K.B. Averyt, M. Tignor, H.L. Miller, IPCC, 2007: Climate Change 2007: The Physical Science Basis., Cambridge University Press, 2007.

[3] P. Häussinger, R. Lohmüller, A.M. Watson, Hydrogen, in: Ullmann's Encyclopedia of Industrial Chemistry, Wiley-VCH Verlag GmbH \& Co. KGaA, 2000.

[4] J. Black, Cost and Performance Baseline for Fossil Energy Plants: Volume 1: Bituminous Coal and Natural Gas to Electricity, in, 2010.

[5] F. Gallucci, E. Fernandez, P. Corengia, M.V. Annaland, Recent advances on membranes and membrane reactors for hydrogen production, Chemical Engineering Science, 92 (2013) 40-66.

[6] V. Boffa, D.H.A. Blank, J.E. ten Elshof, Hydrothermal stability of microporous silica and niobia-silica membranes, Journal of Membrane Science, 319 (2008) 256-263.

[7] M.C. Duke, J.C.D. da Costa, D.D. Do, P.G. Gray, G.Q. Lu, Hydrothermally robust molecular sieve silica for wet gas separation, Advanced Functional Materials, 16 (2006) 1215-1220.

[8] M. Asaeda, Y. Sakou, J. Yang, K. Shimasaki, Stability and performance of porous silica-zirconia composite membranes for pervaporation of aqueous organic solutions, Journal of Membrane Science, 209 (2002) 163-175. 
[9] R. Igi, T. Yoshioka, Y.H. Ikuhara, Y. Iwamoto, T. Tsuru, Characterization of Co-Doped Silica for Improved Hydrothermal Stability and Application to Hydrogen Separation Membranes at High Temperatures, Journal of the American Ceramic Society, 91 (2008) 2975-2981.

[10] T. Tsuru, Development of Metal-doped Silica Membranes for Increased Hydrothermal Stability and Their Applications to Membrane Reactors for Steam Reforming of Methane, Journal of the Japan Petroleum Institute, 54 (2011) 277-286.

[11] D. Uhlmann, S. Smart, J.C. Diniz da Costa, High temperature steam investigation of cobalt oxide silica membranes for gas separation, Separation and Purification Technology, 76 (2010) 171-178.

[12] H.L. Castricum, A. Sah, R. Kreiter, D.H.A. Blank, J.F. Vente, J.E. ten Elshof, Hydrothermally stable molecular separation membranes from organically linked silica, Journal of Materials Chemistry, 18 (2008) 2150-2158.

[13] R.M. de Vos, W.F. Maier, H. Verweij, Hydrophobic silica membranes for gas separation, Journal of Membrane Science, 158 (1999) 277-288.

[14] Q. Wei, Y.-L. Wang, Z.-R. Nie, C.-X. Yu, Q.-Y. Li, J.-X. Zou, C.-J. Li, Facile synthesis of hydrophobic microporous silica membranes and their resistance to humid atmosphere, Microporous and Mesoporous Materials, 111 (2008) 97-103.

[15] H.L. Castricum, A. Sah, R. Kreiter, D.H. Blank, J.F. Vente, J.E. ten Elshof, Hybrid ceramic nanosieves: stabilizing nanopores with organic links, Chem Commun (Camb), (2008) 1103-1105.

[16] M. Kanezashi, K. Yada, T. Yoshioka, T. Tsuru, Organic-inorganic hybrid silica membranes with controlled silica network size: Preparation and gas permeation characteristics, Journal of Membrane Science, 348 (2010) 310-318.

[17] R.M. de Vos, H. Verweij, High-selectivity, high-flux silica membranes for gas separation, Science, 279 (1998) 1710-1711.

[18] H.L. Castricum, G.G. Paradis, M.C. Mittelmeijer-Hazeleger, R. Kreiter, J.F. Vente, J.E. ten Elshof, Tailoring the Separation Behavior of Hybrid Organosilica Membranes by Adjusting the Structure of the Organic Bridging Group, Advanced Functional Materials, 21 (2011) 2319-2329.

[19] H. Qi, J. Han, N. Xu, H.J. Bouwmeester, Hybrid organic-inorganic microporous membranes with high hydrothermal stability for the separation of carbon dioxide, ChemSusChem, 3 (2010) 1375-1378.

[20] V. Boffa, J.E. ten Elshof, A.V. Petukhov, D.H. Blank, Microporous niobia-silica membrane with very low CO2 permeability, ChemSusChem, 1 (2008) 437-443.

[21] G.P. Fotou, Y.S. Lin, S.E. Pratsinis, Hydrothermal Stability of Pure and Modified Microporous Silica Membranes, Journal of Materials Science, 30 (1995) 2803-2808.

[22] M. Kanezashi, M. Sano, T. Yoshioka, T. Tsuru, Extremely thin Pd-silica mixed-matrix membranes with nano-dispersion for improved hydrogen permeability, Chemical Communications, 46 (2010) 61716173.

[23] T. Tsuru, R. Igi, M. Kanezashi, T. Yoshioka, S. Fujisaki, Y. iwamoto, Permeation properties of hydrogen and water vapor through porous silica membranes at high temperatures, AIChE Journal, 57 (2011) 618-629.

[24] K. Yoshida, Y. Hirano, H. Fujii, T. Tsuru, M. Asaeda, Hydrothermal stability and performance of silica-zirconia membranes for hydrogen separation in hydrothermal conditions, Journal of Chemical Engineering of Japan, 34 (2001) 523-530.

[25] M.M. Dubinin, L.V. Radushkevich, The equation of the characteristic curve of activated charcoal, Doklady Akademii Nauk SSSR, 55 (1947) 327-329.

[26] R.J.R. Uhlhorn, M.H.B.J.H.I.t. Veld, K. Keizer, A.J. Burggraaf, Synthesis of ceramic membranes, Journal of Materials Science, 27 (1992) 527-537.

[27] E.J. Kappert, H.J. Bouwmeester, N.E. Benes, A. Nijmeijer, Kinetic analysis of the thermal processing of silica and organosilica, The journal of physical chemistry. B, 118 (2014) 5270-5277.

[28] H.F. Qureshi, A. Nijmeijer, L. Winnubst, Influence of sol-gel process parameters on the microstructure and performance of hybrid silica membranes, Journal of Membrane Science, 446 (2013) 19-25.

[29] J.B. Miller, E.I. Ko, Control of mixed oxide textural and acidic properties by the sol-gel method, Catalysis Today, 35 (1997) 269-292.

[30] G.T. Mamott, P. Barnes, S.E. Tarling, S.L. Jones, C.J. Norman, Dynamic studies of zirconia crystallization, Journal of Materials Science, 26 (1991) 4054-4061. 
[31] L. Winnubst, P.J. de Veen, S. Ran, D.H.A. Blank, Synthesis and characteristics of nanocrystalline 3YTZP and $\mathrm{CuO}$ powders for ceramic composites, Ceramics International, 36 (2010) 847-853.

[32] P. Hacarlioglu, D. Lee, G.V. Gibbs, S.T. Oyama, Activation energies for permeation of He and H2 through silica membranes: An ab initio calculation study, Journal of Membrane Science, 313 (2008) 277283.

[33] R. Kreiter, M. Rietkerk, H. Castricum, H. van Veen, J. ten Elshof, J. Vente, Evaluation of hybrid silica sols for stable microporous membranes using high-throughput screening, Journal of Sol-Gel Science and Technology, (2010) 1-8.

[34] C.J. Brinker, A.J. Hurd, P.R. Schunk, G.C. Frye, C.S. Ashley, Review of sol-gel thin film formation, Journal of Non-Crystalline Solids, 147-148 (1992) 424-436.

[35] A. Clearfield, P.A. Vaughan, The crystal structure of zirconyl chloride octahydrate and zirconyl bromide octahydrate, Acta Crystallographica, 9 (1956) 555-558.

[36] H. Qi, J. Han, N.P. Xu, Effect of calcination temperature on carbon dioxide separation properties of a novel microporous hybrid silica membrane, Journal of Membrane Science, 382 (2011) 231-237.

[37] S. Battersby, S. Smart, B. Ladewig, S. Liu, M.C. Duke, V. Rudolph, J.C.D.d. Costa, Hydrothermal stability of cobalt silica membranes in a water gas shift membrane reactor, Separation and Purification Technology, 66 (2009) 299-305. 
4 Impact of metal doping on the performance of hybrid organic-inorganic silica membranes 


\begin{abstract}
The influence of metal doping on membrane and gas permeation properties of hybrid silica membranes is not yet fully understood. In this work the influence of yttria, zirconia and niobia doping on sol gel synthesis and gas permeation properties of hybrid BTESE (1,2-bis(triethoxysilyl)ethane) derived membranes is described. Doping of yttria leads to a more open structure, while zirconia and niobia lead to a more densified network when compared with undoped hybrid BTESE membranes. For niobia doping, a two-step sol synthesis is necessary, involving prehydrolysis of the BTESE precursor prior to addition of the Nb-alkoxide in the second step. This, however, results in a more open structure due to premature condensation of BTESE before metal addition. Therefore the one-step synthesis used for Zr-BTESE proved to be more effective in increasing the $\mathrm{H}_{2} / \mathrm{CO}_{2}$ and $\mathrm{H}_{2} / \mathrm{N}_{2}$ permselectivity as compared to the twostep synthesis that was needed for Nb-BTESE. Despite careful replication of a decreased $\mathrm{CO}_{2}$ permeance as reported in literature was observed for Nb-BTESE.
\end{abstract}




\subsection{Introduction}

Microporous silica-based membranes are promising for gas separation, due to their thermal and chemical stability and their excellent performance. Sol-gel silica membranes, prepared with tetraethyl orthosilicate (TEOS) as precursor have an excellent performance, but are very susceptible to degradation by water in process streams [1]. Bridged silsesquioxane derived hybrid silica membranes, using BTESE (1,2-bis(triethoxysilyl)ethane) as precursor on the other hand have a very high stability in wet conditions in for example butanol dehydration, but show limited selectivity for gas separation purposes [2].

One of the most interesting gas separation applications in industry is $\mathrm{H}_{2} / \mathrm{CO}_{2}$ separation, as this opens the way to the development of water-gas-shift membrane reactors (WGS-MR) to be used in pre-combustion carbon capture [3]. This is however also one of the most difficult separations for microporous membranes due to the small difference in kinetic diameter between hydrogen $(0.29 \mathrm{~nm})$ and carbon dioxide $(0.33 \mathrm{~nm})$.

A way to improve the hydrothermal stability of TEOS-derived silica membranes is by doping the system with metal ions. One of the first attempts to improve the stability of silica in this way was by doping with alumina and magnesia as presented by Fotou et al. [4]. For unsupported membrane materials they observed, that doping of silica with 3\% alumina did not lead to a loss of surface area after hydrothermal treatment. However, no membrane performance was studied. Yoshida et al. [5] studied the effect of zirconia doping in TEOS. After hydrothermal tests densification of the membrane separation layer was observed for a doping amount of $10 \%$, while higher doping amounts of $30 \%$ and $50 \%$ led to Knudsen type transport after treatment of the membrane under hydrothermal conditions. Closing of the small pores that allow helium and hydrogen permeation and subsequent opening of the bigger pores are explanations for these effects. Several groups investigated cobalt doping and these membranes showed an improvement in hydrothermal stability [6-8]. In these papers a detailed study was performed on the way cobalt was present in the silica structure. XRD measurements confirmed that cobalt was not incorporated in the silica matrix, but as cobalt oxide clusters. The influence of cobalt doping on the pore structure of the membrane is not clear, as no gas permeation tests are done to compare the cobalt doped membranes with undoped silica membranes. Boffa et al. [9] investigated the effect of niobia doping in TEOS-derived silica membranes on the hydrothermal stability and gas separation performance. Not only hydrothermal stability was achieved [10], also 
a low permeance of $\mathrm{CO} 2$ due to niobia doping was observed, which is ascribed to the strong adsorption of $\mathrm{CO} 2$ on the surface hydroxyl groups which are bound to niobia.

A BTESE-derived hybrid silica network is already a hydrothermal stable material on itself, which makes it an excellent starting material for the use as hydrothermally stable membranes, also due to their flexibility [11]. However, the undoped BTESE-derived membranes show poor gas selectivity. The main reason for metal doping in BTESE is therefore to improve the gas permselectivity. Qi et al. [12] were the first to explore metal doping in hybrid silica systems by using niobia as doping. They found a reduction of permeance for all gases that indicates a densified network and a pronounced decrease in $\mathrm{CO}_{2}$ permeance, which is ascribed to the acid character of the $\mathrm{Nb}$-doped system. This pronounced decrease in $\mathrm{CO}_{2}$ permeance is only found when the membranes are calcined at temperatures above $400{ }^{\circ} \mathrm{C}$ [13] due to the weaker acidity of niobia at lower calcination temperatures, as claimed by the authors. Qureshi et al. [14] investigated the effect of boron, niobium and tantalum doping in BTESE. They found however an increased permeance for all gases in all cases of doping, which indicates a more open pore structure. A different sol synthesis method and calcination temperature $\left(300{ }^{\circ} \mathrm{C}\right)$ may be the cause of this increased permeance for all gases in case of Nb-BTESE, when compared with the synthesis of Qi et al.

Wolf et al. [15] investigated alumina, germania and silica doping in BTESE. For aluminia and silica doping, higher permeances were observed with only 4 and $8 \%$ of doping. For 16\% germanium doped BTESE lower permeances for nitrogen and methane were observed, however the impact of germanium doping on the gas separation performance was only minor. Kanezashi et al. [16] investigated alumina doping in hybrid silica with 1,2-bis(triethoxysilyl)methane (BTESM) as precursor and found a decrease in permeance with increasing doping level, indicating that alumina doping densifies the BTESM layer. This is opposite to the findings of Wolf et al. These observed differences might be due to the different synthesis conditions.

In previous work [17] we reported zirconia-doped BTESE that shows a densified network in comparison with undoped BTESE. For these membranes the $\mathrm{H}_{2} / \mathrm{CO}_{2}$ selectivity was increased from 4 to 12 when compared with pure BTESE membranes. In the work, as described in this chapter, the effect of doping yttria, zirconia or niobia to BTESE is investigated. First, the influence of the metal on the reaction kinetics during sol synthesis is investigated by means of 
dynamic light scattering on the synthesized sols. Furthermore the effect of metal doping on the gas separation performance is investigated by means of single gas permeation.

\subsection{Experimental}

All chemicals were used as received. The hybrid silica precursor, 1,2-bis(triethoxysilyl)ethane (BTESE 97\%), and niobium(V) n-butoxide was obtained from ABCR. Zirconium(IV) oxynitrate hydrate (99\%), zirconium(IV) propoxide solution (70 wt.\% in 1-propanol) and ytrrium(III) nitrate hexahydrate (99.8\%) were obtained from Sigma-Aldrich. Ethanol (99\%), 1-propanol $(99 \%)$ and concentrated nitric acid (65\%) were obtained from Merck.

BTESE sols were prepared by the following procedure: $1.04 \mathrm{~mL}$ of a $1.77 \mathrm{~mol} / \mathrm{L} \mathrm{HNO}_{3}$ solution was added to $5.53 \mathrm{~mL}$ ethanol and placed in an ice bath. Subsequently $3.33 \mathrm{~mL}$ of BTESE was dropped slowly into the mixture under vigorous stirring to obtain a final molar ratio of BTESE:EtOH:HNO $3: \mathrm{H}_{2} \mathrm{O}$ of 1:10.8:0.2:6. The mixture was stirred at $30{ }^{\circ} \mathrm{C}$ or $60{ }^{\circ} \mathrm{C}$ for 90 minutes and put in an ice bath to quench the reaction. Ethanol was added to the solution to dilute the sol for dip coating to a final silicon concentration of $0.3 \mathrm{~mol} / \mathrm{L}$.

Yttria doped BTESE was prepared by the following procedure: $0.66 \mathrm{~g}$ yttrium nitrate hexahydrate was dissolved in $0.9 \mathrm{~mL} 2 \mathrm{~mol} / \mathrm{L} \mathrm{HNO}_{3}$ solution, after which $5.77 \mathrm{~mL}$ ethanol was added and placed in an ice bath. Subsequently $3.33 \mathrm{~mL}$ of BTESE was dropped slowly into the mixture under vigorous stirring to obtain a final ratio of BTESE: $\left.\mathrm{YNO}_{3}\right)_{3}: \mathrm{EtOH}: \mathrm{HNO}_{3}: \mathrm{H}_{2} \mathrm{O}$ of 1:0.19:11:0.2:6. The sol reaction of this mixture was performed at $30^{\circ} \mathrm{C}$ or $60^{\circ} \mathrm{C}$ for 90 minutes and put in an ice bath to quench the reaction. Ethanol was added to the solution to dilute the sol for dip coating to a final silicon concentration of $0.3 \mathrm{~mol} / \mathrm{L}$.

Zirconia doped BTESE was prepared by two methods. The first method is a co-condensation of BTESE with $\mathrm{ZrO}\left(\mathrm{NO}_{3}\right)_{2}$ which is described in previous work [17]. In short a mixture of BTESE, $\mathrm{ZrO}\left(\mathrm{NO}_{3}\right)_{2}$, ethanol, $\mathrm{HNO}_{3}$ and water with a ratio of 1:0.19:10.5:0.2:6 is stirred for 90 minutes at $25^{\circ} \mathrm{C}$, after which the solution is cooled in an icebath and diluted with ethanol for coating to a silicon concentration of $0.18 \mathrm{~mol} / \mathrm{L}$. Using this method, sols with different $\mathrm{Zr}$ content were prepared. The other parameters were held constant and the $\mathrm{Zr}$ content was varied in a 1:4, 1:5 and a 1:10 Zr:BTESE molar ratio. The second method is a two-step synthesis. First $0.6 \mathrm{~mL}$ of a $1.77 \mathrm{~mol} / \mathrm{L} \mathrm{HNO}_{3}$ solution was added to $5.5 \mathrm{~mL}$ ethanol and placed in an ice bath. Subsequently $3.3 \mathrm{~mL}$ BTESE was dropped slowly into the mixture under vigorous stirring. The 
mixture was stirred at $60^{\circ} \mathrm{C}$ for 60 minutes and put in an ice bath for 5 minutes. Subsequently $0.2 \mathrm{~mL}$ of a $1.77 \mathrm{~mol} / \mathrm{L} \mathrm{HNO}_{3}$ solution and a solution of $0.8 \mathrm{~mL}$ Zirconium n-propoxide in $5.3 \mathrm{~mL}$ propanol was dropped slowly into the mixture. The mixture was further stirred for 30 minutes at $25^{\circ} \mathrm{C}$, after which it was placed in an ice bath and diluted with $50 \mathrm{~mL}$ ethanol for coating. Final Si concentration in the dip-sol is $0.27 \mathrm{~mol} / \mathrm{L}$ and the $\mathrm{Zr}$ :BTESE ratio is 1:5.

Niobia doped BTESE was prepared in two different ways. One method was the procedure as described by Qi et al. [12] was followed, which involves a two-step approach. First BTESE was prehydrolyzed with half of the acid and water for 90 minutes at $60^{\circ} \mathrm{C}$. After prehydrolysis, the niobium n-butoxide and the other half of the acid and water was added to the mixture to obtain a final ratio of BTESE: $\mathrm{Nb}$ (n-but):EtOH: $\mathrm{HNO}_{3}: \mathrm{H}_{2} \mathrm{O}$ of 1:0.66:22.8:0.07:4.1. This mixture was left to react for another 90 minutes at $60{ }^{\circ} \mathrm{C}$. The final Si concentration in the dip-sol is $0.16 \mathrm{~mol} / \mathrm{L}$, while the Nb:BTESE ratio is 1:1.5. For a second niobia doped BTESE system, a different approach was used with half the amount of water. Another difference between the two sols was that in the latter case $25 \% \mathrm{Nb}$ doping is used and in the first case $40 \%$. This system was prepared as follows: $0.35 \mathrm{~mL}$ of a $1.77 \mathrm{~mol} / \mathrm{L} \mathrm{HNO}_{3}$ solution was added to $5 \mathrm{~mL}$ ethanol and placed in an ice bath. Subsequently $3.33 \mathrm{~mL}$ of BTESE was dropped slowly into the mixture under vigorous stirring. The mixture was refluxed at $60^{\circ} \mathrm{C}$ for 60 minutes and placed in an ice bath. Subsequently, a mixture of $1.37 \mathrm{~mL}$ niobium n-butoxide in $3.16 \mathrm{~mL}$ ethanol was added to the mixture and refluxed for another $30 \mathrm{~min}$ at $60^{\circ} \mathrm{C}$. The final ratio of BTESE: $\mathrm{Nb}$ (n-but):EtOH:HNO $3: \mathrm{H}_{2} \mathrm{O}$ is 1:0.33:15:0.07:2. Afterwards the mixture was placed in an ice bath to quench the reaction and diluted with ethanol for coating. The final Si concentration in the dip sol is $0.3 \mathrm{~mol} / \mathrm{L}$, while the Nb:BTESE ratio is $1: 3$.

All produced sols were stored in a freezer at $-18^{\circ} \mathrm{C}$ before further use to prevent unwanted particle growth. The sol particle size was determined by dynamic light scattering (DLS) using a Malvern Zetasizer Nano ZS. Diluted sols were used for the measurements.

Porous $\alpha$-alumina supports (pore size $80 \mathrm{~nm}$, porosity 35\%) with a diameter of $39 \mathrm{~mm}$ and a thickness of $2 \mathrm{~mm}$ (Pervatech B.V. the Netherlands) were coated twice under cleanroom conditions with a boehmite sol and calcined at $650{ }^{\circ} \mathrm{C}$ at a heating rate of $1{ }^{\circ} \mathrm{C} / \mathrm{min}$ and a dwell of $3 \mathrm{~h}$, resulting in a $\gamma$-alumina intermediate layer with a thickness of $3 \mu \mathrm{m}$ and a pore size of $5 \mathrm{~nm}$ as reported by Uhlhorn et al. [18]. Pure BTESE and metal-doped-BTESE layers were coated in one step under cleanroom conditions onto the supported $\gamma$-alumina membranes using 
an automatic dip-coating machine, with an angular dipping rate of $0.06 \mathrm{rad} \cdot \mathrm{s}^{-1}$. All membranes were calcined under nitrogen at $400{ }^{\circ} \mathrm{C}$ with a heating and cooling rate of $0.5^{\circ} \mathrm{C} / \mathrm{min}$ and a dwell time of $3 \mathrm{~h}$. Only the Nb-BTESE membranes, which were prepared with the procedure as described by Qi et al. [12], were calcined at $450{ }^{\circ} \mathrm{C}$ in order to make a fair comparison with the work of Qi et al.

Single gas permeation was performed on an automated setup (OSMO-Inspector GP, Con-Vergence BV. the Netherlands). A membrane was heated to $200{ }^{\circ} \mathrm{C}$ under nitrogen with a heating rate of $2{ }^{\circ} \mathrm{C} / \mathrm{min}$ to remove the adsorbed water. The permeation measurements were performed directly after heating up to $200{ }^{\circ} \mathrm{C}$ at a transmembrane pressure of 2 bar. The gases were measured in the following order: helium, nitrogen, methane, hydrogen and carbon dioxide. Every gas was measured for $30 \mathrm{~min}$ to ensure a stable flow.

\subsection{Results and discussion}

\subsubsection{Sol characteristics}

BTESE sols were synthesized at $30^{\circ} \mathrm{C}$ and $60^{\circ} \mathrm{C}$ for 90 minutes. The particle size distribution of these sols is shown in Figure 4.1. It is clearly visible that a higher reaction temperature leads to larger particles with a broader particle size distribution. The mean intensity based particle size of BTESE, synthesized at $60{ }^{\circ} \mathrm{C}$, is $14.7 \mathrm{~nm}$. For BTESE synthesized at $30^{\circ} \mathrm{C}$ the mean intensity based particle size is $4.4 \mathrm{~nm}$, which is too small for coating. The pore diameter of the $\gamma$-alumina intermediate layer is $5 \mathrm{~nm}$, so in order to prevent infiltration of the intermediate layer the particle size of the sol should be above $5 \mathrm{~nm}$ [19]. On the other hand, if the particle size is too large, formation of intraparticle defects during gelation/drying can occur, which is detrimental for the 
membrane performance. The particle size, achieved after a sol reaction at $60{ }^{\circ} \mathrm{C}$ for 90 minutes, is in the good range for fabricating a membrane layer, as is shown in Figure 4.2.

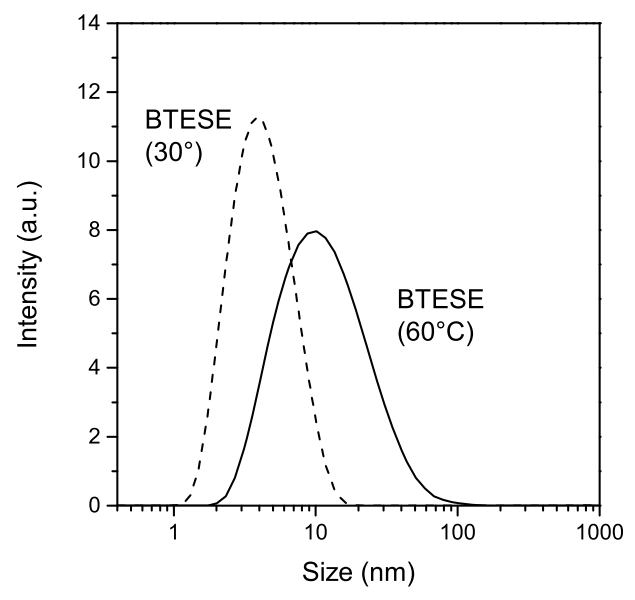

Figure 4.1: Particle size distribution of BTESE sols synthesized at $30^{\circ} \mathrm{C}$ and $60^{\circ} \mathrm{C}$ for 90 minutes

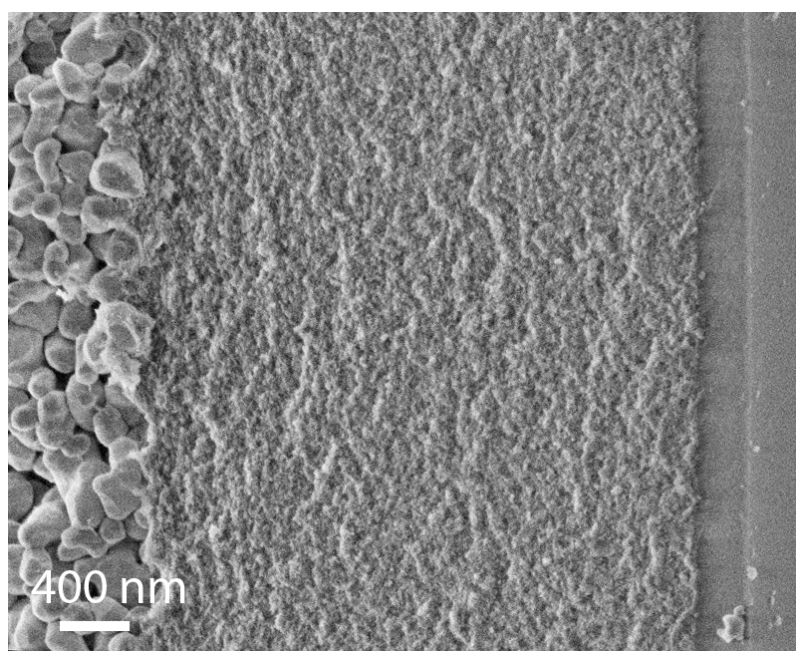

Figure 4.2: SEM image of a BTESE membrane, made from a sol, synthesized at $60^{\circ} \mathrm{C}$. From left to right are visible: $\alpha$-alumina support, $\gamma$-alumina intermediate layer of $3 \mu \mathrm{m}$ thickness, BTESE top layer of $300 \mathrm{~nm}$ thickness 
In previous work [17] it was shown that doping zirconia to BTESE during the sol synthesis, by using the metal nitrate, resulted in gelation of the Zr-BTESE system within 10 minutes when applying the same experimental conditions as used for the undoped BTESE sol synthesis $\left(60^{\circ} \mathrm{C}\right.$, 90 minutes). Therefore the experimental conditions were adapted and the desired sol for membrane fabrication was achieved by applying a reaction temperature of $25^{\circ} \mathrm{C}$ and a reaction time of 90 minutes. It was expected that the sol synthesis also went fast when yttrium nitrate was added to BTESE for fabrication of yttria doped BTESE sols. However, a Y-BTESE sol synthesized at $30{ }^{\circ} \mathrm{C}$ for 90 minutes resulted in a mean intensity based particle size of $4.6 \mathrm{~nm}$ (Figure 4.3). This is only slightly larger compared to the particle size of undoped BTESE synthesized at $30^{\circ} \mathrm{C}$, although still too small for applying a separation layer on the $\gamma$-alumina intermediate layer. SEM micrographs of these systems did not reveal any Y-BTESE selective layer on top of the $\gamma$-alumina, as is shown in Figure 4.4. By using a reaction temperature of $60{ }^{\circ} \mathrm{C}$ and a reaction time of 90 minutes a mean intensity particle size of $16.2 \mathrm{~nm}$ was obtained for Y-BTESE, as shown in Figure 4.3, which is only marginally larger than the particle size of undoped BTESE but in the correct size range for coating. This indicates that yttria, in the form of yttrium nitrate, only has a small influence on the reaction rate and particle growth during BTESE sol synthesis.

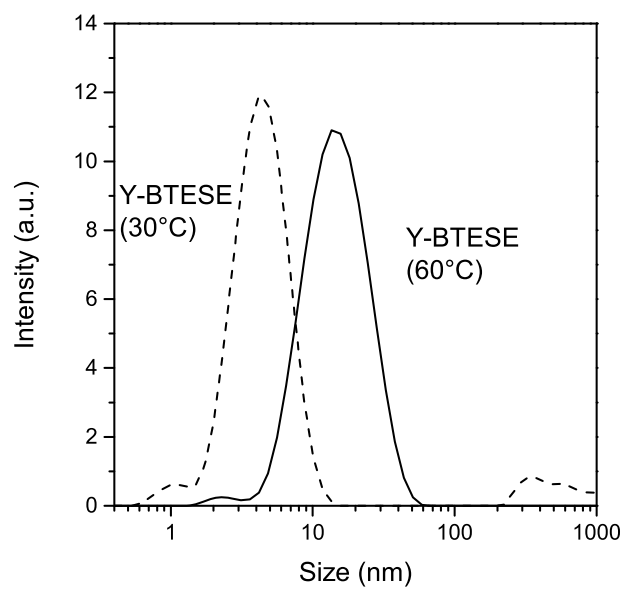

Figure 4.3: Particle size distribution of yttria-doped BTESE sols synthesized at $30^{\circ} \mathrm{C}$ and $60^{\circ} \mathrm{C}$ for 90 minutes 


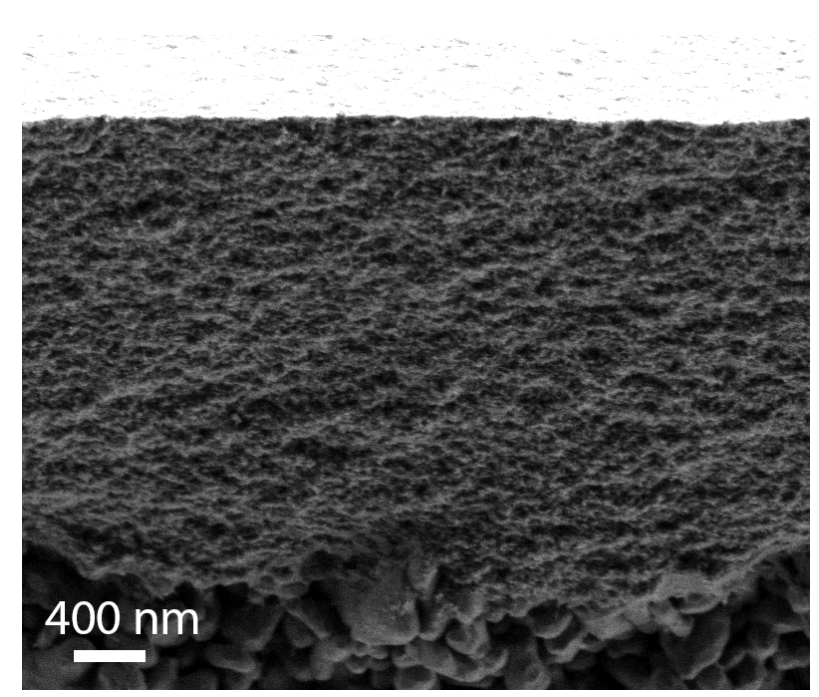

Figure 4.4: SEM image of a membrane made with a Y-BTESE(30) sol. Only the $\alpha$-alumina support (bottom) and the $\gamma$-alumina intermediate layer of $3 \mu \mathrm{m}$ thickness are visible. No well-defined Y-BTESE layer is observed on top of the intermediate layer

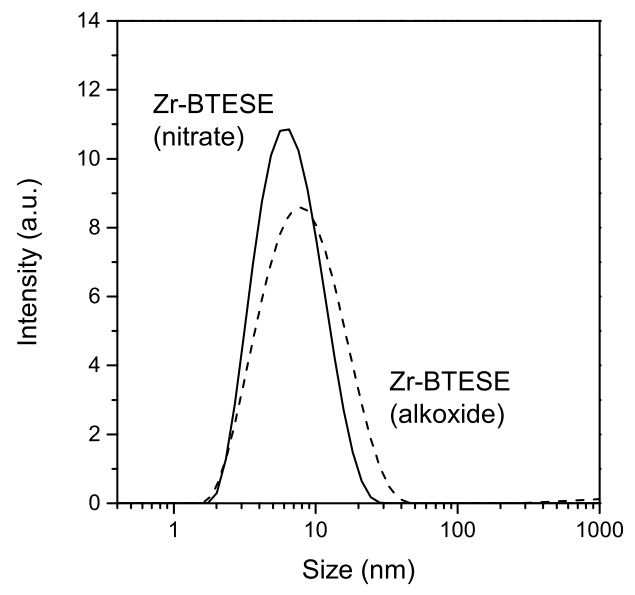

Figure 4.5: Particle size distribution of $16 \%$ Zr-doped BTESE sols prepared with zirconyl nitrate or a zirconium alkoxide source. In both cases a reaction temperature of $30^{\circ} \mathrm{C}$ was used 
The zirconia doped sols were prepared by two different methods, utilizing two different zirconium sources. The particle size distribution for both methods is shown in Figure 4.5. Zr-BTESE prepared by the nitrate route has a mean intensity based particle size of $7.2 \mathrm{~nm}$, while Zr-BTESE prepared by the two-step alkoxide route has a mean intensity based particle size of $9.4 \mathrm{~nm}$ and has a distribution that is slightly broader. The reason that the alkoxide based sol is slightly larger than the nitrate based sol can be due to the fact that the prehydrolysis of BTESE resulted already in some condensation.

For the nitrate route three different amounts of zirconia doping were used. The particle size distribution for the different dopant concentrations is shown in Figure 4.6. A slight increase in average particle size is observed with an increase in dopant concentration, which is expected to be due to the relative fast reaction rate of zirconyl nitrate as compared to BTESE. A second peak is visible for all zirconium concentrations, although the amount of larger particles is negligible. Prior to coating, these larger particles are filtered out and will not influence the coating layer.

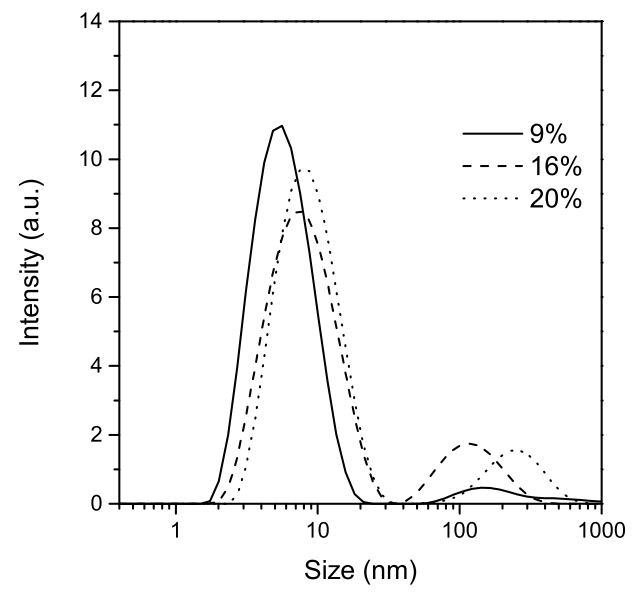

Figure 4.6: Particle size distribution of Zr-BTESE prepared by the nitrate route with 9, 16 and $20 \mathrm{~mol} \%$ zirconia doping

Also for niobium doped BTESE two different methods were used. The first method is a reproduction of the sol synthesis as described by Qi et al. [12] with a doping concentration of 
$40 \%$, while for the second method $25 \%$ of $\mathrm{Nb}$ and half of the amount of water was used. By using a lower amount of water in the second method the hydrolysis rate can be better controlled, which is necessary as niobium alkoxide shows fast hydrolysis behavior. This results in an easier way to obtain the desired (smaller) particles, which are necessary for obtaining a well-defined and defect-free coating on the $\gamma$-alumina intermediate layer. The particle size distribution for both methods is shown in Figure 4.7. The mean intensity based particle size of the sol as prepared by Qi's method (Nb-BTESE (40\%) is $26.1 \mathrm{~nm}$; the particle size of Nb-BTESE (25\%) is $6.2 \mathrm{~mm}$.

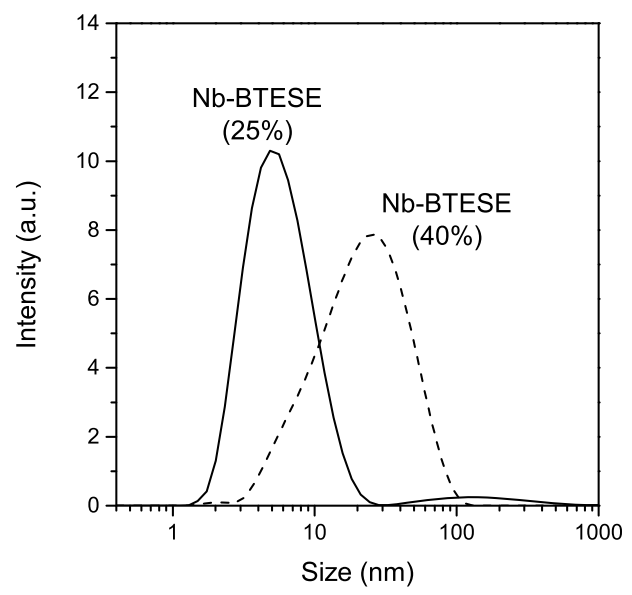

Figure 4.7: Particle size distribution of Nb-BTESE with a $\mathrm{Nb}$ content of $40 \%$, as made by the procedure of $\mathrm{Qi}$ et al. and with a $\mathrm{Nb}$ content of $25 \%$ with a lower hydrolysis ratio 
Table 4.1: Summary of the sol particle size of the produced sols and an indication if a membrane could be formed from the sol

\begin{tabular}{llll}
\hline Sol & $\begin{array}{l}\text { Mean intensity size } \\
(\mathbf{n m})\end{array}$ & $\begin{array}{l}\text { Standard deviation } \\
(\mathbf{n m})\end{array}$ & $\begin{array}{l}\text { Membrane } \\
\text { formed? }\end{array}$ \\
\hline BTESE (30) & 4.4 & 2.2 & No \\
BTESE (60) & 14.7 & 9.8 & Yes \\
Y-BTESE (30) & 4.6 & 1.9 & No \\
Y-BTESE (60) & 16.2 & 8.1 & Yes \\
Zr-BTESE (alkoxide) & 9.4 & 5.9 & Yes \\
Zr-BTESE (nitrate) & 7.2 & 3.7 & Yes \\
Zr-BTESE 9\% & 6.2 & 2.9 & Yes \\
Zr-BTESE 16\% & 8.6 & 4.5 & Yes \\
Zr-BTESE 20\% & 9.3 & 4.9 & Yes \\
Nb-BTESE (25\%) & 6.2 & 3.4 & Yes \\
Nb-BTESE (40\%) & 26.1 & 17.6 & Yes \\
\hline
\end{tabular}

The results of the particle sizes of the synthesized sols are summarized in Table 4.1. The formation of the membrane layers was confirmed by single gas permeation measurements. If the $\mathrm{H}_{2} / \mathrm{CH}_{4}$ permselectivity was higher than the Knudsen selectivity of these gases, it was assumed that a continuous (doped) BTESE layer was formed on the $\gamma$-alumina intermediate layer of the membrane support. From these results it is clear that no membrane layer can be formed from sols containing particles with a mean (intensity based) particle size less than $4.7 \mathrm{~nm}$.

\subsubsection{Gas permeability}

The prepared membranes were tested for single gas permeation at $200{ }^{\circ} \mathrm{C}$ and 2 bar pressure difference. In Figure 4.8 the single gas permeance for undoped BTESE and Y-BTESE is shown. The BTESE membrane shows typical permeance behavior as reported in previous work $[2,17$, 20], with a relatively high $\mathrm{H}_{2}$ permeance of $4.4 \times 10^{-7} \mathrm{~mol} \mathrm{~m}^{-2} \mathrm{~Pa}^{-1} \mathrm{~s}^{-1}$ and a $\mathrm{H}_{2} / \mathrm{CO}_{2}$ permselectivity of 3.9, which is lower than the Knudsen selectivity. The Y-BTESE membranes show a slightly higher permeance for all gases. The permselectivity, however, is slightly lower compared to undoped BTESE; e.g. for of $\mathrm{H}_{2} / \mathrm{N}_{2}$ permselectivities of 10 and 12 are observed for Y-BTESE and undoped BTESE respectively. These higher permeances and lower permselectivities are indicative for a more open pore structure for the Y-BTESE membranes. 


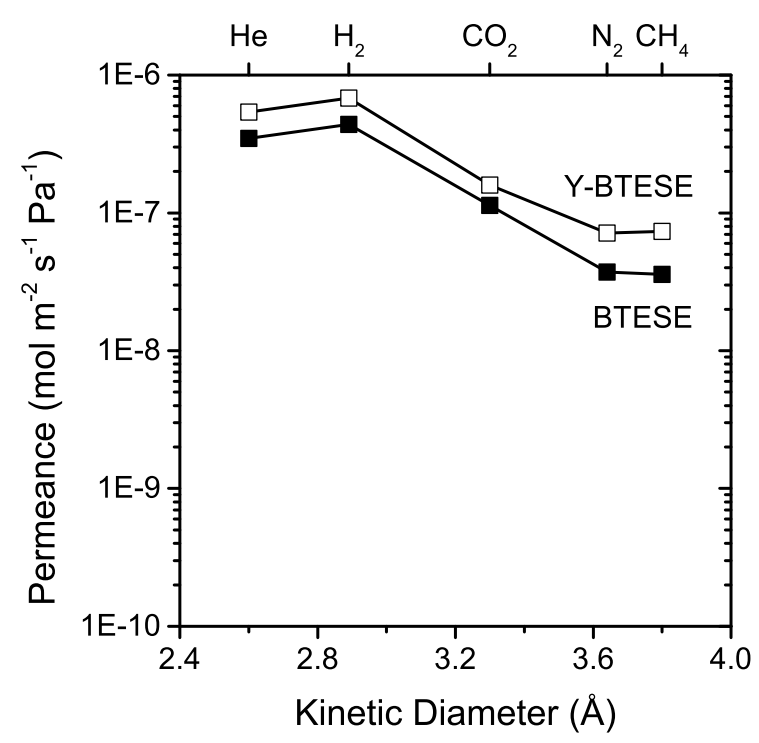

Figure 4.8: Single gas permeation results for undoped BTESE and Y-BTESE

For Zr-BTESE, two different precursors were used as a zirconium source. The single gas permeation results for both Zr-BTESE membranes are shown in Figure 4.9. A zirconia doping of $16 \%$ was used in both cases. Zr-BTESE, prepared with zirconyl nitrate as precursor, has lower permeances for the larger gases compared to Zr-BTESE, prepared by using the alkoxide precursor. These lower permeances are indicative for a denser structure when the nitrate precursor is used during sol synthesis. Also the permselectivity is much higher for the nitrate derived systems compared to the alkoxide-derived systems, with a $\mathrm{H}_{2} / \mathrm{CO}_{2}$ selectivity of 12.3 and 5.3 and $\mathrm{H}_{2} / \mathrm{N}_{2}$ of 83 and 19 respectively. The two-step synthesis used for the zirconium alkoxide precursor may lead to an open network due to the prehydrolysis and partial condensation of BTESE before the addition of zirconium. The one-step process and the low temperature for the synthesis with the zirconyl nitrate precursor leads to a more homogenous sol. A denser network is formed with the nitrate based sol thanks to the homogeneity of the sol compared to the two-step approach with the alkoxide precursor. 


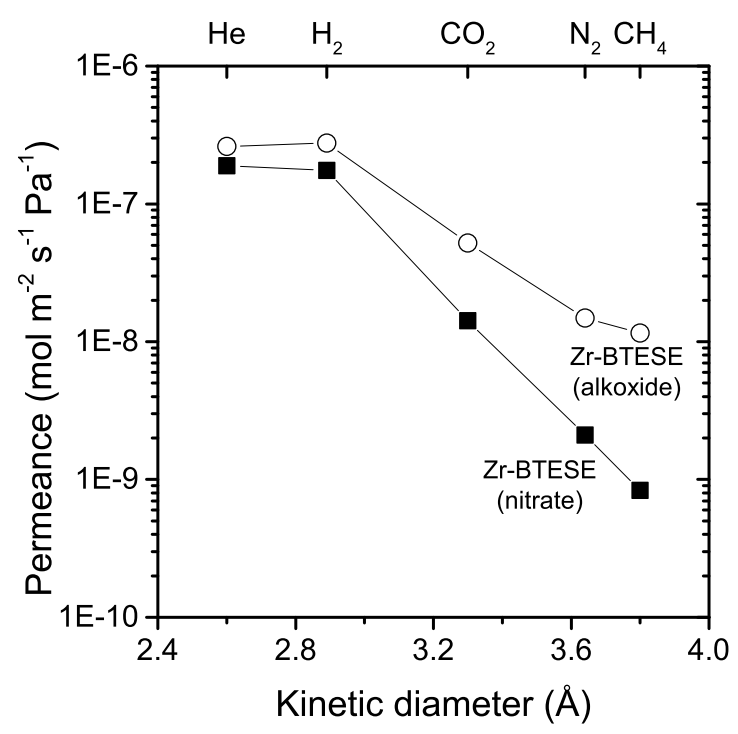

Figure 4.9: Gas permeation at $200^{\circ} \mathrm{C}$ and pressure difference of 2 bar of $16 \mathrm{~mol} \% \mathrm{Zr}$ doped BTESE membranes prepared via the alkoxide and nitrate routes

In Figure 4.10 the single gas permeation results for the membranes with different zirconia doping content are shown. The 16\% doping shows the lowest permeances, while $9 \%$ and $20 \%$ show almost identical behavior. It seems that there is an optimum amount of doping that leads to a densified network for this particular system. It is possible that, due to the high reaction rates of the zirconyl nitrate, the $20 \%$ doping has a higher probability of forming zirconia clusters, which affects the performance in an adverse way. 


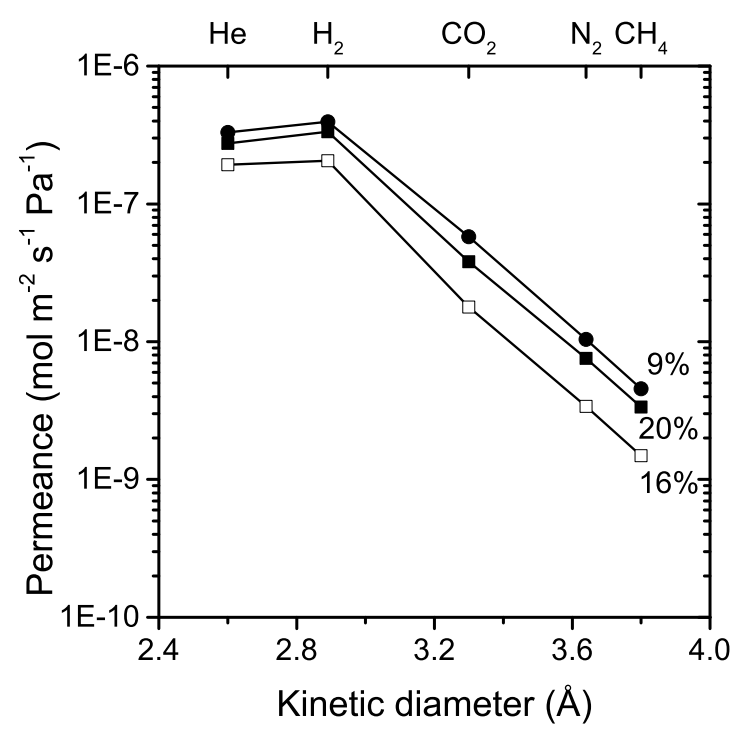

Figure 4.10: Single gas permeation results of Zr-BTESE with different $\mathrm{Zr}$ content

In Figure 4.11A and Table 4.2 the single gas permeation results for Nb-BTESE membranes prepared via different sol synthesis methods are shown. Nb-BTESE (25\%), prepared in this work, shows a higher $\mathrm{He}$ and $\mathrm{H}_{2}$ permeance and lower permselectivities compared to the $\mathrm{Nb}-\mathrm{BTESE}(40 \%)$ membrane by Qi et al. that is calcined at the same temperature $\left(400{ }^{\circ} \mathrm{C}\right)[13]$. In another paper, Qi et al. investigated the influence of the amount of $\mathrm{Nb}$ doping on permeation behavior [21], where little influence of doping amount on gas permeation was found. Therefore it is safe to say that the difference between Nb-BTESE (25\%) prepared in this work and Nb-BTESE (40\%) prepared by Qi et al. at $400{ }^{\circ} \mathrm{C}$ can be ascribed to the difference in sol synthesis method. The hydrolysis ratio, which is defined as the ratio of water to hydrolysable alkoxide groups on the metals $\left(\left[\mathrm{H}_{2} \mathrm{O}\right]:[-\mathrm{OR}]\right)$, is the main difference in the synthesis methods. During prehydrolysis of BTESE the hydrolysis ratio is 0.33 for both synthesis routes. For $\mathrm{Nb}$-BTESE (25\%) only water and acid is added at the start of the synthesis, so after addition of the Nb-precursor a final hydrolysis ratio of 0.25 is obtained. For Nb-BTESE (40\%), according to the method of Qi et al., extra water was added after the addition of the $\mathrm{Nb}$ precursor, which leads to a higher final hydrolysis ratio of 0.44 . Because of the lower hydrolysis ratio used in our work, hydrolysis of the BTESE may not have been completed and this might lead to a more 
open network as proposed by Niimi et al. [21, 22], who showed that for undoped BTESE a stronger densification of the network during gelation is observed when a higher hydrolysis ratio is used. With a lower hydrolysis ratio the hydrolysis of BTESE does not go to completion, resulting in the presence of ethoxy groups during film formation. These ethoxy groups lead to a more open structure as they are removed during firing. Also the shorter synthesis time for Nb-BTESE (25\%) might have led to incomplete hydrolysis. Therefore higher permeances of $\mathrm{He}$ and $\mathrm{H}_{2}$ for $\mathrm{Nb}-\mathrm{BTESE}(25 \%)$ are obtained.

In Figure 4.11B the gas permeation results are compared for Nb-BTESE (40\%) as prepared in this work and the literature data. Although the sol synthesis, membrane fabrication and calcination procedure for this Nb-BTESE (40\%) membrane is identical to the method as described by Qi et al. [12], the membrane does not show the same single gas permeation results as reported by these authors. The helium and hydrogen permeance are similar for both membranes, but striking differences are observed for the $\mathrm{CO}_{2}$ permeance. Qi et al. claim a $\mathrm{H}_{2} / \mathrm{CO}_{2}$ permselectivity of 220 due to a reduced affinity to $\mathrm{CO}_{2}$ by the niobia, while in our work a $\mathrm{H}_{2} / \mathrm{CO}_{2}$ selectivity of only 4.9 was measured with no signs of reduced affinity. Since both membranes are made by the same procedure the results should be comparable. The fact that this is not the case raises some concerns on the experimental method used by Qi et al to determine the gas flow through the membranes, which is especially deviating at lower permeance values (for the gases $\mathrm{CO}_{2}, \mathrm{~N}_{2}$ and $\mathrm{CH}_{4}$ ). 

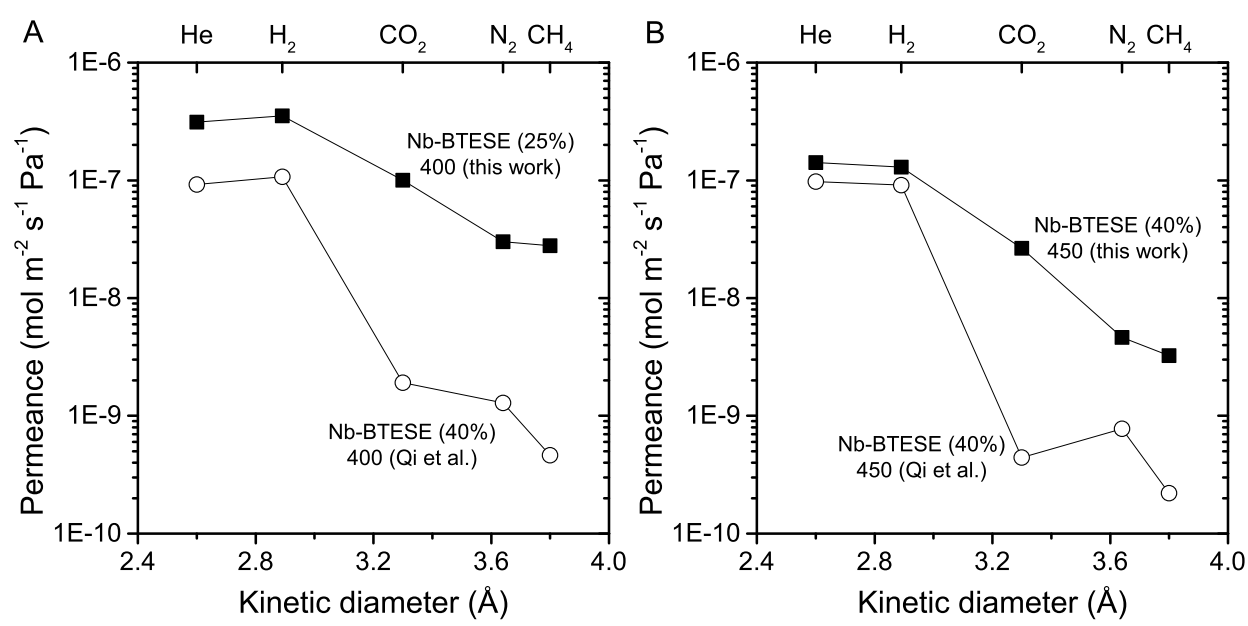

Figure 4.11: Single gas permeation results for Nb-BTESE: (A) comparison in synthesis method between our work and Qi et al. [13]; (B) comparison of Nb-BTESE (40\%) membrane calcined at $450{ }^{\circ} \mathrm{C}$ made in this work and by Qi et al. [12]

Table 4.2: Overview of Nb-BTESE membranes from this work and literature

\begin{tabular}{lrrrrr}
\hline & $\begin{array}{c}\mathrm{T}_{\text {calcination }} \\
\left({ }^{\circ} \mathrm{C}\right)\end{array}$ & $\begin{array}{c}\mathrm{H}_{2} \text { permeance } \\
\left(10^{-9} \mathrm{~mol} \mathrm{~m}^{-2} \mathrm{~s}^{-1}\right. \\
\left.\mathrm{Pa}^{-1}\right)\end{array}$ & \multicolumn{3}{c}{ Permselectivity } \\
& 400 & 354 & 3.5 & 12 & 13 \\
\hline $\begin{array}{l}\text { Nb-BTESE 25\% } \\
\text { (this work) }\end{array}$ & 400 & 107 & 45 & 80 & 230 \\
$\begin{array}{l}\text { Nb-BTESE 40\% } \\
\text { (Qi [13]) }\end{array}$ & 450 & 130 & 4.9 & 28 & 40 \\
$\begin{array}{l}\text { Nb-BTESE 40\% } \\
\text { (this work) }\end{array}$ & 450 & 97 & 220 & 130 & 430 \\
$\begin{array}{l}\text { Nb-BTESE 40\% } \\
\text { (Qi [13]) }\end{array}$ & & & & & \\
\hline
\end{tabular}

In Figure 4.12 an overview of the gas permeation results for the different metal-doped BTESE membranes, as studied in this work is shown. For undoped BTESE and Y-BTESE a higher hydrogen permeance compared to helium permeance is observed, which is due to some Knudsen diffusion in the micropores. This can only occur when the micropores are sufficiently large; therefore the permeance of the larger gases is also higher, which results in lower permselectivity. For the Nb-BTESE and Zr-BTESE membranes a lower hydrogen permeance compared to helium permeance is observed, indicating size selective separation due to the presence of smaller pores. For Nb-BTESE an overall decrease in permeance and somewhat higher permselectivity 
is observed when compared with undoped BTESE membranes. From these results it can be derived that for the Nb-BTESE membranes a smaller average pore size is obtained in comparison with undoped BTESE, but still a relative large number of larger pores are present. Zirconia doping has more strongly reduced the size and/or number of the larger pores, responsible for the transport of the larger gases like $\mathrm{N}_{2}$ and $\mathrm{CH}_{4}$, resulting in an improved permselectivity. From these results it can be concluded that zirconia doping is most effective for increasing the permselectivity of BTESE-derived membranes. This effectiveness can be ascribed to the homogeneity of the sol due to the one-step synthesis approach.

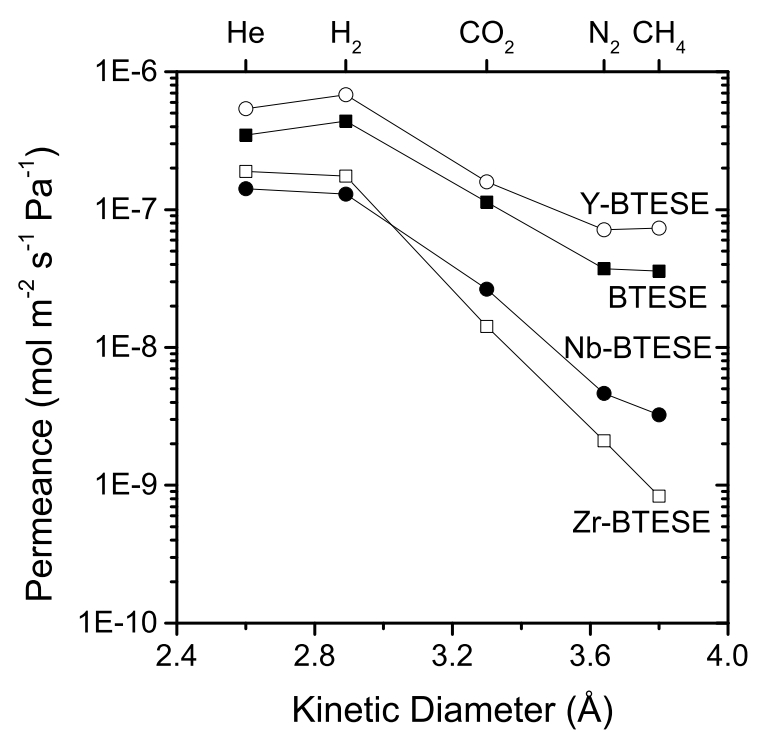

Figure 4.12: Overview of the influence of the metal doping on the gas permeation performance

\subsection{Conclusion}

The effect of metal doping on the synthesis of BTESE-derived sols and the resulting membrane properties are described. Adding yttrium nitrate during the sol synthesis of BTESE had little influence on the reaction speed, while zirconyl nitrate, zirconium propoxide and niobium butoxide accelerate particle growth due to the fast hydrolysis of the precursors.

The mean intensity based particle size, as determined from DLS measurements, is a good indication if a membrane layer can be formed on a porous substrate. In the case of $\gamma$-alumina 
with a pore diameter of $5 \mathrm{~nm}$, a mean intensity based particle size lower than the pore diameter led to infiltration of the sol in the substrate and no improved separation. The sol particle size distribution does only give information about the ability to form a coating layer and gives no further insight in the membrane structure.

Based on gas permeation results, metals with a valence equal or higher to that of silica $\left(\mathrm{Zr}^{4+}\right.$ or $\mathrm{Nb}^{5+}$ ) can be used to increase the gas permeation performance, meaning a higher $\mathrm{H}_{2} / \mathrm{CO}_{2}$ permselectivity. This is however only possible if the incorporation of the metal in the hybrid silica network can be carefully controlled during synthesis. A single-step reaction is recommended, since a two-step reaction can lead to unwanted condensation before metal addition, compromising the pore structure of the membrane. Due to the fast hydrolysis of the niobium pentabutoxide it was necessary for the niobia doped membranes to use a two-step approach. Therefore the zirconia doped membranes are most promising, due to the one-step synthesis and the increased permselectivity over undoped BTESE membranes.

Despite carefully following the procedure used by Qi et al. [12], these literature results could not be reproduced. The helium and hydrogen permeances are more or less similar, however the carbon dioxide permeance shows a big deviation.

\subsection{References}

[1] M.C. Duke, J.C.D. da Costa, D.D. Do, P.G. Gray, G.Q. Lu, Hydrothermally robust molecular sieve silica for wet gas separation, Advanced Functional Materials, 16 (2006) 1215-1220.

[2] H.F. Qureshi, A. Nijmeijer, L. Winnubst, Influence of sol-gel process parameters on the micro-structure and performance of hybrid silica membranes, Journal of Membrane Science, 446 (2013) 19-25.

[3] R. Bredesen, K. Jordal, O. Bolland, High-temperature membranes in power generation with $\mathrm{CO} 2$ capture, Chemical Engineering and Processing, 43 (2004) 1129-1158.

[4] G.P. Fotou, Y.S. Lin, S.E. Pratsinis, Hydrothermal Stability of Pure and Modified Microporous Silica Membranes, Journal of Materials Science, 30 (1995) 2803-2808.

[5] K. Yoshida, Y. Hirano, H. Fujii, T. Tsuru, M. Asaeda, Hydrothermal stability and performance of silicazirconia membranes for hydrogen separation in hydrothermal conditions, Journal of Chemical Engineering of Japan, 34 (2001) 523-530.

[6] D. Uhlmann, S. Liu, B.P. Ladewig, J.C. Diniz da Costa, Cobalt-doped silica membranes for gas separation, Journal of Membrane Science, 326 (2009) 316-321.

[7] R. Igi, T. Yoshioka, Y.H. Ikuhara, Y. Iwamoto, T. Tsuru, Characterization of Co-Doped Silica for Improved Hydrothermal Stability and Application to Hydrogen Separation Membranes at High Temperatures, Journal of the American Ceramic Society, 91 (2008) 2975-2981.

[8] D. Uhlmann, S. Smart, J.C. Diniz da Costa, High temperature steam investigation of cobalt oxide silica membranes for gas separation, Separation and Purification Technology, 76 (2010) 171-178.

[9] V. Boffa, J.E. ten Elshof, A.V. Petukhov, D.H. Blank, Microporous niobia-silica membrane with very low CO2 permeability, ChemSusChem, 1 (2008) 437-443.

[10] V. Boffa, D.H.A. Blank, J.E. ten Elshof, Hydrothermal stability of microporous silica and niobia-silica membranes, Journal of Membrane Science, 319 (2008) 256-263. 
[11] E.J. Kappert, D. Pavlenko, J. Malzbender, A. Nijmeijer, N.E. Benes, P.A. Tsai, Formation and prevention of fractures in sol-gel-derived thin films, Soft Matter, 11 (2015) 882-888.

[12] H. Qi, J. Han, N. Xu, H.J. Bouwmeester, Hybrid organic-inorganic microporous membranes with high hydrothermal stability for the separation of carbon dioxide, ChemSusChem, 3 (2010) 1375-1378.

[13] H. Qi, J. Han, N.P. Xu, Effect of calcination temperature on carbon dioxide separation properties of a novel microporous hybrid silica membrane, Journal of Membrane Science, 382 (2011) 231-237.

[14] H.F. Qureshi, R. Besselink, J.E. ten Elshof, A. Nijmeijer, L. Winnubst, Doped microporous hybrid silica membranes for gas separation, Journal of Sol-Gel Science and Technology, 75 (2015) 180-188.

[15] M.J. Wolf, Microporous membranes for gas separation : a study towards preparation and characterization of different sol-gel derived membrane materials, in, Enschede, the Netherlands, 2015, pp. 126.

[16] M. Kanezashi, S. Miyauchi, H. Nagasawa, T. Yoshioka, T. Tsuru, Gas permeation properties through Al-doped organosilica membranes with controlled network size, Journal of Membrane Science, 466 (2014) 246-252.

[17] M. ten Hove, A. Nijmeijer, L. Winnubst, Facile synthesis of zirconia doped hybrid organic inorganic silica membranes, Separation and Purification Technology, 147 (2015) 372-378.

[18] R.J.R. Uhlhorn, M.H.B.J.H.I.t. Veld, K. Keizer, A.J. Burggraaf, Synthesis of ceramic membranes, Journal of Materials Science, 27 (1992) 527-537.

[19] H.L. Castricum, A. Sah, J.A.J. Geenevasen, R. Kreiter, D.H.A. Blank, J.F. Vente, J.E. ten Elshof, Structure of hybrid organic-inorganic sols for the preparation of hydrothermally stable membranes, Journal of Sol-Gel Science and Technology, 48 (2008) 11-17.

[20] H.L. Castricum, H.F. Qureshi, A. Nijmeijer, L. Winnubst, Hybrid silica membranes with enhanced hydrogen and CO2 separation properties, Journal of Membrane Science, 488 (2015) 121-128.

[21] H. Qi, H. Chen, L. Li, G. Zhu, N. Xu, Effect of Nb content on hydrothermal stability of a novel ethylene-bridged silsesquioxane molecular sieving membrane for $\mathrm{H} 2 / \mathrm{CO} 2$ separation, Journal of Membrane Science, 421-422 (2012) 190-200.

[22] T. Niimi, H. Nagasawa, M. Kanezashi, T. Yoshioka, K. Ito, T. Tsuru, Preparation of BTESE-derived organosilica membranes for catalytic membrane reactors of methylcyclohexane dehydrogenation, Journal of Membrane Science, 455 (2014) 375-383. 

5 Influence of the intermediate layer on the hydrothermal stability of sol-gel derived membranes 


\begin{abstract}
The hydrothermal stability of microporous sol-gel derived membranes is of high importance for implementation of these membranes in industry, as a lot of industrial processes include steam. Often the hydrothermal stability is tested on either the mesoporous intermediate membrane layer or the microporous separation layer of the membrane. In this work an investigation is done on the interaction between the intermediate $\gamma$-alumina layer and the hybrid (BTESE-derived) silica separation layer during hydrothermal treatment. Although bare $\gamma$-alumina is degraded during a hydrothermal treatment, a coating of hydrophobic BTESE on $\gamma$-alumina retains its gas separation performance, albeit with a lower mechanical stability. Applying a monoaluminumphosphate (MAP) coating between the $\alpha$-alumina support and the $\gamma$-alumina layer stabilizes the $\gamma$-alumina membrane. MAP modification however leads to a pore shrinkage in the intermediate layer, which lowers the gas permeance through the BTESE separation layer.
\end{abstract}




\subsection{Introduction}

Sol-gel derived ceramic membranes for gas separation are often made as a multi-graded system. A macroporous support provides the system its mechanical strength; a mesoporous layer provides a smooth surface and a pore size of several nanometers for the application of a defect free microporous separation layer with a pore size of less than $1 \mathrm{~nm}$.

The mesoporous layer is already a membrane by itself that can be used for nanofiltration. A typical pore diameter for these membranes is around $5 \mathrm{~nm}$. Commonly used materials as intermediate layer are $\gamma$-alumina [1, 2], yttria stabilized zirconia [3] or silica-zirconia [4]. These membranes provide a very well defined surface for the deposition of a sol-gel derived microporous top layer, which can have a thickness of less than $100 \mathrm{~nm}$ and hence needs a very smooth surface.

The material that is widely used for mesoporous intermediate layers is $\gamma$-alumina due to the relatively easy way of fabrication and its high surface quality. The hydrothermal stability of such $\gamma$-alumina layers is however rather poor. Gallaher et al. [5] showed for commercial $\gamma$-alumina membranes (Membralox ${ }^{\circledR}$, US Filter) that pore growth occurs after a hydrothermal treatment at $640{ }^{\circ} \mathrm{C}$ with $90 \%$ steam. Nijmeijer et al. [6] observed for pure $\gamma$-alumina, calcined at $825^{\circ} \mathrm{C}$, a pore growth from 4.2 to $6.2 \mathrm{~nm}$ after a hydrothermal treatment at $600{ }^{\circ} \mathrm{C}$. They claimed that doping $\gamma$-alumina with $6 \%$ lanthanum could prevent this pore growth. Zahir et al. [7] also observed pore growth in undoped $\gamma$-alumina, calcined at $600{ }^{\circ} \mathrm{C}$, after hydrothermal treatment at $500{ }^{\circ} \mathrm{C}$. However, in their work it was found that, opposite to the findings of Nijmeijer et al., the addition of $6 \%$ lanthanum could not stop pore growth. Zahir et al. showed that only a mixture of $6 \%$ Lanthanum and 30\% gallium in $\gamma$-alumina could prevent the pore growth during hydrothermal treatment. The reason for the difference between the results of Nijmeijer et al. and Zahir et al. might be the difference in calcination temperature used. The stabilization effects of lanthanum are due to the formation of lanthanumaluminate $\left(\mathrm{LaAlO}_{3}\right)$, which is only formed above $700{ }^{\circ} \mathrm{C}$ [8]. After calcination at $600{ }^{\circ} \mathrm{C}$, as used by Zahir et al. [7], only lanthanum oxide is formed, which apparently does not contribute to the hydrothermal stability.

Nagano et al. [9] doped nickel in $\gamma$-alumina to prevent pore growth in order to increase the hydrothermal stability. They found that that the addition of $5 \%$ nickel was sufficient to prevent pore growth during hydrothermal treatments. Larger amounts of nickel led to the formation of nickel oxide and did not contribute to the hydrothermal stability of the membranes. 
Nijmeijer et al. [6] have also shown that hydrothermal treatments of $\alpha$-alumina supported $\gamma$-alumina membranes can lead to detachment of the $\gamma$-alumina layer from the support. They were successfully able to prevent this delamination by applying a monoaluminumphosphate (MAP) coating between the support and the $\gamma$-alumina layer. The idea was that the chemical bonding between the support and $\gamma$-alumina by MAP is able to overcome the stresses induced by phase transformations and sintering of $\gamma$-alumina. Phosphorus can also be used to stabilize $\gamma$-alumina to higher temperatures, as shown by Gishti et al. [10] for $\mathrm{MoO}_{3}-\mathrm{Al}_{2} \mathrm{O}_{3}$ based catalyst particles. Phosphorus doping is often achieved by impregnation [11,12] or addition in the gelphase $[12,13]$ in the form of phosphoric acid or ammonium phosphate. After calcination the phosphorus is present as a phosphate at the grain boundaries of the alumina, retarding phase transformations.

Although several of investigations have been done on the hydrothermal stability of pure and doped $\gamma$-alumina intermediate layers, only few long-term stability tests have been performed with membrane separation layers coated on pure (non-modified) $\gamma$-alumina. For long-term pervaporation tests Castricum et al. used non-modified $\gamma$-alumina as an intermediate layer for their hybrid sol-gel derived separation layers, based on 1,2-bis(triethoxysilyl)ethane (BTESE) [14]. These membranes were used in butanol dehydration at $95{ }^{\circ} \mathrm{C}$ and performed well for over more than one year. Also cobalt-silica membranes, prepared by the group of $\mathrm{Da}$ Costa are coated on non-modified $\gamma$-alumina and subjected to hydrothermal treatments without significant degradation $[15,16]$. This raises the question whether or not the stability of the intermediate layer plays a big role in the stability of such membranes.

Investigations on the hydrothermal stability of sol-gel derived membranes often focus on the separation layers, not on the interplay between the different layers. In this work a systematic investigation is performed to understand more about the influence of the top-layer on the stability of the intermediate layer. By using a fairly simple hydrothermal treatment test, $\gamma$-alumina and MAP modified $\gamma$-alumina membranes were tested. Hydrothermal stability was monitored by performing permporometry measurements on as-calcined membranes and hydrothermally treated membranes. The hydrothermal stability of the membranes coated with a BTESE separation layer was further evaluated by single gas permeation measurements on as-calcined as well as on hydrothermally treated membranes. 


\subsection{Experimental}

\subsubsection{Membrane preparation}

A boehmite sol was prepared using the procedure as described elsewhere [1]. In short, aluminum-tri-sec-butoxide was precipitated in water of $94{ }^{\circ} \mathrm{C}$ and peptized by $\mathrm{HNO}_{3}$ to obtain a boehmite sol with a particle size of around $50 \mathrm{~nm}$. Prior to coating, the boehmite sol was mixed with a PVA solution, which acts as a binder and drying aid.

Disc shaped, porous $\alpha$-alumina supports (pore size $80 \mathrm{~nm}$, porosity 35\%) with a diameter of $39 \mathrm{~mm}$ and a thickness of $2 \mathrm{~mm}$ (Pervatech B.V. the Netherlands) were coated twice under cleanroom conditions with a boehmite sol and calcined at $650{ }^{\circ} \mathrm{C}$ at a heating and cooling rate of $1{ }^{\circ} \mathrm{C} / \mathrm{min}$ and a dwell time of $3 \mathrm{~h}$. Monoaluminumphosphate (MAP) modification was performed by coating the $\alpha$-alumina supports with a $5 \mathrm{wt} \%$ MAP (Fluka) in water solution. After MAP coating, the supports were dried at $300^{\circ} \mathrm{C}$ with a heating and cooling rate of $1{ }^{\circ} \mathrm{C} / \mathrm{min}$ and a dwell time of $3 \mathrm{~h}$ prior to coating the boehmite sol.

BTESE sols were prepared by the following procedure: $1.04 \mathrm{~mL}$ of a $1.77 \mathrm{~mol} / \mathrm{L} \mathrm{HNO}_{3}$ solution was added to $5.53 \mathrm{~mL}$ ethanol and placed in an ice bath. Subsequently $3.33 \mathrm{~mL}$ of BTESE was dropped slowly into the mixture under vigorous stirring to obtain a final molar ratio of BTESE:EtOH:HNO $3: \mathrm{H}_{2} \mathrm{O}$ of 1:10.8:0.2:6. The mixture was allowed to react at $60^{\circ} \mathrm{C}$ for 90 minutes and put in an ice bath to quench the reaction. Ethanol was added to the solution to dilute the sol for dip coating to a final silicon concentration of $0.3 \mathrm{~mol} / \mathrm{L}$.

BTESE was coated once on the $\gamma$-alumina as well as on the MAP modified $\gamma$-alumina membranes under cleanroom conditions. The membranes were fired under nitrogen at $400{ }^{\circ} \mathrm{C}$ with a heating rate of $0.5^{\circ} \mathrm{C} / \mathrm{min}$ and a dwell time of $3 \mathrm{~h}$.

\subsubsection{Hydrothermal treatment}

The hydrothermal treatment was performed in a simple reflux setup. The membrane was placed in a holder with the separation layer facing upwards and placed above the water level in the reflux setup. The water was heated by an oil bath with a temperature of $110^{\circ} \mathrm{C}$ to ensure a steam temperature of $100{ }^{\circ} \mathrm{C}$. The test was continued for $72 \mathrm{~h}$, after which the membrane was removed from the setup and dried at room temperature. 


\subsubsection{Characterization}

Permporometry was performed in a home-made apparatus to determine the pore size of the mesoporous layer. The pore-size of the membrane was determined using cyclohexane as the condensable gas. The desorption mode was used to determine the actual pore-size of the membrane. Full details about the equipment and the calculation method used can be found in the paper by Cao et al. [17].

High resolution scanning electron microscopy (SEM) was performed with a Zeiss Merlin FESEM on membrane cross-sections to study the thickness and morphology of the layers. The cross sections were placed on a sample holder and partly covered with aluminum tape to prevent sample charging. No further pretreatment was done on the samples and images were acquired at an accelerating voltage of $1 \mathrm{kV}$. For EDX the accelerating voltage was increased to $10 \mathrm{kV}$ to make sure all the elements were detectable.

The membrane performance was characterized by means of single gas permeation. The membranes were measured in a "dead-end" mode. A feed pressure of 3 bara was applied to the membrane, while the permeate pressure was kept at atmospheric pressure. The pressure difference over the membrane was measured by a differential pressure sensor (GE Druck STX2100). The flow through the membrane was determined by a Bronkhorst EL-FLOW mass flow meter. The membranes were pretreated by heating to $200{ }^{\circ} \mathrm{C}$ under a helium flow with a rate of $1.5^{\circ} \mathrm{C} / \mathrm{min}$ to ensure complete removal of water from the membranes. After this conditioning step, the following gases were measured (in order of measurement): $\mathrm{He}, \mathrm{N}_{2}, \mathrm{CH}_{4}$, $\mathrm{H}_{2}$, and $\mathrm{CO}_{2}$. Measurements were performed at $200{ }^{\circ} \mathrm{C}$ with a transmembrane pressure of 2 bar. All gases were equilibrated for at least half an hour to ensure a constant flux. Two membranes were made from each sol and gas permeation results were averaged over the two membranes. The difference between the two membranes measured was within the experimental error.

\subsection{Results}

Figure 5.1 shows the permporometry results for $\gamma$-alumina and MAP modified $\gamma$-alumina membranes before and after hydrothermal treatment. The Kelvin radius of the as prepared $\gamma$-alumina is $2.7 \mathrm{~nm}$. It is assumed that the $\gamma$-alumina layer is completely destroyed by the hydrothermal treatment, since the pore size cannot be determined by permporometry on the membrane after hydrothermal treatment as no significant transition in permeance as function of 86 
the Kelvin radius was observed. The as prepared MAP modified $\gamma$-alumina has a Kelvin radius of $2.0 \mathrm{~nm}$, which is smaller compared to $\gamma$-alumina. After hydrothermal treatment the Kelvin radius of this membrane reduces to $1.7 \mathrm{~nm}$.
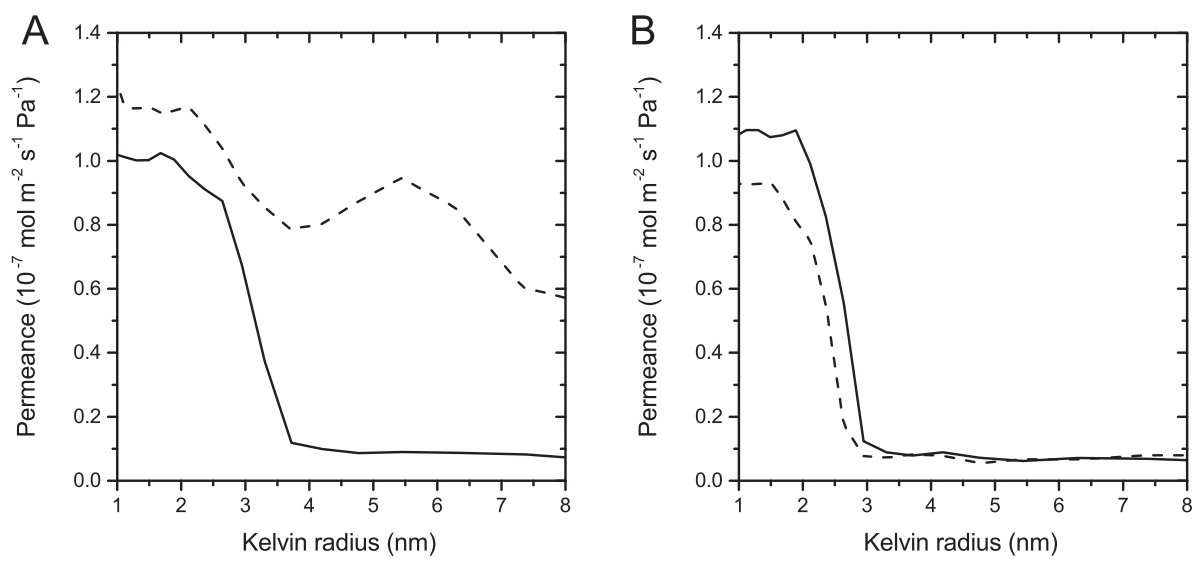

Figure 5.1: Permporometry of (A) $\gamma$-alumina and (B) MAP modified $\gamma$-alumina membrane layers as prepared (solid line) and after hydrothermal treatment (dashed line)

The morphology of the membranes after the hydrothermal treatment was studied with SEM on membrane cross-sections. In Figure 5.2A an overview is given of the hydrothermally treated $\gamma$-alumina membrane, where two regions can be distinguished on the surface of the membrane: a relative smooth surface with visible cracks and circle-shaped conglomerates with a diameter of about $1 \mathrm{~mm}$. These conglomerates consist of several aggregates. A close-up of the relative smooth surface is depicted in Figure 5.2B. Cracks and delamination of the layer and surface erosion are visible. The layer thickness is varying between 2 and $2.5 \mu \mathrm{m}$, which is slightly thinner compared to an as-calcined membrane which has a thickness of $3 \mu \mathrm{m}$. A close-up of a circular conglomerate is depicted in Figure 5.2C. The aggregates have a size of 5 to $50 \mu \mathrm{m}$ and have a crystalline nature, as some crystal planes are visible. It seems that the aggregates are formed on top of the $\gamma$-alumina membrane, although the thickness between the aggregates has reduced to $1.5 \mu \mathrm{m}$, suggesting dissolution and recrystallization of membrane material. 

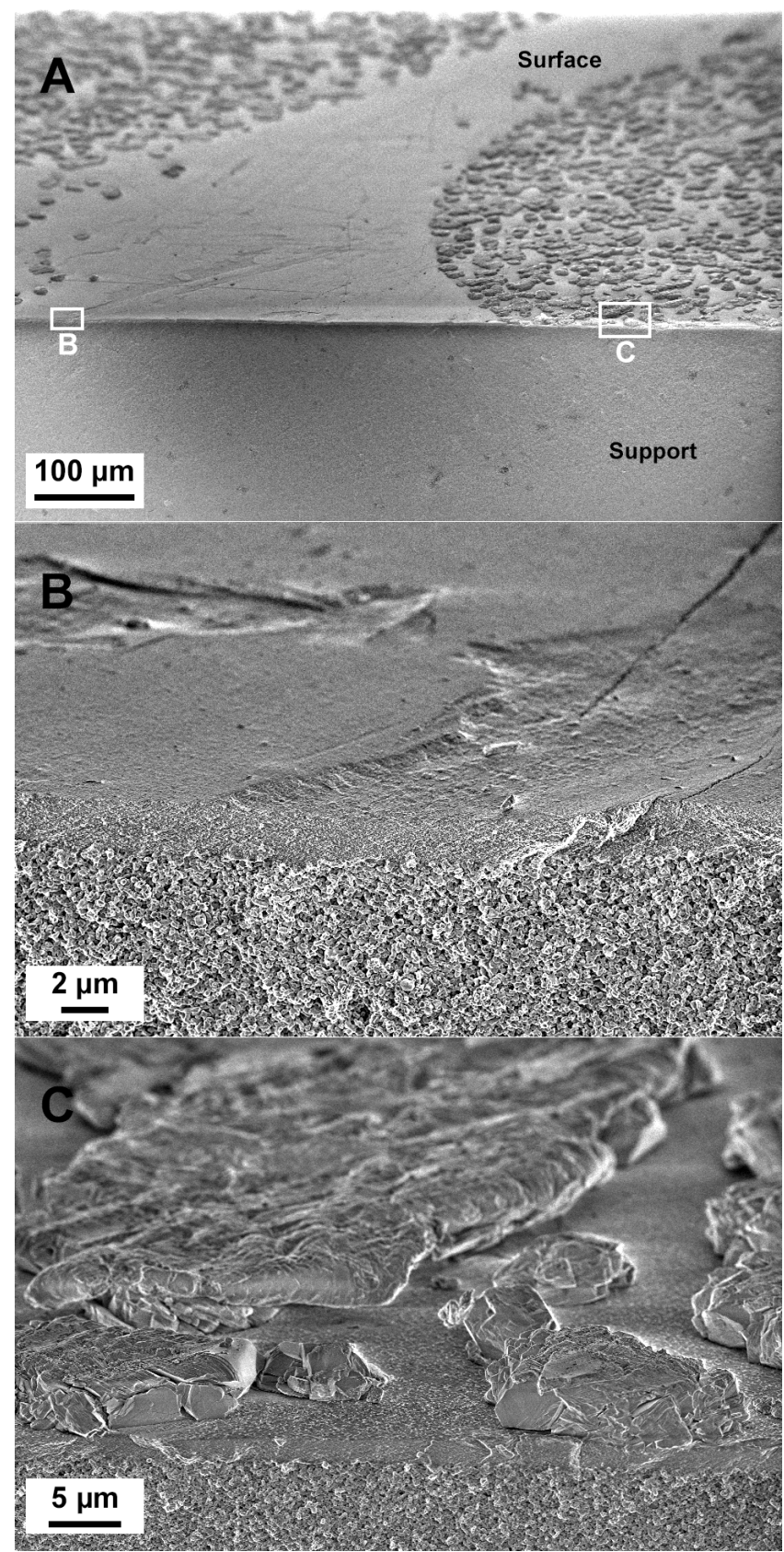

Figure 5.2: SEM micrographs of hydrothermally treated $\gamma$-alumina. Overview of surface with circle shaped conglomerates (A), detail of surface between conglomerates (B), detail of surface in the conglomerate with aggregates in the range of 5-50 $\mu \mathrm{m}(\mathrm{C})$ 
Figure 5.3 shows a secondary electron image of the hydrothermally treated $\gamma$-alumina membrane on which EDX analysis has been done. The letters in the image correspond to the data points in Table 5.1. In order to get a better understanding on the type of material that is deposited, the atomic ratios were calculated from the EDX results. The aggregates (data points A and B in Figure 5.3) have an $\mathrm{Al}: \mathrm{O}$ atomic ratio of around 1:2.5, which corresponds to a 50:50 mixture of $\mathrm{AlOOH}$ and $\mathrm{Al}(\mathrm{OH})_{3}$. The layer $(\mathrm{C})$ and the support (D) have an $\mathrm{Al}: \mathrm{O}$ ratio of around 1:1.5 and corresponds to $\mathrm{Al}_{2} \mathrm{O}_{3}$, which indicates that the layer is still $\gamma$-alumina.

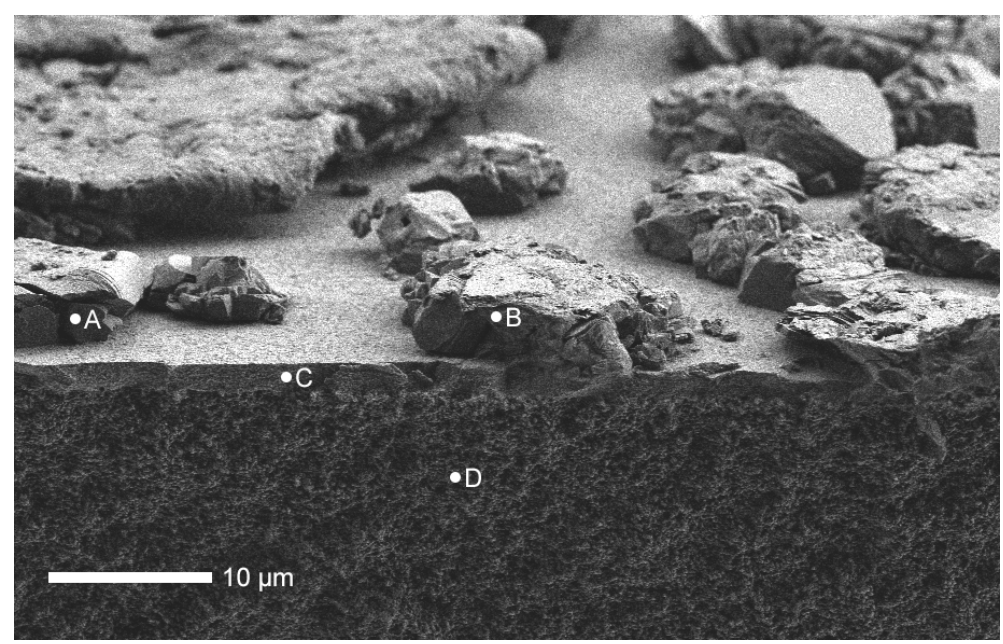

Figure 5.3: SEM micrograph of hydrothermally treated $\gamma$-alumina containing "aggregates" on the surface. The letters correspond to the regions were an EDX measurement has been done

Table 5.1: EDX results from SEM image in Figure 5.3

\begin{tabular}{llll}
\hline Position & $\mathrm{Al}\left(\right.$ atom $\left.^{0}\right)$ & $\mathrm{O}(\operatorname{atom} \%)$ & Phase \\
\hline $\mathrm{A}$ & 28 & 72 & $\mathrm{AlOOH} / \mathrm{Al}(\mathrm{OH})_{3}$ \\
$\mathrm{~B}$ & 29 & 71 & $\mathrm{AlOOH} / \mathrm{Al}(\mathrm{OH})_{3}$ \\
C & 39 & 61 & $\mathrm{Al}_{2} \mathrm{O}_{3}$ \\
D & 45 & 55 & $\mathrm{Al}_{2} \mathrm{O}_{3}$ \\
\hline
\end{tabular}

In Figure 5.4 a SEM image of a hydrothermally treated MAP modified $\gamma$-alumina membrane is shown. No visible changes are observed after hydrothermal treatment. In Table 5.2 the Al:P 
atomic ratios, as determined by EDX, are given for as prepared MAP modified $\gamma$-alumina and after hydrothermal treatment. The designations middle and top correspond to the first and second $\gamma$-alumina coating layer respectively. In the as prepared membranes small amounts of phosphorus are detectable in the $\gamma$-alumina top layer as well as in the $\alpha$-alumina support. After hydrothermal treatment a significant increase in phosphorus in the $\gamma$-alumina layer is observed.

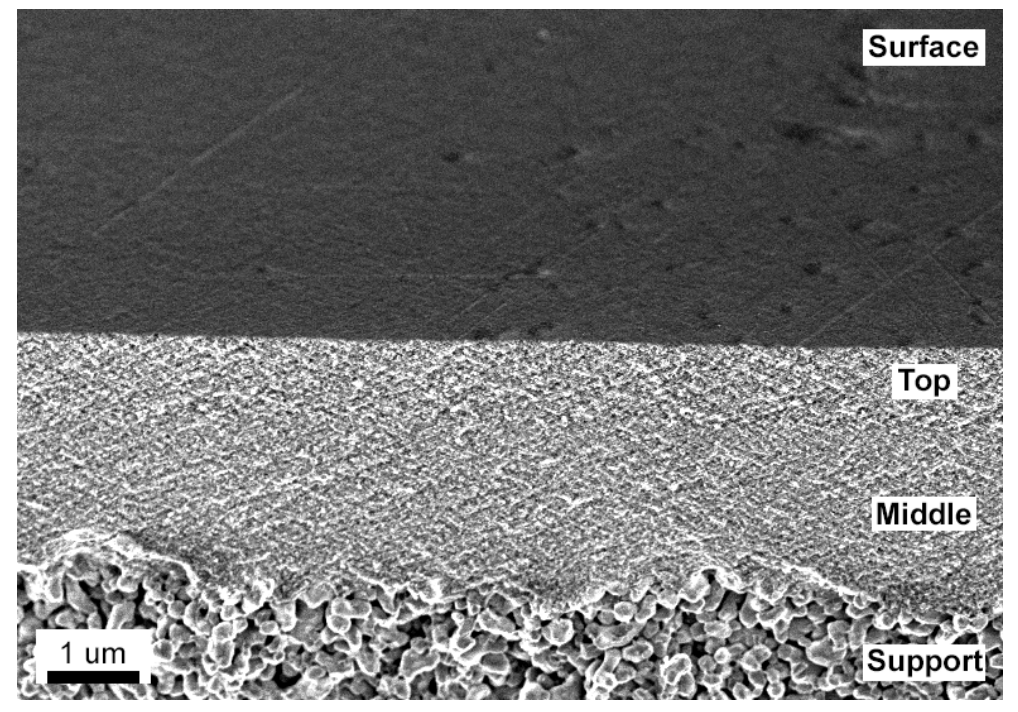

Figure 5.4: SEM micrograph of hydrothermally treated MAP modified $\gamma$-alumina

Table 5.2: EDX results for MAP modified $\gamma$-alumina before and after hydrothermal treatment

\begin{tabular}{lll} 
& & Atom ratio Al:P \\
\hline As prepared & Top & $1: 0.03$ \\
& Middle & $1: 0.04$ \\
& Support & $1: 0.02$ \\
\hline After treatment & Top & $1: 0.10$ \\
& Middle & $1: 0.11$ \\
\hline
\end{tabular}

In a second series of experiments a BTESE sol-gel layer was applied on the mesoporous $\gamma$-alumina and the MAP modified $\gamma$-alumina membranes and subsequently calcined at $400{ }^{\circ} \mathrm{C}$ for $3 \mathrm{~h}$ under nitrogen atmosphere. Figure 5.5 shows the SEM micrographs of BTESE coated on $\gamma$-alumina and MAP modified $\gamma$-alumina membranes after hydrothermal treatment. In both cases the $\gamma$-alumina layer seems to remain intact, which implies that the intermediate layer still have 90 
the original thickness of around $3 \mu \mathrm{m}$ and no aggregates or cracks are formed. However, for the $\gamma$-alumina intermediate layer severe detachment of BTESE is observed (see Figure 5A). Initial detachment caused by the handling (fracturing of the membrane) was visible, but further detachment happened during SEM imaging due to charging effects. The BTESE membrane on a MAP modified $\gamma$-alumina membrane did not show any detachment.

A

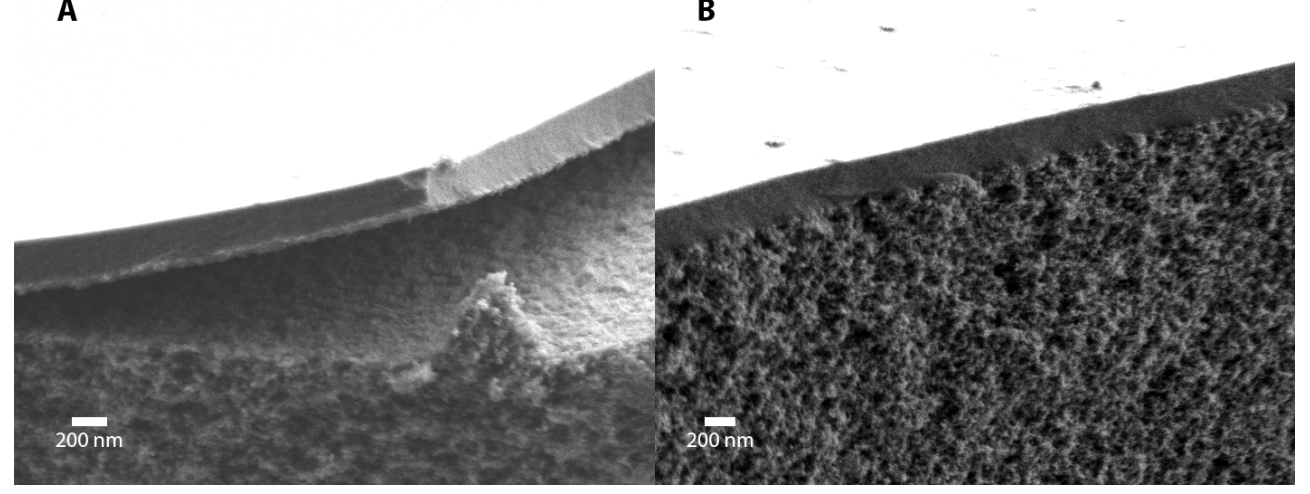

Figure 5.5: SEM micrographs of hydrothermally treated BTESE on a $\gamma$-alumina membrane (A) and MAP modified $\gamma$-alumina membrane (B). The detachment in A has partially happened during imaging

The single gas permeance of BTESE membranes as function of the gas kinetic diameter is given in Figure 5.6. The as prepared BTESE membranes on $\gamma$-alumina membrane and MAP modified $\gamma$-alumina membrane show a similar permeance. BTESE on a $\gamma$-alumina membrane shows no major changes after hydrothermal treatment. The permeances for helium, carbon dioxide and nitrogen are more or less the same as for an as prepared membrane. Only methane shows an increase from $2.410^{-8}$ to $5.310^{-8} \mathrm{~mol} \mathrm{~m}^{-2} \mathrm{~Pa}^{-1} \mathrm{~s}^{-1}$. After hydrothermal treatment of BTESE on a MAP modified $\gamma$-alumina membrane an overall reduction in permeance is observed, which is more pronounced for the bigger gases. 


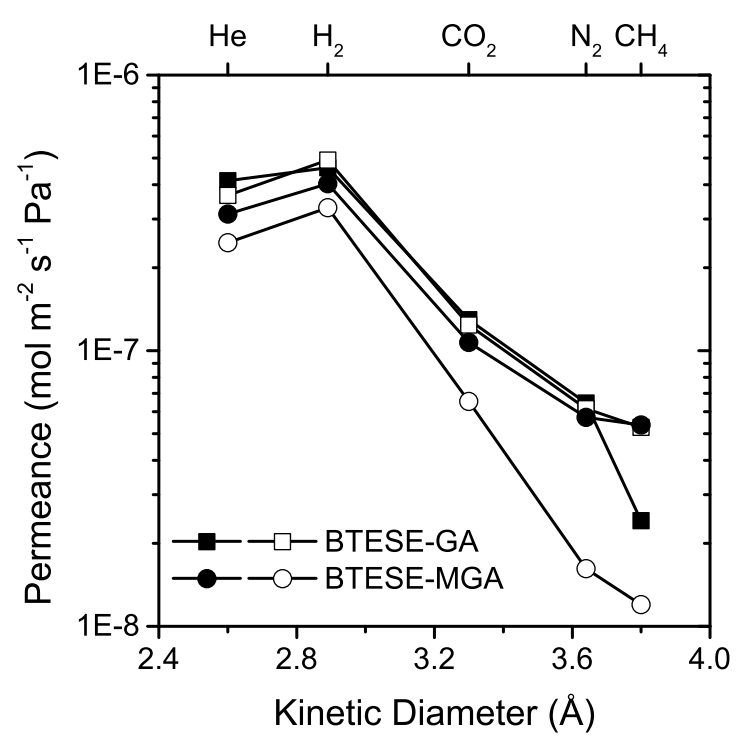

Figure 5.6: Single gas permeation results of BTESE on a $\gamma$-alumina membrane (GA) and a MAP modified $\gamma$-alumina membrane (MGA). Closed symbols are as prepared membranes; open symbols are hydrothermally treated membranes

\subsection{Discussion}

After the hydrothermal treatment the pore size of the $\gamma$-alumina membrane could not be determined by means of permporometry (see Figure 5.1). This indicates that either the pores have grown to a size of more than $20 \mathrm{~nm}$ (as being the upper limit of the permporometry analysis method used) or that large cracks or voids are formed. SEM images (Figure 5.2) reveal two distinct regions on the surface of these membranes, one region with aggregates and one with a relative smooth surface that shows cracks and delamination. The cracks and delamination are probably the cause of the inability to determine a pore size by permporometry after hydrothermal treatment.

The circular shape of the regions with aggregates indicates that these regions had water droplets on the surface during hydrothermal treatment. These droplets were also visible during the experiment. The aggregates on the surface have an elemental composition that corresponds to a mixture of $\mathrm{AlOOH}$ and $\mathrm{Al}(\mathrm{OH})_{3}$ with a ratio of 1:1. In literature [18-20] bayerite $\left(\mathrm{Al}(\mathrm{OH})_{3}\right)$ and boehmite $(\mathrm{AlOOH})$ is found in aqueous $\gamma$-alumina suspensions, which are left for two months at room temperature. Lefèvre et al. [21] showed that $\gamma$-alumina is slowly hydrating in water at 
room temperature to form bayerite by first forming an intermediate amorphous phase. After immersion of $\gamma$-alumina for four days in water, bayerite was already observed by Lefèvre et al. The higher temperature of $100{ }^{\circ} \mathrm{C}$, used in this work, probably accelerates these reactions resulting in the formation of a bayerite phase after $72 \mathrm{~h}$ of hydrothermal treatment.

It is common design philosophy for membrane based gas and vapor separation systems to avoid condensation on the membrane at all times. It is therefore highly unlikely that liquid water would be present on the membrane surface in a commercial process. However, the region where no water droplets were observed shows cracks and delamination, resulting in an inability to measure a pore size with permporometry. A decreased thickness is also observed; the thickness is reduced from $3 \mu \mathrm{m}$ for an as prepared membrane to a thickness between 2 to $2.5 \mu \mathrm{m}$ after hydrothermal treatment, caused by the hydrolytic attack. The observed cracks and delaminations are in line with the observations made by Nijmeijer et al. [6] for pure $\gamma$-alumina after an hydrothermal treatment for $100 \mathrm{~h}$ at $600{ }^{\circ} \mathrm{C}$, so without the presence of liquid water.

The hydrothermal testing conditions, as described in this work are not directly comparable with the operation conditions as used by Nijmeijer et al. [6] and Zahir et al. [7]. Both authors applied much higher temperatures $\left(>500{ }^{\circ} \mathrm{C}\right)$. However, due to the presence of liquid water in this work, the degradation was regarded to be more severe. Zahir et al did see some small aggregates on the surface of $\gamma$-alumina after hydrothermal treatment, but no further investigations were done on the formation of new crystalline phases. Nijmeijer et al. did see delamination of the $\gamma$-alumina layer after hydrothermal treatment, but no aggregates were formed. However, also in the work of Nijmeijer et al. no further investigations were done on the chemical composition or crystal phase of the delaminated layer.

The presence of phosphorus in the $\gamma$-alumina layer, as observed by EDX measurements, shows that phosphorus, originating from the MAP treatment of the surface of the $\alpha$-alumina support, migrates through the $\gamma$-alumina. Since MAP is applied by means of dipcoating of an $\alpha$-alumina support with a MAP solution, the capillary forces cause the MAP to infiltrate into the $\alpha$-alumina support. After coating with MAP (and drying at $300{ }^{\circ} \mathrm{C}$ ), the membranes were two times coated with a boehmite sol and calcined at $650{ }^{\circ} \mathrm{C}$ to form the $\gamma$-alumina layer. During this calcination treatment the phosphorus migrates throughout the alumina. In this case the thermal migration is not a fast process, since the differences in phosphorus content between $\alpha$-alumina and $\gamma$-alumina before hydrothermal treatment are very small (see Table 2 ). It seems however that the 
phosphorus migration is accelerated by water during hydrothermal testing as after this treatment two to three times more phosphorous per unit of volume is present in the $\gamma$-alumina than in the $\alpha$-alumina. This faster migration might be caused by the presence of phosphate ions during the hydrothermal treatment. It is shown that phosphorus stabilizes transition aluminas due to the phosphate attachment on the surface hydroxyl groups which deactivates the active sites for nucleation $[10,11,22]$. The mechanism of stabilization as proposed by Gishti et al. [10] is shown in Figure 5.7.

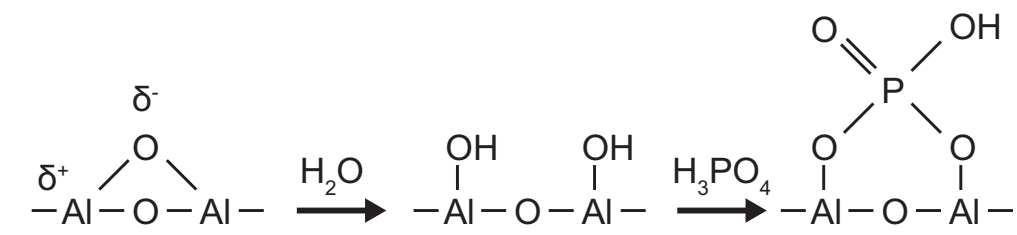

Figure 5.7: Stabilization mechanism of phosphorus on alumina, as proposed by Qishti [10]

Due to the stabilization by phosphor no degradation of the $\gamma$-alumina layer was observed after hydrothermal treatment. A small decrease in pore radius from 2.0 to $1.7 \mathrm{~nm}$ was observed after hydrothermal treatment (see Fig 1B). This pore shrinkage is in contradiction with the results as mentioned by Nijmeijer et al. [6], where pore growth was observed from a pore radius of 4.2 to $6.2 \mathrm{~nm}$ in MAP modified $\gamma$-alumina after a hydrothermal treatment at $600{ }^{\circ} \mathrm{C}$ and $30 \mathrm{bar}$. The difference in behavior of the membranes as discussed by Nijmeijer et al. and the results as described in this work, can be due to the difference in calcination temperatures for the formation of the $\gamma$-alumina layer which were respectively 825 and $650{ }^{\circ} \mathrm{C}$. It is shown by Gishti et al. [10] that the addition of phosphorus increases the thermal stability of $\gamma$-alumina by suppressing the transformation towards $\alpha$-alumina when calcined at $1050{ }^{\circ} \mathrm{C}$. However, with too little phosphorus $(0.4 \%)$ a small fraction of $\alpha$-alumina was visible. Since the phosphorus needs to migrate from the support towards the $\gamma$-alumina in the case of this work and the work of Nijmeijer et al., it is possible that during calcination some regions with low phosphorus content were present in the $\gamma$-alumina layer. It is therefore plausible that during calcination at $825^{\circ} \mathrm{C}$ some nucleation points for transformation to other transition aluminas, like $\delta$-alumina [23] may have been formed. These nucleation points can give rise to further transformation during hydrothermal treatment and hence lead to pore growth. 
The $\gamma$-alumina membranes that have been coated with BTESE do not show any loss of selectivity or increase in permeation after hydrothermal treatment. However, detachment of the BTESE layer from the $\gamma$-alumina membrane was visible after fracturing the membrane for SEM analysis. The detachment of the BTESE layer proceeded further during SEM imaging, which is a very strong indication of poor attachment of this layer after hydrothermal treatment. The reason why a $\gamma$-alumina membrane coated with BTESE is not degrading as much as a bare $\gamma$-alumina membrane can be twofold. First of all, due to the hydrophobic coating there is no free $\gamma$-alumina surface that is accessible for liquid water. Therefore, no dissolution and recrystallization can take place. Secondly, due to its flexibility of the BTESE layer, the BTESE coating can counter the stresses induced by the hydrolytic attack. Although the structure of the underlying $\gamma$-alumina might change during hydrothermal treatment, which was shown for a bare $\gamma$-alumina membrane, fracturing of the BTESE layer is prevented due to its flexibility.

A BTESE coating on a MAP modified $\gamma$-alumina membrane did not show any signs of delamination after hydrothermal testing. However, slightly lower permeances are observed after hydrothermal treatment. It is possible that due to the pore shrinkage in the MAP-modified $\gamma$-alumina intermediate layer the BTESE separation layer is compressed, leading to these lower permeances.

\subsection{Conclusion}

It is shown that a hydrothermal treatment at low temperature and high water activity strongly degrades a $\gamma$-alumina membrane. These results are in line with what is found in literature for tests at higher temperature and water vapor pressures.

A MAP-modified $\gamma$-alumina membrane shows a slight decrease in pore size after hydrothermal treatment. MAP modification does lead to a hydrothermally stable $\gamma$-alumina membrane due to stabilization by phosphorus components, especially after hydrothermal treatment, due to an accelerated migration of phosphorus into the $\gamma$-alumina layer under hydrothermal conditions. Therefore, MAP modification can be a viable way of stabilizing $\gamma$-alumina.

Gas permeation experiments on $\gamma$-alumina membranes with a hybrid silica (BTESE-derived) coating show identical permeance values for fresh and hydrothermally treated membranes. From these results one might conclude that BTESE-coated $\gamma$-alumina membranes do not show any 
sign of degradation after hydrothermal treatment. However, severe detachment of the BTESE layer from the $\gamma$-alumina membrane was found during SEM imaging.

A slight decrease in gas permeance was observed after hydrothermal treatment of a BTESEcoated MAP-modified $\gamma$-alumina membrane, which is likely due to the decrease in pore size of the MAP-modified $\gamma$-alumina intermediate layer. SEM analysis showed that the BTESE layer was firmLy attached to the MAP-modified $\gamma$-alumina membrane, not like the BTESE layer coated on an unmodified $\gamma$-alumina membrane.

\subsection{References}

[1] R.J.R. Uhlhorn, M.H.B.J.H.I.t. Veld, K. Keizer, A.J. Burggraaf, Synthesis of ceramic membranes, Journal of Materials Science, 27 (1992) 527-537.

[2] A.F.M. Leenaars, A.J. Burggraaf, The preparation and characterization of alumina membranes with ultrafine pores. 2. The formation of supported membranes, Journal of Colloid and Interface Science, 105 (1985) 27-40.

[3] T. van Gestel, D. Sebold, F. Hauler, W.A. Meulenberg, H.-P. Buchkremer, Potentialities of microporous membranes for $\mathrm{H} 2 / \mathrm{CO} 2$ separation in future fossil fuel power plants: Evaluation of SiO2, ZrO2, Y2O3$\mathrm{ZrO} 2$ and TiO2-ZrO2 sol-gel membranes, Journal of Membrane Science, 359 (2010) 64-79.

[4] S. Araki, Y. Kiyohara, S. Imasaka, S. Tanaka, Y. Miyake, Preparation and pervaporation properties of silica-zirconia membranes, Desalination, 266 (2011) 46-50.

[5] G.R. Gallaher, P.K.T. Liu, Characterization of ceramic membranes I. Thermal and hydrothermal stabilities of commercial $40 \AA$ membranes, Journal of Membrane Science, 92 (1994) 29-44.

[6] A. Nijmeijer, H. Kruidhof, R. Bredesen, H. Verweij, Preparation and Properties of Hydrothermally Stable g-Alumina Membranes, Journal of the American Ceramic Society, 84 (2001) 136-140.

[7] M.H. Zahir, K. Sato, H. Mori, Y. Iwamoto, M. Nomura, S.-i. Nakao, Preparation and Properties of Hydrothermally Stable $\gamma$-alumina-Based Composite Mesoporous Membranes, Journal of the American Ceramic Society, 89 (2006) 2874-2880.

[8] A.K. Adak, P. Pramanik, Synthesis and characterization of lanthanum aluminate powder at relatively low temperature, Materials Letters, 30 (1997) 269-273.

[9] T. Nagano, K. Sato, T. Saitoh, S. Takahashi, Hydrothermal stability of mesoporous Ni-doped \&gamma;Al2O3, Journal of the Ceramic Society of Japan, 117 (2009) 832-835.

[10] K. Gishti, A. Iannibello, S. Marengo, G. Morelli, P. Tittarelli, On the role of phosphate anion in the MoO3-Al2O3 based catalysts, Applied Catalysis, 12 (1984) 381-393.

[11] R.L. Cordero, F.J. Gil Llambías, J.M. Palacios, J.L.G. Fierro, A.L. Agudo, Surface changes of alumina induced by phosphoric acid impregnation, Applied Catalysis, 56 (1989) 197-206.

[12] J. Wang, Y. Wang, J. Wen, M. Shen, W. Wang, Effect of phosphorus introduction strategy on the surface texture and structure of modified alumina, Microporous and Mesoporous Materials, 121 (2009) 208-218.

[13] W. Gu, M. Shen, X. Chang, Y. Wang, J. Wang, Gelification process to prepare phosphate modified alumina: Study on structure and surface properties, Journal of Alloys and Compounds, 441 (2007) 311-316. [14] H.L. Castricum, R. Kreiter, H.M. van Veen, D.H.A. Blank, J.F. Vente, J.E. ten Elshof, Highperformance hybrid pervaporation membranes with superior hydrothermal and acid stability, Journal of Membrane Science, 324 (2008) 111-118.

[15] S. Battersby, S. Smart, B. Ladewig, S. Liu, M.C. Duke, V. Rudolph, J.C.D.d. Costa, Hydrothermal stability of cobalt silica membranes in a water gas shift membrane reactor, Separation and Purification Technology, 66 (2009) 299-305. 
[16] D. Uhlmann, S. Smart, J.C. Diniz da Costa, High temperature steam investigation of cobalt oxide silica membranes for gas separation, Separation and Purification Technology, 76 (2010) 171-178.

[17] G.Z. Cao, J. Meijerink, H.W. Brinkman, A.J. Burggraaf, Permporometry Study on the Size Distribution of Active Pores in Porous Ceramic Membranes, Journal of Membrane Science, 83 (1993) 221-235.

[18] C. Dyer, P.J. Hendra, W. Forsling, M. Ranheimer, Applications of fourier transform Raman spectroscopy $\backslash 3$-IIISurface hydration of aqueous $\gamma$-Al2O3 studied by Fourier transform Raman and infrared spectroscopy-I. Initial results, Spectrochimica Acta Part A: Molecular Spectroscopy, 49 (1993) 691-705.

[19] E. Laiti, P. Persson, L.-O. Öhman, Balance between Surface Complexation and Surface Phase Transformation at the Alumina/Water Interface, Langmuir : the ACS journal of surfaces and colloids, 14 (1998) 825-831.

[20] H. Wijnja, C.P. Schulthess, ATR-FTIR and DRIFT spectroscopy of carbonate species at the aged $\gamma$ Al2O3/water interface, Spectrochimica Acta Part A: Molecular and Biomolecular Spectroscopy, 55 (1999) 861-872.

[21] G. Lefèvre, M. Duc, P. Lepeut, R. Caplain, M. Fédoroff, Hydration of $\gamma$-alumina in Water and Its Effects on Surface Reactivity, Langmuir : the ACS journal of surfaces and colloids, 18 (2002) 7530-7537.

[22] G.A.H. Mekhemer, A.K.H. Nohman, N.E. Fouad, H.A. Khalaf, Surface to bulk characterization of phosphate modified aluminas, Colloids and Surfaces A: Physicochemical and Engineering Aspects, 161 (2000) 439-446.

[23] K. Wefers, C. Misra, Oxides and hydroxides of aluminum, Alcoa Research Laboratories, 1987. 

6 Hydrothermal stability of TEOS, BTESE and Zr-BTESE derived membranes 


\begin{abstract}
Sol-gel derived membranes are interesting candidates for gas separation purposes. However, silica based membranes show poor hydrothermal stability, while hybrid silica membranes show poor gas separation performance. Recently we reported Zr-BTESE with increased permeation performance compared with undoped BTESE. In this work the hydrothermal stability of TEOS, BTESE and Zr-BTESE derived membranes is tested with a number of hydrothermal tests. A relative simple hydrothermal setup of a membrane suspended above boiling water is evaluated as a simple screening test. Furthermore hydrothermal tests with water gas shift (WGS) composition streams were employed. BTESE and Zr-BTESE membranes started to degrade at $400{ }^{\circ} \mathrm{C}$ after $72 \mathrm{~h}$. At $300^{\circ} \mathrm{C}$ and below BTESE showed no change in permeance, while Zr-BTESE showed some flux decline. However the $\mathrm{H}_{2} / \mathrm{CO}_{2}$ selectivity for $\mathrm{Zr}$-BTESE increased from 12 to 35 for an untreated membrane and $300{ }^{\circ} \mathrm{C}$ treated membrane respectively, which is attributed to a change in acidic behavior of the zirconia due to water chemisorption.
\end{abstract}




\subsection{Introduction}

Membranes are an interesting alternative for several conventional separation processes, thanks to the ability to integrate reaction and separation into one unit. The use of membranes is also more energy efficient, since no phase changes are needed as compared to distillation. Since the separation can be done at high operating temperatures, there is less need for heat exchange as compared to adsorptive processes.

Most processes that are of industrial interest for the integration of a membrane separation step often include steam or water vapor, for example in methane steam reforming (MSR) or the water gas shift reaction (WGS). To date one of the best performing ceramic membranes for gas separation applications are microporous silica membranes, made by sol-gel synthesis using tetraethyl orthosilicate (TEOS) as a precursor [1]. However, these membranes are known to be unstable under hydrothermal conditions due to the reactivity of the formed silanol groups. [2, 3] The last decade a lot of research was done on the hydrothermal stabilization of these silica membranes.

In order to improve the hydrothermal stability of silica membranes De Vos et al. [2] added methylated silica to the silica system in order to obtain a more hydrophobic membrane and hence to decrease the water adsorption ability. The stability under hydrothermal conditions improved, but not sufficiently for industrial applications, as during pervaporation studies on the dehydration of butanol the lifetime of this newly developed membrane only increased from 25 to 50 days when compared with pure silica membranes [4]. Castricum et al. [5] used 1,2-bis(triethoxysilyl)ethane (BTESE) as a precursor for the fabrication of hybrid silica membranes in order to improve the hydrothermal stability. These hybrid silica membranes showed stable flux values for more than one year in butanol dehydration by pervaporation [4].

These BTESE derived membranes have shown excellent stability under pervaporation conditions. However, the gas separation selectivity of these membranes is rather low due to the relative loose network as compared to TEOS derived pure silica membranes [6, 7]. Recently we reported zirconia doped BTESE membranes, which show, when compared with undoped BTESE, an increased hydrogen selectivity towards gases like $\mathrm{CO}_{2}, \mathrm{~N}_{2}$ and $\mathrm{CH}_{4}$ [8].

In several publications attention is paid to the hydrothermal stability of pure and metal doped silica as well as hybrid silica membranes [3, 9-11]. It is however very difficult to make a 
comparison between these results, as different experimental conditions, substrates and intermediate layers are used. To eliminate these factors a planar $\alpha$-alumina substrate coated with $\gamma$-alumina was chosen as a starting material, as these supports have a well-defined surface morphology and can be highly-reproducibly fabricated. In this way a fair comparison between the different membrane materials can be made. In this article we focus on TEOS derived silica as well as on BTESE and Zr-doped BTESE derived hybrid silica membranes. The influence of hydrothermal treatment conditions on the gas permeation performance of BTESE and Zr-BTESE membranes is described.

\subsection{Experimental}

All chemicals were used as received. The hybrid silica precursor, 1,2-bis(triethoxysilyl)ethane (BTESE 97\%), was obtained from ABCR. A zirconyl nitrate solution $\left(\mathrm{ZrO}\left(\mathrm{NO}_{3}\right)_{2} \quad(99 \%\right.$, $35 \mathrm{wt} . \%$ in dilute nitric acid) was obtained from Sigma-Aldrich. Ethanol (99\%), tetraethyl orthosilicate (TEOS 99\%) and concentrated nitric acid (65\%) were obtained from Merck.

Silica (TEOS derived) sols were produced by a procedure as described by De Vos en Verweij [1]. A one-step synthesis was performed at $60^{\circ} \mathrm{C}$ for 180 minutes with a TEOS:EtOH: $\mathrm{H}_{2} \mathrm{O}: \mathrm{HNO}_{3}$ ratio of 1:3.8:6.3:0.085, after which the solution is diluted 19 times prior to coating on the membrane supports. BTESE and Zr-BTESE sols were produced by a procedure described in [8]. BTESE was synthesized at $60^{\circ} \mathrm{C}$ for 90 minutes with a BTESE:EtOH:HNO $3: \mathrm{H}_{2} \mathrm{O}$ ratio of 1:10.8:0.2:6 and diluted 6 times for coating. Zr-BTESE was synthesized at $25{ }^{\circ} \mathrm{C}$ for 90 minutes with a BTESE: $\mathrm{ZrO}\left(\mathrm{NO}_{3}\right)_{2}: \mathrm{EtOH}: \mathrm{HNO}_{3}: \mathrm{H}_{2} \mathrm{O}$ ratio of 1:0.19:10.5:0.2:6 and diluted 10 times for coating.

Porous $\alpha$-alumina supports (pore diameter $80 \mathrm{~nm}$, porosity 35\%) with a diameter of $39 \mathrm{~mm}$ and a thickness of $2 \mathrm{~mm}$ (Pervatech B.V. the Netherlands) were coated twice under cleanroom conditions with a boehmite sol and calcined at $650{ }^{\circ} \mathrm{C}$ at a heating rate of $1{ }^{\circ} \mathrm{C} / \mathrm{min}$ and a dwell time of $3 \mathrm{~h}$, resulting in a $\gamma$-alumina intermediate layer with a thickness of $3 \mu \mathrm{m}$ and a pore diameter of $5 \mathrm{~nm}$ as reported by Uhlhorn et al. [12]. TEOS, BTESE and Zr-BTESE layers were coated in one step under cleanroom conditions onto the supported $\gamma$-alumina membranes using an automatic dip-coating machine, with an angular dipping rate of $0.06 \mathrm{rad} \cdot \mathrm{s}^{-1}$. TEOS derived silica membranes were fired in air at $600{ }^{\circ} \mathrm{C}$ at a heating/cooling rate of $0.5^{\circ} \mathrm{C} / \mathrm{min}$ and a dwell 
of $3 \mathrm{~h}$, while BTESE and Zr-BTESE derived hybrid silica membranes were fired at $400{ }^{\circ} \mathrm{C}$ in nitrogen atmosphere at a heating/cooling rate of $0.5 \mathrm{C} / \mathrm{min}$ and a dwell time of $3 \mathrm{~h}$.

Due to limitations in sealing materials in the gas permeation equipment it was not possible to perform high temperature (above $250^{\circ} \mathrm{C}$ ) in-situ hydrothermal stability tests. Therefore ex-situ tests were chosen to make a comparison between the different membranes.

A first screening on the stability of the membranes was performed in a simple reflux setup to see if the membranes can resist a hydrothermal treatment. The membrane was put in a holder a few centimeters above the water level with the silica separation layer facing upwards. The water was heated by an oil bath having a temperature of $110{ }^{\circ} \mathrm{C}$ to ensure the water was boiling (steam temperature $100{ }^{\circ} \mathrm{C}$ ). These tests in $\mathrm{H}_{2} \mathrm{O}$-saturated stagnant air were continued for $72 \mathrm{~h}$, after which the membranes were removed from the set up and dried at room temperature.

Hydrothermal tests at 200, 300, 400 and $500{ }^{\circ} \mathrm{C}$ were performed at atmospheric pressure with a gas composition of $51 \% \mathrm{v} / \mathrm{v} \mathrm{H}_{2} \mathrm{O}, 34 \% \mathrm{v} / \mathrm{v} \mathrm{CO}$ and $15 \% \mathrm{v} / \mathrm{v} \mathrm{H}_{2}$, which is regarded as the gas phase composition in the water gas shift (WGS) reaction of syngas $\left(\mathrm{CO}+\mathrm{H}_{2}\right)$. The membranes were placed in a tubular furnace which was flushed with the simulated WGS mixture with a flow of $92 \mathrm{~mL} / \mathrm{min}$. These tests were conducted for $72 \mathrm{~h}$, after which the membranes were removed from the furnace and dried at room temperature.

In total 12 different membrane samples were obtained for further study on gas permeation performance as a way to determine the hydrothermal stability. The samples, including sample codes, as used in this study are summarized in Table 6.1.

Single gas permeation was performed on an automated setup. A membrane was heated to $200{ }^{\circ} \mathrm{C}$ under nitrogen with a heating rate of $2{ }^{\circ} \mathrm{C} / \mathrm{min}$ to remove the adsorbed water. The permeation measurements were performed at $200{ }^{\circ} \mathrm{C}$ at a transmembrane pressure of $2 \mathrm{bar}$. The gases were measured in the following order: helium, nitrogen, methane, hydrogen and carbon dioxide. The permeance of every gas was measured for $30 \mathrm{~min}$ to ensure a stable flow. The permselectivity was calculated by the following formula in which $F_{a}$ is the permselectivity and $Q$ the pure gas permeance.

$$
F_{\alpha} x / y=\frac{Q_{x}}{Q_{y}}
$$


Table 6.1: Membrane samples used

\begin{tabular}{|c|c|c|c|}
\hline \multirow[t]{2}{*}{ Sample code } & \multirow[t]{2}{*}{ Material } & \multicolumn{2}{|c|}{ Hydrothermal treatment } \\
\hline & & Temperature $\left({ }^{\circ} \mathrm{C}\right)$ & Atmosphere \\
\hline $\mathrm{T}$ & TEOS & - & - \\
\hline $\mathrm{T} 100$ & TEOS & 100 & $\mathrm{H}_{2} \mathrm{O}$-Saturated air \\
\hline $\mathrm{B}$ & BTESE & - & - \\
\hline B100 & BTESE & 100 & $\mathrm{H}_{2} \mathrm{O}$-Saturated air \\
\hline B300 & BTESE & 300 & Simulated WGS* \\
\hline B400 & BTESE & 400 & Simulated WGS \\
\hline Z & Zr-BTESE & - & - \\
\hline Z100 & Zr-BTESE & 100 & $\mathrm{H}_{2} \mathrm{O}$-Saturated air \\
\hline Z200 & Zr-BTESE & 200 & Simulated WGS \\
\hline Z300 & Zr-BTESE & 300 & Simulated WGS \\
\hline Z400 & Zr-BTESE & 400 & Simulated WGS \\
\hline Z500 & Zr-BTESE & 500 & Simulated WGS \\
\hline
\end{tabular}

Besides gas permeation tests on the membranes as indicated in Table 1, also in situ hydrothermal treatment was performed in the same setup on a Zr-BTESE sample to investigate the rate of change during hydrothermal treatment. This implies that, after all gas permeation measurements at $200{ }^{\circ} \mathrm{C}$ were performed, a wet nitrogen flow $\left(x_{\mathrm{H}_{2} \mathrm{O}}=0.01\right.$, corresponding to a steam partial pressure of $1 \mathrm{kPa}$ ) of $100 \mathrm{~mL} / \mathrm{min}$ was passed over the feed-side of the membrane at a pressure of $1 \mathrm{barg}$ for $1 \mathrm{~h}$. After this treatment the membrane was dried by a dry nitrogen stream for 10 minutes at $200{ }^{\circ} \mathrm{C}$ before a new permeation measurement was performed. This process of water treatment, followed by drying and permeation analysis, was repeated several times.

Water desorption behavior as a function of temperature was investigated by thermogravimetric analysis. BTESE and Zr-BTESE sols were dried and ground to a powder. The powders were fired using the same temperature program as used for the membranes. Subsequently $0.1 \mathrm{~g}$ of the powder was suspended in $5 \mathrm{~mL}$ of water and placed in an oven for 16 hours at $100{ }^{\circ} \mathrm{C}$. Thermogravimetric analysis was performed on these oven-dried powders, using a Netzsch STA $449 \mathrm{~F} 3$ Jupiter with a nitrogen flow of $70 \mathrm{~mL} \mathrm{~min}^{-1}$. Measurements were taken at a heating rate of $5{ }^{\circ} \mathrm{C} / \mathrm{min}$ from $35^{\circ} \mathrm{C}$ to $400{ }^{\circ} \mathrm{C}$. 


\subsection{Results and discussion}

All membranes were optically smooth before and after hydrothermal treatment, independent of the treatment used. This ensured that no formation of macroscopic defects had occurred during dipping, calcination and hydrothermal treatments. Figure 6.1 shows the gas permeance as function of the gas kinetic diameter for TEOS (A), BTESE (B) and Zr-BTESE (C) derived membranes before and after a hydrothermal treatment at $100{ }^{\circ} \mathrm{C}$ using a simple reflux setup. A fresh TEOS derived silica membrane, so prior to any hydrothermal treatment, shows excellent permselectivity, which is comparable of what is observed in literature [9]. After the hydrothermal test in a water-saturated atmosphere at $100{ }^{\circ} \mathrm{C}$ the performance of the TEOS derived silica membrane clearly changes and shows the same permeance and permselectivity as the $\gamma-\mathrm{Al}_{2} \mathrm{O}_{3}$ intermediate layer, which indicates that the selective layer has lost its structural integrity. Therefore, no further hydrothermal treatment tests on TEOS derived silica membranes were performed. A BTESE derived membrane shows virtually no change in permeance after hydrothermal treatment which is in line with the stability found in pervaporation at $150{ }^{\circ} \mathrm{C}$ for these membranes [5]. The permeance of Zr-BTESE has dropped slightly, but no significant changes in permselectivity are observed. 

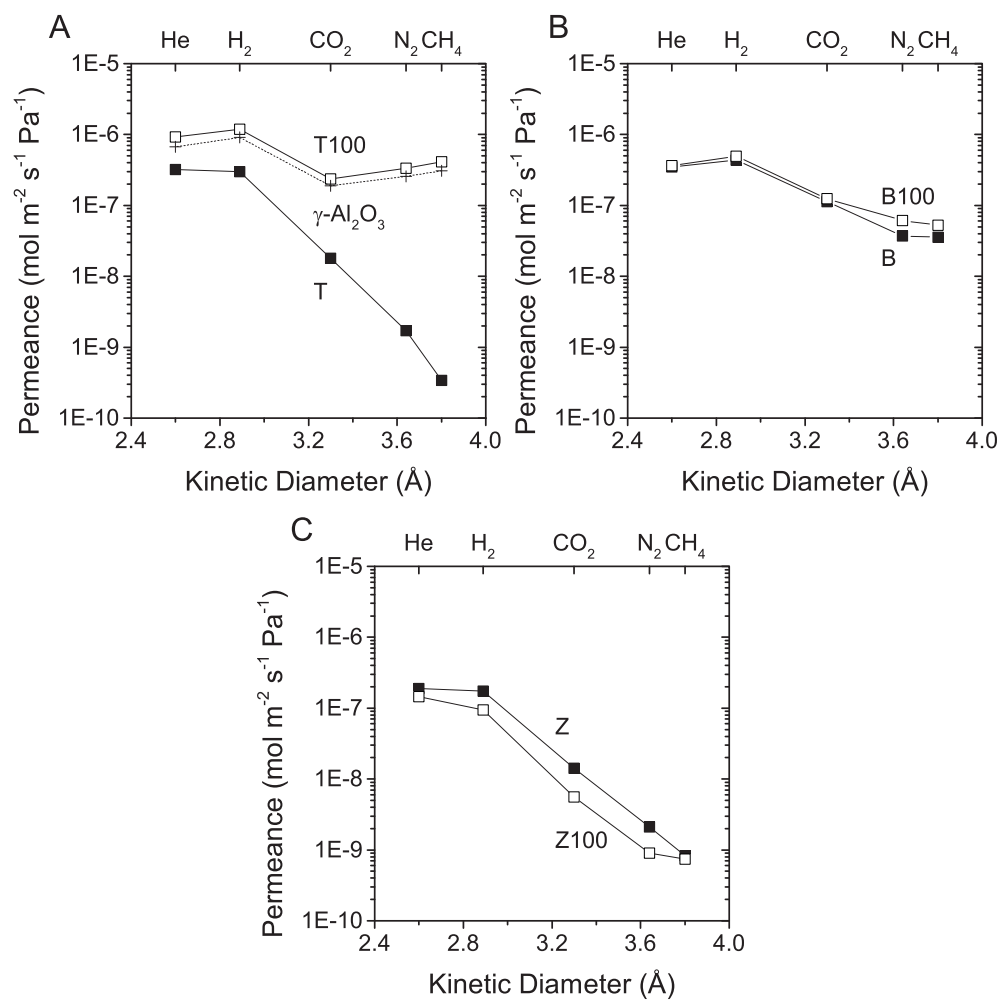

Figure 6.1: Gas permeance versus kinetic diameter measured at $200^{\circ} \mathrm{C}$ with a transmembrane pressure of 2 bar for TEOS derived silica and $\gamma-\mathrm{Al}_{2} \mathrm{O}_{3}$ (A), BTESE derived hybrid silica (B), and Zr-BTESE derived hybrid silica (C) membranes; closed symbols: as prepared membranes; open symbols: after a treatment with boiling water for 72 hours

Figure 6.2 shows the gas permeance as a function of kinetic diameter for a pristine BTESE derived hybrid silica membrane and for BTESE derived hybrid silica membrane treated hydrothermally at $300{ }^{\circ} \mathrm{C}$ and $400{ }^{\circ} \mathrm{C}$. After a treatment at $300{ }^{\circ} \mathrm{C}$ (sample B300) virtually no change in permeance is observed. After a hydrothermal treatment at $400{ }^{\circ} \mathrm{C}$ (sample B400) lower permeances are obtained for helium and hydrogen, which is indicative for densification. However, the permeance for nitrogen and methane has increased, which would indicate pore widening. It seems that some degradation is starting to occur at $400{ }^{\circ} \mathrm{C}$. Kappert et al. [13] showed in their kinetic analyses, by using thermogravimetric analysis combined with mass spectrometry, that the onset of decomposition in an inert atmosphere of the ethylene bridge for BTESE-derived membranes is around $500{ }^{\circ} \mathrm{C}$. This onset temperature is determined with purified gases and oxygen traps to ensure a complete oxygen-free environment. It is possible that during the hydrothermal treatment some traces of oxygen were present, which would lower 106 
the onset temperature of decomposition. Also a longer-term exposure at high temperatures, as used in this work $(72 \mathrm{~h})$, compared with the exposure time as used by Kappert et al. $(<1 \mathrm{~h})$ might have an influence on the (thermal) stability of the organic network in these hybrid systems.

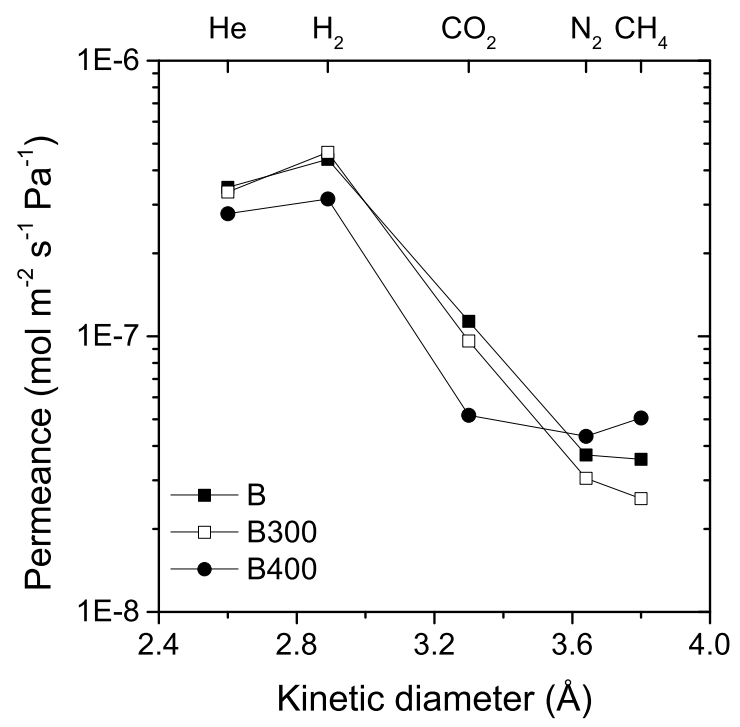

Figure 6.2: Permeance versus gas kinetic diameter, measured at $200^{\circ} \mathrm{C}$ at a transmembrane pressure of 2 bar, for a pristine BTESE derived hybrid silica membrane (B) and BTESE derived hybrid silica membranes hydrothermally treated for 72 hours at 300 or $400{ }^{\circ} \mathrm{C}$ under WGS conditions (B300, B400) 


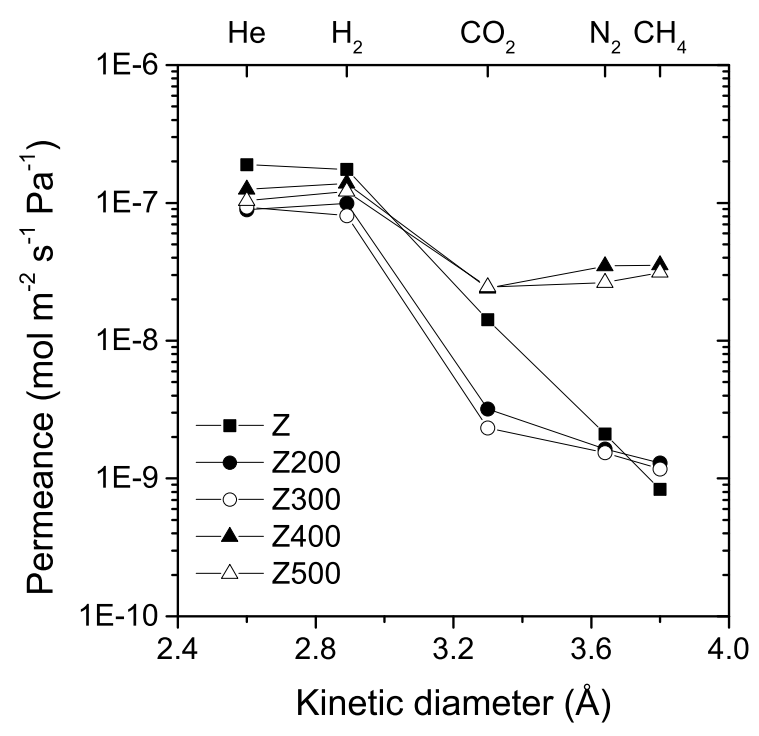

Figure 6.3: Permeance versus kinetic diameter measured at $200^{\circ} \mathrm{C}$ with a transmembrane pressure of 2 bar for Zr-BTESE derived hybrid silica membranes

Figure 6.3 shows the permeance as function of gas kinetic diameter for a pristine Zr-BTESE derived hybrid silica membrane and hydrothermally treated Zr-BTESE derived hybrid silica membranes. At a treatment temperature of $400{ }^{\circ} \mathrm{C}$ and higher a strong increase in nitrogen and methane permeance is observed, indicating a clear degradation of the BTESE derived hybrid silica selective layer after these hydrothermal treatments. So, also here it can be observed that for the BTESE derived hybrid silica membrane systems there is a loss in permselectivity after a treatment under WGS conditions at temperatures of $400^{\circ} \mathrm{C}$ or higher. After WGS-conditions treatments at 200 or $300{ }^{\circ} \mathrm{C}(\mathrm{Z} 200$ and Z300) a slightly lower permeance is observed for helium and hydrogen, while the permeance for nitrogen and methane is virtually unchanged. Remarkably is the drop in carbon dioxide permeance, as it is stronger than what is found in the simple test at $100{ }^{\circ} \mathrm{C}$ (see Figure 6.1). The $\mathrm{H}_{2} / \mathrm{CO}_{2}$ permselectivity is increased by almost a factor 3 for Z200 and Z300 (see Table 6.2). 
Table 6.2: Hydrogen permeance and permselectivity of pristine and hydrothermally treated Zr-BTESE membranes

\begin{tabular}{lllll}
\hline Membrane & $\begin{array}{l}\mathrm{H}_{2} \text { permeance } \\
10^{-7} \mathrm{~mol} \mathrm{~m}^{-2} \mathrm{~s}^{-1} \mathrm{~Pa}^{-1}\end{array}$ & $\mathrm{~F}_{\alpha} \mathrm{H}_{2} / \mathrm{CO}_{2}$ & $\mathrm{~F}_{\alpha} \mathrm{H}_{2} / \mathrm{N}_{2}$ & $\mathrm{~F}_{\alpha} \mathrm{H}_{2} / \mathrm{CH}_{4}$ \\
\hline $\mathrm{Z}$ & 1.8 & 12 & 83 & 210 \\
$\mathrm{Z} 100$ & 0.9 & 17 & 100 & 130 \\
$\mathrm{Z} 200$ & 1.0 & 31 & 61 & 77 \\
Z300 & 0.8 & 35 & 52 & 69 \\
\hline
\end{tabular}

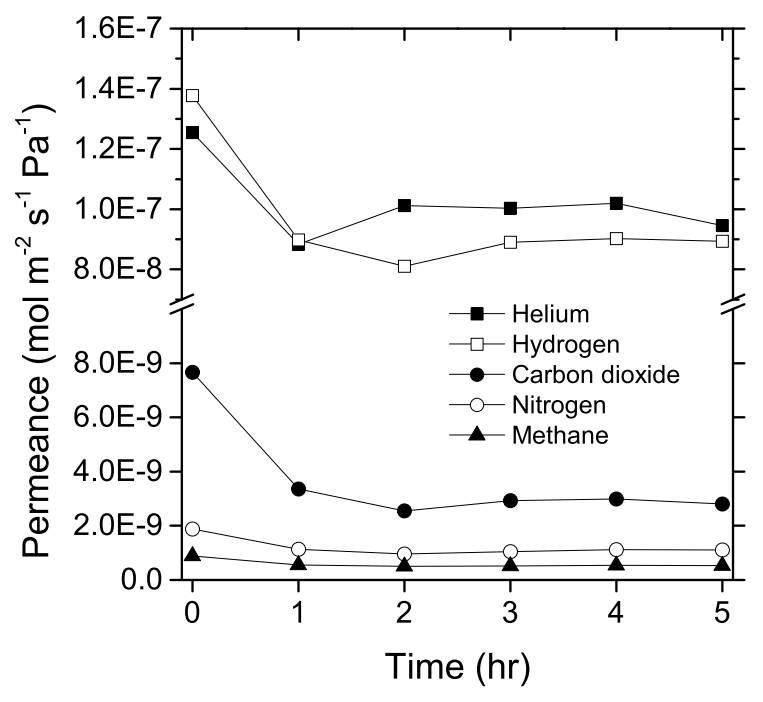

Figure 6.4: Time course of permeance of a Zr-BTESE derived hybrid silica membrane measured at $200{ }^{\circ} \mathrm{C}$ with a transmembrane pressure of 2 bar after several hydrothermal treatment cycles at $200^{\circ} \mathrm{C}$

The static tests as discussed up till now only give an indication of changes in permeances after a certain time of hydrothermal treatment $(72 \mathrm{~h})$. However, no information can be obtained in this way on how fast a steady state is achieved during such a treatment. Therefore gas permeance measurements were performed after one hour hydrothermal treatment at $200{ }^{\circ} \mathrm{C}$, on a Zr-BTESE derived hybrid silica membrane, while this treatment-measurement cycle was repeated 5 times. Figure 6.4 shows gas permeances as function of time of this hydrothermal treatment. After one hour of hydrothermal treatment a drop in permeance is observed. Especially the smaller gases (helium and hydrogen) show a sharp decrease in permeance. After this initial drop the permeance stabilizes and after two hours of hydrothermal treatment no 
further change in permeance was observed. The permeance values after 5 hours obtained during the in-situ treatment are in good agreement with the results from the 72 hours static test at $200{ }^{\circ} \mathrm{C}$ (see Figure 4).

The lower permeances for the smaller gases after hydrothermal treatment at $200{ }^{\circ} \mathrm{C}$ of the Zr-BTESE membranes could be explained by two mechanisms. One mechanism is densification due to structural relaxation, which is however a slow process due to diffusion limitations. Such a process takes 50 hours or more [14]. However, in our work we observed a fast decline in permeance of the smaller gases within 2 hours during the in-situ measurements after which the permeance of these gases was stable.

Besides, if structural relaxation is responsible for a change in pore morphology, it is expected that this also might occur for the undoped BTESE membranes. However, the undoped BTESE membranes do not show a lower permeance after hydrothermal treatment (compare B and B300 in Figure 6.2 with $\mathrm{Z}$ and Z300 in Figure 6.3). These results are indicative that for the Zr-BTESE membranes another process than structural relaxation is responsible for the lower permeances of the smaller gases after hydrothermal treatment.

An example of another process, that can lead to lower permeances, is the partial blocking of the pores by water. For that reason the dehydration behaviour is studied of hydrothermally treated calcined powders as function of temperature by means of TGA (Figure 6.5). The TGA curve of the BTESE derived hybrid silica powder only shows loosely bound water which desorbs at temperatures below $100{ }^{\circ} \mathrm{C}$. The Zr-BTESE derived hybrid silica powder on the other hand continues to release water above $100{ }^{\circ} \mathrm{C}$, so after the initial loss of physisorbed water. Diffusion limitations due to a smaller pore size of Zr-BTESE derived hybrid silica membranes in comparison with BTESE derived hybrid silica membranes [8] might be an explanation for this continued release, but is unlikely due to the low heating rate $\left(5^{\circ} \mathrm{C} / \mathrm{min}\right)$. 


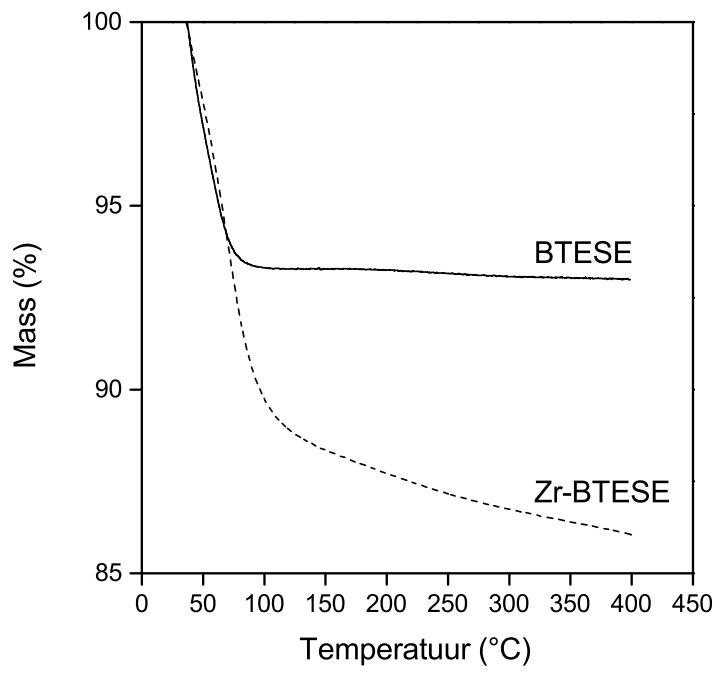

Figure 6.5: TGA curve of drying calcined BTESE and Zr-BTESE membrane material with a heating rate of $5^{\circ} \mathrm{C} / \mathrm{min}$ under nitrogen

A strong interaction between $\mathrm{ZrO}_{2}$ and water is likely the cause of this continuous water loss. There are numerous studies on the adsorption of water on zirconia [15-18], which show that there is a very strong chemisorption of water onto zirconia. Desorption of water from zirconia is therefore not complete at temperatures below $400{ }^{\circ} \mathrm{C}$. In catalysis, silica-zirconia mixed oxides are used as an acid catalyst [19], in which the nature of the acidity of the catalyst can be tuned by the silica-zirconia ratio. It is shown by Garcia-Sancho et al. [20] that Brønsted acid sites can be generated in $\mathrm{Zr}$-doped MCM-41 by a treatment in steam at $315^{\circ} \mathrm{C}$. Qi et al. [11] observed an increase in $\mathrm{H}_{2} / \mathrm{CO}_{2}$ selectivity during steam treatment of Nb-BTESE derived hybrid silica membranes at $200{ }^{\circ} \mathrm{C}$ and they ascribed this to the formation of Brønsted acid sites, which were removed during calcination. In the work of Qi et al. it was hypothesized that the high acidity of these sites results in a decrease in affinity for $\mathrm{CO}_{2}$ and hence in a lower $\mathrm{CO}_{2}$ permeance than for undoped BTESE derived hybrid silica membranes. Boffa et al. [21] stated that the lower $\mathrm{CO}_{2}$ permeance in niobia doped silica membranes is due to the strong adsorption of $\mathrm{CO}_{2}$ on the surface of the membranes. This behavior was claimed because of the fact that, by means of FTIR 
analysis, $\mathrm{CO}_{2}$ adsorption on hydroxyl groups was observed. However, in that work also $\mathrm{CO}_{2}$ adsorption was observed for undoped (pure) silica membranes.

By making use of the literature data it can be assumed that the presence of Brønsted acid sites on zirconia, formed during hydrothermal treatment of Zr-BTESE derived hybrid silica membranes, are responsible for the deviating $\mathrm{CO}_{2}$ permeance, when compared with the untreated Zr-BTESE derived hybrid silica membranes. However a sufficient high temperature is necessary for creating these Brønsted acid sites. If the permeance and permselectivy results of the Z100 membrane are compared with Z200 and Z300 membranes, it can be seen that for the Z100 membrane no significant increase in $\mathrm{H}_{2} / \mathrm{CO}_{2}$ permselectivity is observed (see Table 2). It seems that the formation of Brønsted sites by water vapor only occurs at higher temperatures. The lower permeances for the Z100 membrane, compared with an undoped BTESE derived hybrid silica membrane, can therefore purely be ascribed to the chemisorption of water in the pores of the membrane. For the Z200 and Z300 membranes the creation of Brønsted sites leads to a further decrease in $\mathrm{CO}_{2}$ permeance due to reduced $\mathrm{CO}_{2}$ affinity, which is beneficial for a better $\mathrm{H}_{2} / \mathrm{CO}_{2}$ selectivity.

\subsection{Conclusions}

A hydrothermal treatment at $100^{\circ} \mathrm{C}$, using a reflux setup, can be effectively used as a simple screening tool for analyzing the hydrothermal stability of ceramic membranes. Pure silica (TEOS) membranes were, as expected, not able to retain their separation performance after this hydrothermal treatment, while BTESE and Zr-BTESE hybrid silica membranes did not show any selectivity loss.

At an hydrothermal treatment temperature of $400^{\circ} \mathrm{C}$ and above the BTESE and Zr-BTESE derived hybrid silica membranes start to degrade, most likely due to the presence of (traces of) oxygen in the gas stream, resulting in decomposition of the ethylene bridge of this hybrid system.

The BTESE derived hybrid silica membranes show very limited change after hydrothermal treatment at temperatures of $300{ }^{\circ} \mathrm{C}$ or lower. However, the Zr-BTESE hybrid silica membranes show a decrease in flux, especially for $\mathrm{CO}_{2}$. The Brønsted-acidic nature of $\mathrm{Zr} / \mathrm{Si}$ mixed oxides is regarded to be the cause of this relative strong decrease in $\mathrm{CO}_{2}$ permeance. 


\subsection{Acknowledgements}

We acknowledge financial support for this research from ADEM, A green Deal in Energy Materials of the Ministry of Economic Affairs of The Netherlands (www.adem-innovationlab.nl). We also acknowledge Desiree van Holt from Forschungszentrum Jülich for performing the ex-situ hydrothermal treatment at higher temperatures.

\subsection{References}

[1] R.M. de Vos, H. Verweij, High-selectivity, high-flux silica membranes for gas separation, Science, 279 (1998) 1710-1711.

[2] R.M. de Vos, W.F. Maier, H. Verweij, Hydrophobic silica membranes for gas separation, Journal of Membrane Science, 158 (1999) 277-288.

[3] M.C. Duke, J.C.D. da Costa, D.D. Do, P.G. Gray, G.Q. Lu, Hydrothermally robust molecular sieve silica for wet gas separation, Advanced Functional Materials, 16 (2006) 1215-1220.

[4] H.L. Castricum, A. Sah, R. Kreiter, D.H. Blank, J.F. Vente, J.E. ten Elshof, Hybrid ceramic nanosieves: stabilizing nanopores with organic links, Chem Commun (Camb), (2008) 1103-1105.

[5] H.L. Castricum, A. Sah, J.A.J. Geenevasen, R. Kreiter, D.H.A. Blank, J.F. Vente, J.E. ten Elshof, Structure of hybrid organic-inorganic sols for the preparation of hydrothermally stable membranes, Journal of Sol-Gel Science and Technology, 48 (2008) 11-17.

[6] M. Kanezashi, K. Yada, T. Yoshioka, T. Tsuru, Organic-inorganic hybrid silica membranes with controlled silica network size: Preparation and gas permeation characteristics, Journal of Membrane Science, 348 (2010) 310-318.

[7] H.F. Qureshi, A. Nijmeijer, L. Winnubst, Influence of sol-gel process parameters on the micro-structure and performance of hybrid silica membranes, Journal of Membrane Science, 446 (2013) 19-25.

[8] M. ten Hove, A. Nijmeijer, L. Winnubst, Facile synthesis of zirconia doped hybrid organic inorganic silica membranes, Separation and Purification Technology, 147 (2015) 372-378.

[9] V. Boffa, D.H.A. Blank, J.E. ten Elshof, Hydrothermal stability of microporous silica and niobia-silica membranes, Journal of Membrane Science, 319 (2008) 256-263.

[10] M. Kanezashi, T. Sasaki, H. Tawarayama, T. Yoshioka, T. Tsuru, Hydrogen Permeation Properties and Hydrothermal Stability of Sol-Gel-Derived Amorphous Silica Membranes Fabricated at High Temperatures, Journal of the American Ceramic Society, 96 (2013) 2950-2957.

[11] H. Qi, J. Han, N. Xu, H.J. Bouwmeester, Hybrid organic-inorganic microporous membranes with high hydrothermal stability for the separation of carbon dioxide, ChemSusChem, 3 (2010) 1375-1378.

[12] R.J.R. Uhlhorn, M.H.B.J.H.I.t. Veld, K. Keizer, A.J. Burggraaf, Synthesis of ceramic membranes, Journal of Materials Science, 27 (1992) 527-537.

[13] E.J. Kappert, H.J. Bouwmeester, N.E. Benes, A. Nijmeijer, Kinetic analysis of the thermal processing of silica and organosilica, The journal of physical chemistry. B, 118 (2014) 5270-5277.

[14] V.B. Lazarev, G.P. Panasyuk, G.P. Boudova, I.L. Voroshilov, Thermogravimetric Study of the Kinetics of Structural Relaxation of Amorphous Silica, Journal of Thermal Analysis, 23 (1982) 73-81.

[15] P.A. Agron, E.L. Fuller, H.F. Holmes, IR studies of water sorption on $\mathrm{ZrO} 2$ polymorphs. I, Journal of Colloid and Interface Science, 52 (1975) 553-561.

[16] J. Nawrocki, P.W. Carr, M.J. Annen, S. Froelicher, A TGA investigation of hydrated monoclinic zirconia, Analytica Chimica Acta, 327 (1996) 261-266.

[17] A.V. Radha, O. Bomati-Miguel, S.V. Ushakov, A. Navrotsky, P. Tartaj, Surface Enthalpy, Enthalpy of Water Adsorption, and Phase Stability in Nanocrystalline Monoclinic Zirconia, Journal of the American Ceramic Society, 92 (2009) 133-140.

[18] P. Raghu, N. Rana, C. Yim, E. Shero, F. Shadman, Adsorption of moisture and organic contaminants on hafnium oxide, zirconium oxide, and silicon oxide gate dielectrics, Journal of the Electrochemical Society, 150 (2003) F186-F193. 
[19] J.B. Miller, E.I. Ko, Control of mixed oxide textural and acidic properties by the sol-gel method, Catalysis Today, 35 (1997) 269-292.

[20] C. García-Sancho, R. Moreno-Tost, J. Mérida-Robles, J. Santamaría-González, A. Jiménez-López, P. Maireles-Torres, Zirconium doped mesoporous silica catalysts for dehydration of glycerol to high addedvalue products, Applied Catalysis A: General, 433-434 (2012) 179-187.

[21] V. Boffa, J.E. ten Elshof, A.V. Petukhov, D.H. Blank, Microporous niobia-silica membrane with very low CO2 permeability, ChemSusChem, 1 (2008) 437-443. 
7 Sol gel silica derived microporous membranes for $\mathrm{H}_{2} / \mathrm{CO}_{2}$ separation: current status, limitations and perspectives 


\begin{abstract}
The development of sol-gel derived microporous membranes for $\mathrm{H}_{2} / \mathrm{CO}_{2}$ separation is ongoing for a number of years. However, most research on this type of membranes is still on a lab-scale. In this chapter the current status of sol-gel silica derived microporous membranes is reviewed. The limitations are addressed to provide perspectives on the areas where improvements are needed.
\end{abstract}




\subsection{Introduction}

Based on predictions made by the Energy Information Administration (EIA), world electricity production will increase between 2010 and 2040 by $93 \%$, with an average annual growth of $2.2 \%$ [1]. Although the use of renewable sources for electricity will increase with an average annual growth of $2.8 \%$, the share of coal and natural gas in 2040 is expected to be still $36 \%$ and $24 \%$ respectively. This increase in coal and gas demand for energy production will lead to a rise in carbon dioxide emissions. Carbon dioxide emissions are seen as the major contributor to global warming [2]. Therefore the need for carbon capture and storage to mitigate the increased carbon intensity of our society is increasing.

A promising method of carbon capture is the pre-combustion carbon capture process, in which a fossil fuel is converted to syngas, consisting of $\mathrm{H}_{2}$ and $\mathrm{CO}$, which is further converted towards $\mathrm{H}_{2}$ and $\mathrm{CO}_{2}$ by the water gas shift (WGS) reaction. The hydrogen is separated and used for combustion, while the carbon dioxide is further cleaned for storage. Using membranes to separate the hydrogen from carbon dioxide can be highly beneficial, as it opens up the use of a membrane reactor that can shift the equilibrium of the WGS reaction towards the product (hydrogen and $\mathrm{CO}_{2}$ ) side due to hydrogen removal from the reaction zone. This leads to a more energy efficient process. Several types of hydrogen selective membranes are available, of which extensive reviews are made [3-5].

Palladium membranes have an excellent $\mathrm{H}_{2} / \mathrm{CO}_{2}$ selectivity and high hydrogen flux, but suffer severely from sulfur poisoning $[3,4]$. This is especially problematic for coal-based fuels as these often contain sulfur. Microporous ceramic membranes are not susceptible to sulfur poisoning [6] and are therefore able to perform in sulfur rich environments. However, at the moment the major drawback in application of microporous membranes is the limited $\mathrm{H}_{2} / \mathrm{CO}_{2}$ selectivity and the limited knowledge about the long-term hydrothermal stability of such membranes. Therefore the use of microporous membranes for carbon capture is still only applied on lab-scale for developmental purposes.

The aim of this review is to investigate the current status of microporous ceramic membranes for gas separation with a focus on pre-combustion carbon capture. A discussion will be made on what has been done to address the current issues on $\mathrm{H}_{2} / \mathrm{CO}_{2}$ selectivity and hydrothermal stability and what needs to be done for industrial implementation of these membranes. 


\subsection{Current status}

\subsubsection{Silica membranes}

De Vos and Verweij [7] showed that a tetraethylorthosilicate (TEOS) derived silica membrane can have excellent gas separation properties, as for a silica membrane calcined at $600{ }^{\circ} \mathrm{C} \mathrm{a}_{2}$ permeance of $5 \times 10^{-7} \mathrm{~mol} \mathrm{~m}^{-2} \mathrm{~s}^{-1} \mathrm{~Pa}^{-1}$ and a $\mathrm{H}_{2} / \mathrm{CO}_{2}$ permselectivity of 70 was measured, which should make these membranes suitable for membrane-WGS operation. Luiten et al. [8] were able to obtain similar results with planar substrates, while for tubular substrates a permselectivity of around 40 was obtained. Asaeda et al. [9] obtained a $\mathrm{H}_{2}$ permeance of $1.2 \times 10^{-6} \mathrm{~mol} \mathrm{~m}^{-2} \mathrm{~s}^{-1}$ $\mathrm{Pa}^{-1}$ with a $\mathrm{H}_{2} / \mathrm{CO}_{2}$ permselectivity of 3.7 for TEOS derived silica membranes by using the hotcloth coating method, where the sol is coated on a hot tube by using a cloth that is impregnated with the sol. This technique induces a rapid gelation of the sol, which leads to a more open network and hence a lower permselectivity. For WGS application these TEOS derived silica membranes can however not be used, because the hydrothermal of these membranes is rather poor due to hydrolytic attack of water on the silanol groups, leading to the formation of mobile silanols and resulting in the destruction of the membrane. [10,11].

In order to increase the stability of such membranes, two methods are being pursued. The first method is to limit the mobility of the silanols by introducing metals into the matrix, while the second method tries to limit the access of water to the silanol groups by incorporation of hydrophobic moieties. These methods will now be discussed with regard to $\mathrm{H}_{2} / \mathrm{CO}_{2}$ selectivity and hydrothermal stability.

\subsubsection{Metal doping}

The effect of metal ( $\mathrm{Al}$, $\mathrm{Ti}$, or $\mathrm{Zr}$ ) doping on the microstructure of unsupported microporous silica flakes was explored by De Lange et al. [12]. The focus of this research was a study on the structural development during sol synthesis and gelation/calcination. After calcination a lower porosity in the unsupported membrane material was found for these metal-doped silica flakes in comparison with standard (non-doped) silica. However, no hydrothermal stability was studied in this work. Fotou et al. [13] investigated metal ( $\mathrm{Al}$ or $\mathrm{Mg}$ ) doping in silica in order to improve the hydrothermal stability of unsupported membrane material. They showed that $3 \%$ alumina doping did not show any difference in pore structure of the as-prepared material. However, after hydrothermal treatment at $600{ }^{\circ} \mathrm{C}$ for 30 hours only a $37 \%$ decline in micropore volume was 
observed for the aluminium doped silica, while the undoped silica had a decline in micropore volume of $77 \%$. Doping silica with 3\% magnesia resulted already upon drying in a loss of surface area from $920 \mathrm{~m}^{2} / \mathrm{g}$ for undoped silica to $340 \mathrm{~m}^{2} / \mathrm{g}$ for the magnesia doped silica. The surface area was further reduced upon calcination and subsequent hydrothermal treatment. Fotou et al. [13] stated that magnesia induces the sintering of amorphous silica thereby densifying the amorphous network and is therefore not a suitable dopant for hydrothermal stabilization.

Yoshida et al. [14] investigated the effect of zirconia doping on the hydrothermal stability of silica membranes. A 10\% zirconia doped silica membrane showed, after hydrothermal treatment at $500{ }^{\circ} \mathrm{C}$ with a steam pressure of $40 \mathrm{kPa}(10 \mathrm{~h})$ and $100 \mathrm{kPa}(10 \mathrm{~h})$, a drop in $\mathrm{H}_{2}$ permeance from $3.1 \times 10^{-7}$ to $8.8 \times 10^{-8} \mathrm{~mol} \mathrm{~m}^{-2} \mathrm{~s}^{-1} \mathrm{~Pa}^{-1}$. However, the permselectivity towards $\mathrm{CO}_{2}$ increased from 60 to 200 at a measurement temperature of $500{ }^{\circ} \mathrm{C}$, which indicates that the membrane was still very much intact. In order to prevent the big initial loss in hydrogen permeance during hydrothermal treatment steam firing was tried. This resulted in a gradual permeance drop from $4.4 \times 10^{-7}$ to $1.8 \times 10^{-7} \mathrm{~mol} \mathrm{~m}^{-2} \mathrm{~s}^{-1} \mathrm{~Pa}^{-1}$ during hydrothermal testing at $500{ }^{\circ} \mathrm{C}$. An increase in zirconia doping to $50 \%$ led to a membrane with Knudsen selectivity, which remained stable in hydrogen permeance after hydrothermal treatment. The $50 \%$ zirconia doped silica is therefore not of interest for gas separation. However, it formed the basis of the silica-zirconia intermediate layer used by the group of Tsuru [15-17] in later work.

Kanezashi et al. [18, 19] studied nickel doping in silica in order to increase the hydrothermal stability. The $33 \%$ nickel-doped silica membranes that were fired (calcined) in air at $500{ }^{\circ} \mathrm{C}$ showed a severe decrease in permeance for $\mathrm{He}, \mathrm{H}_{2}$ and $\mathrm{N}_{2}$ during steam treatment at $500{ }^{\circ} \mathrm{C}$ at a steam pressure of $70 \mathrm{kPa}$, while the $\mathrm{H}_{2} / \mathrm{N}_{2}$ permselectivity increased little. When fired in steam these nickel-doped silica membranes showed a smaller decline in permeance of $\mathrm{He}$ and $\mathrm{H}_{2}$ after hydrothermal treatment, while the $\mathrm{N}_{2}$ permeance decreased more severely, which led to an increase in $\mathrm{H}_{2} / \mathrm{N}_{2}$ permselectivity from 160 to 482. It is assumed that steam firing already leads to a more densified silica matrix, which "traps" the nickel oxide in the silica matrix. This would prevent further densification of the nickel doped silica membrane during hydrothermal treatment, since the nickel oxide particles cannot form a segregated phase. Although sufficiently high $\mathrm{H}_{2} / \mathrm{N}_{2}$ selectivities are reported, no data are available on the $\mathrm{CO}_{2}$ permeance of these membranes. 
Several groups $[6,15,20-25]$ explored the effect of cobalt doping in silica on the hydrothermal stability of these membranes. Cobalt, which is incorporated as an oxide in the form of $\mathrm{Co}_{3} \mathrm{O}_{4}$, is able to both improve the hydrothermal stability as well as the gas permeation performance with a maximum effect at a doping content of $33 \%$, where a $\mathrm{H}_{2} / \mathrm{N}_{2}$ selectivity of 1000 can be achieved [23]. These membranes show a slight increase in hydrogen permeance under reducing atmosphere due to the reduction of cobalt oxide. The reduction of cobalt oxide and the hydrogen permeance increase can be reversed in an oxidizing atmosphere, which indicates that the cobalt is incorporated in the silica matrix in a stable way [23]. Battersby et al. [20-22] investigated the use of cobalt-doped silica membranes in a water gas shift membrane reactor. With single gas permeation tests $\mathrm{H}_{2} / \mathrm{CO}_{2}$ permselectivities of up to 160 are reported, while the mixed gas selectivity with a $50 / 50 \mathrm{H}_{2} / \mathrm{CO}_{2}$ feed is around 50 . The hydrogen permeance is in the range of $10^{-8} \mathrm{~mol} \mathrm{~m}^{-2} \mathrm{~s}^{-1} \mathrm{~Pa}^{-1}$ and therefore rather low. This is probably due to the high number of coating steps, 6 in total, that are needed to obtain a defect free membrane, resulting in a separation layer with a thickness of $250 \mathrm{~nm}$ [21].

Boffa et al. [26] investigated niobia doping in silica to increase the $\mathrm{H}_{2} / \mathrm{CO}_{2}$ selectivity of the membranes. The niobia was incorporated to lower the $\mathrm{CO}_{2}$ affinity due to the presence of Brønsted acidic sites in the membrane. A $\mathrm{H}_{2}$ permeance in the order of $0.4-4 \times 10^{-8} \mathrm{~mol} \mathrm{~m}^{-2} \mathrm{~s}^{-1}$ $\mathrm{Pa}^{-1}$ was measured, which is rather low. $\mathrm{A} \mathrm{H}_{2} / \mathrm{CO}_{2}$ selectivity in the order of $20-40$ was obtained, which shows that niobia can be used to effectively reduce the $\mathrm{CO}_{2}$ permeance, since the obtained $\mathrm{H}_{2} / \mathrm{N}_{2}$ and $\mathrm{H}_{2} / \mathrm{CH}_{4}$ selectivities are only 6.3 and 7.2 respectively. After hydrothermal treatemtent at $150{ }^{\circ} \mathrm{C}$ for $70 \mathrm{~h}$ and at $200{ }^{\circ} \mathrm{C}$ for $70 \mathrm{~h}$ the hydrogen permeance dropped to $68 \%$ of the initial permeance [27]. Although the membranes are stable, the initial low $\mathrm{H}_{2}$ permeance and the low $\mathrm{H}_{2} / \mathrm{N}_{2}$ and $\mathrm{H}_{2} / \mathrm{CH}_{4}$ selectivity are not sufficient for industrial application.

From the results as discussed above, metal doping seems to be a suitable route to increase the hydrothermal stability of silica derived membranes. However the exact mechanism of stabilization is not known, especially for the nickel and cobalt doped membranes, where the dopant is present as metal oxide particles. Also these metal oxide particles are reduced to metal particles in reducing atmosphere, which is the case with hydrogen as the major component in WGS streams. The reduction of the metal oxide to metal leads to a decrease in particle volume, which causes pore formation or widening in the silica matrix. 


\subsubsection{Hydrophobization}

A number of different methods are used to make silica membranes more hydrophobic. First attempts used methyl triethoxy silane (MTES) as a second silicon source during sol-gel synthesis, leading to a more hydrophobic surface [11]. However, no hydrothermal stability data of these membranes were provided. The research that started with MTES was later expanded to a broad range of covalently bonded pendant groups [16, 28-30]. For example, Wei et al. [29] used (trifluoropropyl)triethoxysilane as a second precursor to create a hydrophobic membrane having a water contact angle of $115^{\circ}$. The membranes were tested under hydrothermal conditions for over $200 \mathrm{~h}$ and remained stable, while having a hydrogen permeance of $1.6 \times 10^{-6} \mathrm{~mol} \mathrm{~m}^{-2} \mathrm{~Pa}^{-1}$ $\mathrm{s}^{-1}$. The $\mathrm{H}_{2} / \mathrm{CO}_{2}$ permselectivity was 8 , which is rather low for silica derived membranes. Also a considerable $\mathrm{SF}_{6}$ permeance was measured, indicating that these membranes do have large pores.

A different method is the use of a carbon source during the sol syntheses, which is later partially pyrolized to obtain carbon particles in the silica matrix. Duke et al. [10] utilized this technique by including hexyltriethylammonium bromide in the silica sol, which was later carbonized during firing in air at $500{ }^{\circ} \mathrm{C}$. The xerogel and membrane characteristics showed only little degradation after hydrothermal testing, however the $\mathrm{H}_{2} / \mathrm{CO}_{2}$ and $\mathrm{H}_{2} / \mathrm{N}_{2}$ selectivity of those membranes was 7.6 and 3.1, which is close to the Knudsen values. Therefore such membranes are of little interest for gas separation applications.

Although hydrophobization is in theory a good way to improve the hydrothermal stability of these TEOS-derived silica membranes, it is rather difficult to obtain defect free membranes. Another reason for concern is the fact that by carbon templating the carbon can be gasified in the presence of water and hydrogen. Therefore, it is not of interest to further study these type of hydrophobized silica membranes in the framework of WGS-MR application.

\subsubsection{Hybrid organic-inorganic materials based on bridged silsesquioxanes}

The idea of hydrophobization of the silica membranes led to the use of bridged silsesquioxanes as a precursor for the fabrication of sol-gel derived silica membranes. A big advantage of making membranes with these materials is that one can obtain a well-dispersed organic-inorganic matrix. The most used precursor for these systems is 1,2-bis(triethoxysilyl)ethane (BTESE), although other bridged silsesquioxanes are investigated for this purpose as well [31]. 
Castricum et al. [32] were the first to report a BTESE membrane which was suitable for pervaporation, while Kanezashi et al. [17] showed as one of the first the gas permeation properties of such membranes. The gas separation performance of these membranes is rather low, especially for $\mathrm{H}_{2} / \mathrm{CO}_{2}$ separation as the $\mathrm{H}_{2} / \mathrm{CO}_{2}$ selectivity is often around 4, which is even less than Knudsen selectivity, as was also observed by other groups [17, 33-35]. The reason behind this low performance is twofold. First of all a large amount of hydroxyl groups are present in the membrane as dehydroxylation is restricted due to the low calcination temperatures, used to prevent degradation of the carbon bridge of BTESE [36]. Due to these hydroxyl groups the affinity towards $\mathrm{CO}_{2}$ is high, which often leads to a negative apparent activation energy for permeation [31]. Secondly the presence of the carbon (ethylene) bridge leads to a larger pore, as visualized by Kanezashi et al. [34] see Figure 7.1. In order to use BTESE as a precursor for the fabrication of hybrid silica membranes for $\mathrm{H}_{2} / \mathrm{CO}_{2}$ separation in a WGS-MR the selectivity of these membranes should be increased. Here two routes will be discussed to improve the selectivity. The first route is by tuning the by sol-gel procedure to reduce the number of hydroxyl groups and to densify the structure. Secondly metal doping to reduce the pore size will be discussed. 
(a)<smiles>CCO[Si](OCC)(OCC)OCC</smiles>

Tetra-ethoxy-silane (TEOS)

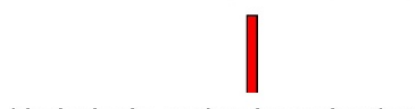

Hydrolysis and polymerization reaction

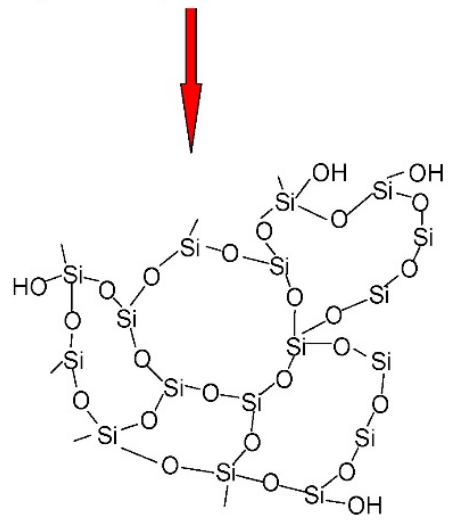

(b)<smiles>CCO[Si](CC)(OCC)OCC</smiles>

Bis-tri-ethoxysilyl-ethane (BTESE)

Hydrolysis and polymerization reaction

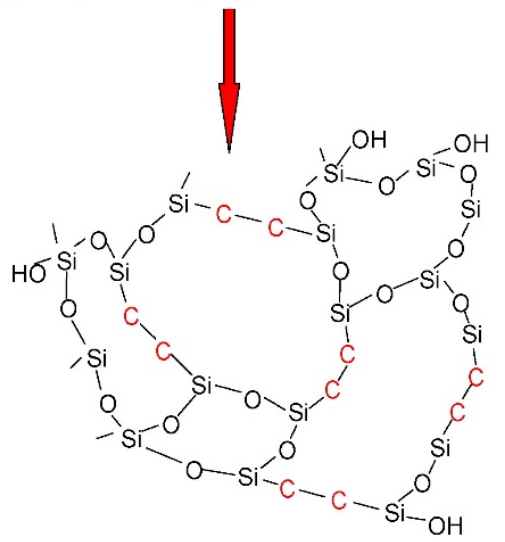

Figure 7.1: Schematic image of the amorphous silica networks derived by (a) TEOS and (b) BTESE, as proposed by Kanezashi et al. [34]

\subsubsection{Sol-gel tuning}

The BTESE membranes were originally envisioned for pervaporation purposes such as alcohol dehydration [32], where a high hydrothermal stability is needed due to the high water content of such streams. The relative loose structure of these membranes led to a high water permeation with a good retention of butanol, but when applied for ethanol and methanol dehydration, alcohol retention was much lower [37].

Niimi et al. [38] observed a decrease in pore size when the hydrolysis ratio (mol water/mol ethoxy groups) during BTESE sol synthesis, performed at $25^{\circ} \mathrm{C}$ for 1 hour, was changed from 1 to 40. This decrease in pore size, as analyzed by PALS measurements, was confirmed by gas permeation measurements, where an increase in hydrolysis ratio leads to an increased selectivity of helium over larger gases (nitrogen and larger). They ascribe this to the complete hydrolysis of the ethoxy groups during sol synthesis, resulting in a network without residual ethoxy groups. They state that residual ethoxy groups do not take part in the cross-linking during the 
coating/gelation step, leading to a more open network [38]. However, the influence of the hydrolysis ratio on the permeance of the smaller gases, like helium, hydrogen and carbon dioxide is very minimal. The pore sizes as calculated by PALS measurements are $0.4 \mathrm{~nm}$ for a hydrolysis ratio of 240, which explains the limited effect on the permeance of the smaller gases $\left(\mathrm{He}, \mathrm{H}_{2}\right.$, $\left.\mathrm{CO}_{2}\right)$.

Castricum et al. [39] investigated the influence of acid concentration on the gas permeation performance of BTESE membranes. By changing the acid ratio $\left(\left[\mathrm{H}^{+}\right] /[\mathrm{Si}]\right)$ from 0.1 to 0.01 the $\mathrm{H}_{2} / \mathrm{N}_{2}$ permselectivity increased from 20 to $>80$. The effect of the acid ratio was more pronounced for the bigger gases $\left(\mathrm{N}_{2}\right.$ and $\left.\mathrm{CH}_{4}\right)$ when coated on a dry substrate. Here a strong influence of the support on the performance of the membranes was found. Residual water in the mesopores of the intermediate layer can lead to a faster reaction during gelation, which strengthens the siloxane network, resulting in the formation of larger pores during drying. As stated by Castricum et al. it is important to carefully control the humidity condition of the supports prior to coating, since moisture in the intermediate layers can lead to larger pores due to a faster reactions during gelation. The variations in the acid ratio had little effect for the smaller gases $\left(\mathrm{He}, \mathrm{H}_{2}\right.$ and $\left.\mathrm{CO}_{2}\right)$, which is consistent with the findings of Niimi et al. [38].

From the results, obtained up till now, it is concluded that by tuning the sol-gel process for BTESE derived systems only the permeance of the larger gases like nitrogen and methane can be decreased. However, a change in $\mathrm{H}_{2} / \mathrm{CO}_{2}$ selectivity, that is necessary for application in a WGS-MR, was not observed. This is probably due to the relative large pore size as a result of the carbon bridge in the network structure.

\subsubsection{Metal doping}

As stated above it is not possible to increase the $\mathrm{H}_{2} / \mathrm{CO}_{2}$ selectivity of BTESE membranes to the high values that are needed for a WGS-MR by only tuning the sol-gel process. Therefore other alternatives are explored, like metal doping to either decrease the pore size or change the affinity towards $\mathrm{CO}_{2}$, so that the $\mathrm{CO}_{2}$ permeance is lowered and hence the selectivity is increased.

Qi et al. [40] were the first to implement metal doping in BTESE membranes by using niobium as a dopant. Based on the results of Boffa et al. [26] with niobium doping in silica, niobium was chosen to decrease the $\mathrm{CO}_{2}$ permeance of the BTESE membrane. A high $\mathrm{H}_{2} / \mathrm{CO}_{2}$ selectivity of 220 was observed by Qi et al. after calcination at $450{ }^{\circ} \mathrm{C}$, which they ascribed to the Brønsted 
acidity of the niobium sites. The hydrogen permeance of the Nb-BTESE membrane was $10^{-7}$ $\mathrm{mol} \mathrm{m} \mathrm{Pa}^{-1} \mathrm{~s}^{-1}$, which is a factor 2 lower in comparison with the undoped BTESE membranes. This lower permeance is an indication for network densification. Qureshi et al. [41] investigated $\mathrm{Nb}$ doping to BTESE as well, though they were not successful in reproducing the low $\mathrm{CO}_{2}$ permeance and high $\mathrm{H}_{2} / \mathrm{CO}_{2}$ permselectivity as observed by Qi et al. The Nb-BTESE membrane prepared by Qureshi et al. showed a hydrogen permeance of $5.03 \times 10^{-7} \mathrm{~mol} \mathrm{~m}^{-2} \mathrm{~Pa}^{-}$ ${ }^{1} \mathrm{~s}^{-1}$ and a $\mathrm{H}_{2} / \mathrm{CO}_{2}$ permselectivity of 3.5 , which is similar to an undoped BTESE membrane. This is probably caused by the difference in synthesis conditions. Qureshi et al. used a prehydrolysis step of 2 hours at $20^{\circ} \mathrm{C}$, prior to the addition of the $\mathrm{Nb}$-precursor to the reaction mixture. This pre-hydrolysis step was determined to be optimal as analyzed by time resolved FTIR measurements. After 2 hours of pre-hydrolysis the amount of water is at a minimum, which prevents too fast hydrolysis of the niobium ethoxide precursor. At the same time the amount of silanol groups is at a maxium, which should ensure a homogenous dispersion of niobium in BTESE. Also a lower acid concentration was used by Qureshi et al. as compared to the work of Qi et al. In general the experimental conditions, as used by Qureshi et al. have resulted in a more open pore structure. In Chapter 4 of this thesis an attempt was made to reproduce the results obtained by Qi et al. Despite careful replication of sol synthesis, coating conditions and firing conditions no high $\mathrm{H}_{2} / \mathrm{CO}_{2}$ permselectivity was observed.

Qureshi et al. [41] investigated, besides niobia doping, also boron and tantalum doping. The tantalum doped BTESE membrane showed a similar permeance and selectivity as the niobium doped membrane as described above. It was expected that for both tantalum and niobium a more densified network would be formed due to their relative higher valence. Both Nb-and Ta-BTESE systems were made with the same procedure, meaning a prehydrolysis step of BTESE of $2 \mathrm{~h}$ at $20^{\circ} \mathrm{C}$. It seems that this sol synthesis route is not much of use for the fabrication of highly selective $\mathrm{H}_{2} / \mathrm{CO}_{2}$ gas separation membranes. Boron doped BTESE was produced in a one-step synthesis, because of the similar reaction rates of boron alkoxides and BTESE [41]. A more open network was observed with boron doping in comparison with an undoped membrane, which is caused by the lower valency of boron compared to silicon. The $\mathrm{H}_{2} / \mathrm{CO}_{2}$ selectivity was only 4 and hence not of interest for a WGS-MR.

Wolf [42] investigated the influence of alumina, germania and silica doping in BTESE on gas permeation. However, no significant differences in $\mathrm{H}_{2} / \mathrm{CO}_{2}$ selectivity were observed. The $\mathrm{H}_{2} / \mathrm{CO}_{2}$ selectivity was in the range of 3.6 to 5.3 , which is too low for WGS-MR application. In 
fact, here the doping seemed to have little effect at all on membrane performance. Kanezashi et al. [43] however found a densified network after alumina doping in bis(triethoxysilyl)methane (BTESM) membranes using aluminum nitrate as a precursor, suggesting that there is a positive influence of alumina on the pore size control of the BTESM film. They ascribe this positive influence to the octahedral coordination of the alumina. However, the $\mathrm{H}_{2} / \mathrm{CO}_{2}$ selectivity was only slightly changed from 4.1 for undoped BTESM to 5.4 for 5\% doped Al-BTESM. Therefore alumina doping seems not a suitable route to decrease the pore size for $\mathrm{H}_{2} / \mathrm{CO}_{2}$ separation.

In Chapter 3 of this thesis doping of zirconia into BTESE was proposed as a way to increase the $\mathrm{H}_{2} / \mathrm{CO}_{2}$ selectivity. By using a one-step approach with zirconyl nitrate as the zirconium precursor, defect free membranes were obtained after optimization of the dip-sol concentration. With $16 \% \mathrm{Zr}$ doping a hydrogen permeance of $1.8 \times 10^{-7} \mathrm{~mol} \mathrm{~m}^{-2} \mathrm{~Pa}^{-1} \mathrm{~s}^{-1}$ was obtained, which is a factor 2 lower than the undoped BTESE. However the $\mathrm{H}_{2} / \mathrm{CO}_{2}$ permselectivity was increased from 4 to 16 as compared to undoped BTESE, which is a factor 4 increase. In Chapter 4 of this thesis the use of a zirconia alkoxide precursor was explored. However, the alkoxide route did not provide a comparable result due to the difficult control of the (pre)hydrolysis of this zirconium precursor.

The advantages of metal doped hybrid silica over metal doped silica is that the hybrid silica is inherently hydrothermal stable, which implies that the metals used for doping are only needed for network alterations, not for stability. However, due to the fast hydrolysis of the dopant precursor a two-step approach is often applied, where BTESE is first pre-hydrolyzed before dopant addition. This however introduces difficulties in controlling the premature condensation of BTESE. Therefore a one-step approach is preferable. A one-step approach can be realized by lowering the reaction rates in order to have a closer match by using a for example a less-reactive precursor or by lowering the reaction temperature.

\subsection{Limitations}

\subsubsection{Thermal and hydrothermal stability}

In order to be successful in operating a microporous membrane in a WGS-MR, the membrane should not show any signs of flux decline and degradation under operating conditions. Whereas for the silica derived membranes the largest limitations are in the actual hydrothermal stability, 
for the hybrid silica derived membranes the main limitation is the operation temperature, which must be below $400{ }^{\circ} \mathrm{C}$, due to the thermal instability of the carbon-carbon bond.

Cobalt doped silica showed a major hydrogen permeance decline during gas permeation tests under hydrothermal conditions [23, 25]. After the initial drop in hydrogen permeance, which occurred in the first 25 hours of hydrothermal treatment, only $10 \%$ of the initial hydrogen permeance remained. The selectivity of hydrogen over nitrogen however remained stable. Combined with the already low hydrogen permeance of the pristine membranes it is questionable whether this type of membrane can become feasible in the future.

In Chapter 6 it was demonstrated that a Zr-BTESE membrane degrades after hydrothermal testing at $400{ }^{\circ} \mathrm{C}$ for $72 \mathrm{~h}$ while it remains stable at $300{ }^{\circ} \mathrm{C}$. TGA measurements on undoped BTESE, as performed by Kappert et al. [36], show that the onset of degradation of the hybrid network in an inert atmosphere starts around $450{ }^{\circ} \mathrm{C}$. Since these measurements were conducted with $<1 \mathrm{ppb}$ oxygen it can be assumed that under industrial circumstances with some oxygen as contaminant the degradation starts at a lower temperature,

The temperature limitation of the hybrid silica implies that these materials can only be used in membrane reactors operating at low temperatures, i.e. between $200{ }^{\circ} \mathrm{C}$ and $350{ }^{\circ} \mathrm{C}$. This is the normal operating range of a low temperature water gas shift reactor [44]. For implementation of a hybrid silica membrane in a WGS-MR a high temperature pre-shift is necessary to convert most of the $\mathrm{CO}$ towards $\mathrm{H}_{2}$ and $\mathrm{CO}_{2}$, due to the exothermic nature of the reaction. In this way the temperatures in the WGS-MR can remain low.

\subsubsection{Long term stability}

Long term stability in an academic setting, which is often in the order of days, is often not the long term stability industry is looking for, as industry wants to see a stability test of the order of months. Therefore little data are available in literature on long term stability tests that last for more than one month.

For BTESE membranes in pervaporation long term measurements were performed by Castricum et al. [45]. The selectivity remained constant during a period of over 400 days. The water flux however declined from 20 to $15 \mathrm{~kg} \mathrm{~m}^{-2} \mathrm{~h}^{-1}$ and could be fitted by an exponential decay. The exact mechanism behind this aging is still not known, although it is assumed that the reorganization of the siloxane bonds is a major contributor. It is necessary to obtain a good 
understanding of the processes that determine the flux decline during long term application of such membranes.

Long term tests are impractical for screening purposes, therefore some screening tools are needed. In the work, as described in Chapters 5 and 6 a simple setup for hydrothermal stability tests is applied. Although relative mild conditions are used in a period of only 3 days, the presence of liquid water due to condensation led to complete destruction of $\gamma$-alumina and silica membranes. This means that although the test seems mild it is harsh enough for screening purposes.

\subsubsection{Permeance}

The hydrogen permeance of the membrane defines the amount of area that is needed to fulfil a certain hydrogen flow. Franz et al. [46] investigated a number of pre-combustion carbon capture configurations for a $770 \mathrm{MW}$ reference power plant. They showed that a membrane area of 95,000 $\mathrm{m}^{2}$ was necessary for a minimal efficiency loss with a WGS-MR, based on a hydrogen permeance of $1 \times 10^{-7} \mathrm{~mol} \mathrm{~m}^{-2} \mathrm{~Pa}^{-1} \mathrm{~s}^{-1}$. The $\mathrm{H}_{2} / \mathrm{CO}_{2}$ selectivity was set to 500 to minimize the emission of $\mathrm{CO}_{2}$, which would otherwise lead to an increase in costs. In this configuration the efficiency loss was only $5.8 \%$, which is lower than the $10.3 \%$ as calculated for a conventional Selexol process. The large required membrane area shows that an increase in permeance is desired to lower the area needed.

A way to increase permeance is to reduce the resistance of the separation layer by reducing thickness of the separation layer. However, in order to do so a few prerequisites are needed. First of all, the support should have a low transport resistance and a high surface quality. Furthermore, the reduction of layer thickness increases the chance of defects, therefore careful control of the coating conditions are needed. For very thin membranes $(<100 \mathrm{~nm})$ often a multiple coating step is used to reduce defects. This increases the manufacturing time, since most time is needed for the firing steps.

Besides, transport limitations through the support of current membranes are still quite high, especially for the disc-shaped membranes used in this thesis. Due to the low porosity of $30 \%$ and a uniform, relative small, pore size of $80 \mathrm{~nm}$ they are not suitable for high permeable membrane layers as the resistance through these supports is high [47]. However, the reason to use these membranes in this research is the high surface quality of the supports. This allows the 
application of well-defined coatings without defects and is therefore an ideal platform for membrane development.

For scale-up purposes tubular membranes are often considered as these are better to implement in a reactor design. These tubular membranes are usually made by extrusion and consist of a coarse grained bulk. However, due to the presence of these coarse grains the surface quality of these tubular membranes is lower than for the disc shaped membranes as used in the work, described in this thesis. To overcome this inhomogeneity issue of commercial tubular membranes a number of coatings are applied to reduce the pore size and to improve the surface quality, necessary for applying a defect-free separation layer. These intermediate coating layers again can lead to lower permeances as well as to an increase in manufacturing time.

The most common coating method used is dip-coating, where a high surface quality of the support is needed for realizing a defect free coating. The advantage of dip-coating is that it is a proven technique for large-scale coating applications. Another deposition technique used for sol-gel derived membranes is the so-called "hot-coating" technique [15, 18, 23, 34, 48, 49], where a support is heated till $180{ }^{\circ} \mathrm{C}$ and the membrane layer is applied by contacting the membrane with a cloth that is wetted by a sol. The philosophy behind this coating method is that due to the hot surface instantaneous drying occurs, which limits the infiltration of the sol into the membrane support. Although the coating method leads to thin layers, the amount of defects is still high, as often $\mathrm{SF}_{6}$ permeance is measured [34].

It is observed that due to the flexibility of hybrid silica the coating conditions for dip-coating are less critical as compared to the coating conditions for silica. It was shown by Kappert et al. [50] that on a smooth silicon wafer the critical thickness for TEOS derived silica, above which cracks are formed, is $300 \mathrm{~nm}$ while for BTESE layers this critical thickness is more than $1 \mu \mathrm{m}$, being more than a factor three higher. BTESE derived membrane layers are often coated only once [35], while silica derived layers are often coated multiple times, from 2 layers as used by de Vos et al. [7] up to 6 layers as used by Battersby et al. [22]. An increase in the number of coating steps drastically increases the manufacturing time for such membranes.

\subsection{Perspectives}

Maas et al. [51] reported an economic evaluation to assess the three routes of carbon capture and storage using membrane separation: oxy-fuel combustion, pre-combustion carbon capture 
and post-combustion carbon capture. Pre-combustion carbon capture with a water-gas-shift membrane reactor (WGS-MR) led to the lowest efficiency loss, although an economic feasibility is only possible with a carbon allowance cost of more than $30 € /$ ton $\mathrm{CO}_{2}$. The assumptions for membrane performance as used in the study of Maas et al., are a $\mathrm{H}_{2}$ permeance of $10^{-7} \mathrm{~mol} \mathrm{~m}^{-2}$ $\mathrm{s}^{-1} \mathrm{~Pa}^{-1}$ and a hydrogen selectivity of 500 towards $\mathrm{CO}_{2}, \mathrm{CO}$ and $\mathrm{N}_{2}$. The hydrogen permeance target is reasonable achievable with the current membranes. The $\mathrm{H}_{2} / \mathrm{CO}_{2}$ selectivity is however rather ambitious, especially for hybrid silica derived membranes. The highest reported $\mathrm{H}_{2} / \mathrm{CO}_{2}$ selectivity reported in literature for hybrid silica derived membranes is 220 for Nb-BTESE [40], although the results were not reproducible as described in Chapter 4 of this thesis. Also for the TEOS derived membranes the $\mathrm{H}_{2} / \mathrm{CO}_{2}$ selectivity does not exceed above 200. A lower selectivity of hydrogen over carbon dioxide does not lead to an efficiency loss but to a possible increased cost of electricity due to carbon emissions. However, a lower target selectivity might increase the feasibility of WGS-MR for pre-combustion carbon capture.

Hydrophobization of TEOS derived silica does not lead to an appropriate separation capability as the selectivity of most of these hydrophobized membranes are in the Knudsen range. However, the stability of these membranes is sufficiently high. Therefore these membranes may be useful in other processes like liquid filtration or pervaporation.

The metal doped TEOS derived silica membranes do show a sufficient high selectivity and are reasonably stable. However the main concerns for metal-doped TEOS derived silica membranes are the low hydrogen permeances that are obtained, especially after hydrothermal treatment. The initial drop during hydrothermal treatment is quite severe. It is shown that by using a steamfiring method during calcination this initial drop can be mitigated [23]. The exact mechanism of the stabilization effect of cobalt is not really known, although numerous studies have been done on the applicability of such membranes in membrane reactors. However, it seems that metaloxide particles would not be the ideal way to stabilize such materials. It is assumed that atomically dispersed cobalt oxide with covalent bonding to the silica matrix would have a bigger impact on the hydrothermal stability of such membranes, since the effects for binary oxides are more pronounced in homogenously mixed oxides [52].

For BTESE derived materials the synthesis conditions are yet to be optimized. It is shown that, by varying the hydrolysis ratio [38] and/or the acid ratio [39] during sol syntheses, the nitrogen and methane permeance of these hybrid membranes can be significantly reduced. Careful 
screening with SAXS [33, 39], nmR [53, 54] and DLS [37] is necessary to tune the network formation to lower the permeance for the larger gases. In order to reduce the carbon dioxide permeance metal doping is necessary, since the network formed by BTESE has a pore size that is too big to block carbon dioxide effectively, due to the carbon bridges in the BTESE sol gel network.

One of the most promising metals to be used in altering the pore size of BTESE derived networks is zirconia. As shown in Chapters 3, 4 and 6, zirconia can effectively be used to decrease $\mathrm{CO}_{2}$ permeance, especially after hydrothermal treatment. However further optimizations are possible to increase the selectivity and permeance, for example by tuning the sol-gel parameters [39].

Although the focus in development of new $\mathrm{H}_{2} / \mathrm{CO}_{2}$-selective membranes now mostly is on the separation layers, a suitable support is of utmost importance as well. The intermediate layers that are used mostly are $\gamma$-alumina or silica-zirconia. While $\gamma$-alumina in itself is not hydrothermally stable, modification by doping with phosphorus and/or lanthanum has led to stable intermediate layers. On the other hand zirconia intermediate layers [55] are also of interest, due to the high stability under acidic conditions.

Another point of extreme importance is the need for suitable supports. Multichannel monoliths can greatly enhance the surface/volume ratio. However the implementation of such monoliths in a membrane reactor can be problematic in terms of catalyst placement. Therefore the use of tubes or hollow fibers is more preferable. Ceramic hollow fibers can be made with the same dimensions as their polymeric counterparts, therefore the surface/volume ratio can be largely increased with respect to the conventional tubular membranes [56].

\subsection{Conclusion}

The metal doped silica membranes show high selectivity and good hydrothermal stability. The permeance of such membranes are however rather low, which limits their use in an industrial application.

The most promising route is the use of metal doped hybrid silica membranes, in particular zirconia doped membranes. However, great care should be taken with the synthesis conditions, since premature hydrolysis can lead to membranes with a poor selectivity. 
Based on the large membrane areas that are needed for pre-combustion carbon capture it would be beneficial to further increase the hydrogen permeance targets. Therefore thinner membrane layers are needed, which are only feasible with a high support quality. Therefore the development of the next generation membranes should be twofold; not only focus on the actual gas separation layer, but also to pay attention to the supports so that large membrane areas can be made cheap and with a high surface quality to apply very thin, less than $100 \mathrm{~nm}$, membrane separation layers.

\subsection{References}

[1] Energy Information Administration, International Energy Outlook 2013 With Projections to 2040, U.S. Government Printing Office, 2013.

[2] Intergovernmental Panel on Climate Change, Climate Change 2013 - The Physical Science Basis: Working Group I Contribution to the Fifth Assessment Report of the Intergovernmental Panel on Climate Change, Cambridge University Press, 2014.

[3] R. Bredesen, K. Jordal, O. Bolland, High-temperature membranes in power generation with CO2 capture, Chemical Engineering and Processing, 43 (2004) 1129-1158.

[4] F. Gallucci, E. Fernandez, P. Corengia, M.V. Annaland, Recent advances on membranes and membrane reactors for hydrogen production, Chemical Engineering Science, 92 (2013) 40-66.

[5] N.W. Ockwig, T.M. Nenoff, Membranes for Hydrogen Separation, Chemical Reviews, 107 (2007) 40784110.

[6] D. Uhlmann, S. Smart, J.C. Diniz da Costa, H2S stability and separation performance of cobalt oxide silica membranes, Journal of Membrane Science, 380 (2011) 48-54.

[7] R.M. de Vos, H. Verweij, High-selectivity, high-flux silica membranes for gas separation, Science, 279 (1998) 1710-1711.

[8] M.W.J. Luiten, N.E. Benes, C. Huiskes, H. Kruidhof, A. Nijmeijer, Robust method for micro-porous silica membrane fabrication, Journal of Membrane Science, 348 (2010) 1-5.

[9] M. Asaeda, S. Yamasaki, Separation of inorganic/organic gas mixtures by porous silica membranes, Separation and Purification Technology, 25 (2001) 151-159.

[10] M.C. Duke, J.C.D. da Costa, D.D. Do, P.G. Gray, G.Q. Lu, Hydrothermally robust molecular sieve silica for wet gas separation, Advanced Functional Materials, 16 (2006) 1215-1220.

[11] R.M. de Vos, W.F. Maier, H. Verweij, Hydrophobic silica membranes for gas separation, Journal of Membrane Science, 158 (1999) 277-288.

[12] R.S.A. de Lange, K.N.P. Kumar, J.H.A. Hekkink, G.M.H. van de Velde, K. Keizer, A.J. Burggraaf, W.H. Dokter, H.F. van Garderen, T.P.M. Beelen, Microporous $\mathrm{SiO} 2$ and $\mathrm{SiO} 2 / \mathrm{MOx}(\mathrm{M}=\mathrm{Ti}, \mathrm{Zr}, \mathrm{Al})$ for ceramic membrane applications: A microstructural study of the sol-stage and the consolidated state, Journal of Sol-Gel Science and Technology, 2 (1994) 489-495.

[13] G.P. Fotou, Y.S. Lin, S.E. Pratsinis, Hydrothermal Stability of Pure and Modified Microporous Silica Membranes, Journal of Materials Science, 30 (1995) 2803-2808.

[14] K. Yoshida, Y. Hirano, H. Fujii, T. Tsuru, M. Asaeda, Hydrothermal stability and performance of silica-zirconia membranes for hydrogen separation in hydrothermal conditions, Journal of Chemical Engineering of Japan, 34 (2001) 523-530.

[15] T. Tsuru, R. Igi, M. Kanezashi, T. Yoshioka, S. Fujisaki, Y. iwamoto, Permeation properties of hydrogen and water vapor through porous silica membranes at high temperatures, AIChE Journal, 57 (2011) 618-629.

[16] H.R. Lee, T. Shibata, M. Kanezashi, T. Mizumo, J. Ohshita, T. Tsuru, Pore-size-controlled silica membranes with disiloxane alkoxides for gas separation, Journal of Membrane Science, 383 (2011) 152158. 
[17] M. Kanezashi, K. Yada, T. Yoshioka, T. Tsuru, Design of Silica Networks for Development of Highly Permeable Hydrogen Separation Membranes with Hydrothermal Stability, J. Am. Chem. Soc., 131 (2009) 414-415.

[18] M. Kanezashi, M. Asaeda, Hydrogen permeation characteristics and stability of Ni-doped silica membranes in steam at high temperature, Journal of Membrane Science, 271 (2006) 86-93.

[19] M. Kanezashi, T. Fujita, M. Asaeda, Nickel Doped Silica Membranes for Separation of Helium from Organic Gas Mixtures, Separation Science and Technology, 40 (2005) 225-238.

[20] S. Battersby, M.C. Duke, S. Liu, V. Rudolph, J.C.D.d. Costa, Metal doped silica membrane reactor: Operational effects of reaction and permeation for the water gas shift reaction, Journal of Membrane Science, 316 (2008) 46-52.

[21] S. Battersby, S. Smart, B. Ladewig, S. Liu, M.C. Duke, V. Rudolph, J.C.D.d. Costa, Hydrothermal stability of cobalt silica membranes in a water gas shift membrane reactor, Separation and Purification Technology, 66 (2009) 299-305.

[22] S. Battersby, T. Tasaki, S. Smart, B. Ladewig, S. Liu, M.C. Duke, V. Rudolph, J.C. Diniz da Costa, Performance of cobalt silica membranes in gas mixture separation, Journal of Membrane Science, 329 (2009) 91-98.

[23] R. Igi, T. Yoshioka, Y.H. Ikuhara, Y. Iwamoto, T. Tsuru, Characterization of Co-Doped Silica for Improved Hydrothermal Stability and Application to Hydrogen Separation Membranes at High Temperatures, Journal of the American Ceramic Society, 91 (2008) 2975-2981.

[24] D. Uhlmann, S. Liu, B.P. Ladewig, J.C. Diniz da Costa, Cobalt-doped silica membranes for gas separation, Journal of Membrane Science, 326 (2009) 316-321.

[25] D. Uhlmann, S. Smart, J.C. Diniz da Costa, High temperature steam investigation of cobalt oxide silica membranes for gas separation, Separation and Purification Technology, 76 (2010) 171-178.

[26] V. Boffa, J.E. ten Elshof, A.V. Petukhov, D.H. Blank, Microporous niobia-silica membrane with very low CO2 permeability, ChemSusChem, 1 (2008) 437-443.

[27] V. Boffa, D.H.A. Blank, J.E. ten Elshof, Hydrothermal stability of microporous silica and niobia-silica membranes, Journal of Membrane Science, 319 (2008) 256-263.

[28] Q. Wei, Y.-L. Wang, Z.-R. Nie, C.-X. Yu, Q.-Y. Li, J.-X. Zou, C.-J. Li, Facile synthesis of hydrophobic microporous silica membranes and their resistance to humid atmosphere, Microporous and Mesoporous Materials, 111 (2008) 97-103.

[29] Q. Wei, F. Wang, Z.-R. Nie, C.-L. Song, Y.-L. Wang, Q.-Y. Li, Highly Hydrothermally Stable Microporous Silica Membranes for Hydrogen Separation, The Journal of Physical Chemistry B, 112 (2008) 9354-9359.

[30] S. Gopalakrishnan, Y. Yoshino, M. Nomura, B.N. Nair, S.-I. Nakao, A hybrid processing method for high performance hydrogen-selective silica membranes, Journal of Membrane Science, 297 (2007) 5-9.

[31] H.L. Castricum, G.G. Paradis, M.C. Mittelmeijer-Hazeleger, R. Kreiter, J.F. Vente, J.E. ten Elshof, Tailoring the Separation Behavior of Hybrid Organosilica Membranes by Adjusting the Structure of the Organic Bridging Group, Advanced Functional Materials, 21 (2011) 2319-2329.

[32] H.L. Castricum, A. Sah, R. Kreiter, D.H. Blank, J.F. Vente, J.E. ten Elshof, Hybrid ceramic nanosieves: stabilizing nanopores with organic links, Chem Commun (Camb), (2008) 1103-1105.

[33] H.L. Castricum, G.G. Paradis, M.C. Mittelmeijer-Hazeleger, W. Bras, G. Eeckhaut, J.F. Vente, G. Rothenberg, J.E. ten Elshof, Tuning the nanopore structure and separation behavior of hybrid organosilica membranes, Microporous and Mesoporous Materials, 185 (2014) 224-234.

[34] M. Kanezashi, K. Yada, T. Yoshioka, T. Tsuru, Organic-inorganic hybrid silica membranes with controlled silica network size: Preparation and gas permeation characteristics, Journal of Membrane Science, 348 (2010) 310-318.

[35] H.F. Qureshi, A. Nijmeijer, L. Winnubst, Influence of sol-gel process parameters on the microstructure and performance of hybrid silica membranes, Journal of Membrane Science, 446 (2013) 19-25.

[36] E.J. Kappert, H.J. Bouwmeester, N.E. Benes, A. Nijmeijer, Kinetic analysis of the thermal processing of silica and organosilica, The journal of physical chemistry. B, 118 (2014) 5270-5277.

[37] R. Kreiter, M. Rietkerk, H. Castricum, H. van Veen, J. ten Elshof, J. Vente, Evaluation of hybrid silica sols for stable microporous membranes using high-throughput screening, Journal of Sol-Gel Science and Technology, (2010) 1-8. 
[38] T. Niimi, H. Nagasawa, M. Kanezashi, T. Yoshioka, K. Ito, T. Tsuru, Preparation of BTESE-derived organosilica membranes for catalytic membrane reactors of methylcyclohexane dehydrogenation, Journal of Membrane Science, 455 (2014) 375-383.

[39] H.L. Castricum, H.F. Qureshi, A. Nijmeijer, L. Winnubst, Hybrid silica membranes with enhanced hydrogen and CO2 separation properties, Journal of Membrane Science, 488 (2015) 121-128.

[40] H. Qi, J. Han, N. Xu, H.J. Bouwmeester, Hybrid organic-inorganic microporous membranes with high hydrothermal stability for the separation of carbon dioxide, ChemSusChem, 3 (2010) 1375-1378.

[41] H.F. Qureshi, R. Besselink, J.E. ten Elshof, A. Nijmeijer, L. Winnubst, Doped microporous hybrid silica membranes for gas separation, Journal of Sol-Gel Science and Technology, 75 (2015) 180-188.

[42] M.J. Wolf, Microporous membranes for gas separation : a study towards preparation and characterization of different sol-gel derived membrane materials, in, Enschede, the Netherlands, 2015, pp. 126.

[43] M. Kanezashi, S. Miyauchi, H. Nagasawa, T. Yoshioka, T. Tsuru, Gas permeation properties through Al-doped organosilica membranes with controlled network size, Journal of Membrane Science, 466 (2014) 246-252.

[44] P. Häussinger, R. Lohmüller, A.M. Watson, Hydrogen, in: Ullmann's Encyclopedia of Industrial Chemistry, Wiley-VCH Verlag GmbH \& Co. KGaA, 2000.

[45] H.L. Castricum, R. Kreiter, H.M. van Veen, D.H.A. Blank, J.F. Vente, J.E. ten Elshof, Highperformance hybrid pervaporation membranes with superior hydrothermal and acid stability, Journal of Membrane Science, 324 (2008) 111-118.

[46] J. Franz, P. Maas, V. Scherer, Economic evaluation of pre-combustion CO2-capture in IGCC power plants by porous ceramic membranes, Applied Energy, (2014).

[47] A. Nijmeijer, Hydrogen-selective silica membranes for use in membrane steam reforming, in, Enschede, 1999, pp. 136.

[48] M. Asaeda, Y. Sakou, J. Yang, K. Shimasaki, Stability and performance of porous silica-zirconia composite membranes for pervaporation of aqueous organic solutions, Journal of Membrane Science, 209 (2002) 163-175.

[49] H.R. Lee, M. Kanezashi, Y. Shimomura, T. Yoshioka, T. Tsuru, Evaluation and fabrication of poresize-tuned silica membranes with tetraethoxydimethyl disiloxane for gas separation, AIChE Journal, 57 (2011) 2755-2765.

[50] E.J. Kappert, D. Pavlenko, J. Malzbender, A. Nijmeijer, N.E. Benes, P.A. Tsai, Formation and prevention of fractures in sol-gel-derived thin films, Soft Matter, 11 (2015) 882-888.

[51] P. Maas, N. Nauels, L. Zhao, P. Markewitz, V. Scherer, M. Modigell, D. Stolten, J.F. Hake, Energetic and economic evaluation of membrane-based carbon capture routes for power plant processes, International Journal of Greenhouse Gas Control, 44 (2016) 124-139.

[52] J.B. Miller, E.I. Ko, Control of mixed oxide textural and acidic properties by the sol-gel method, Catalysis Today, 35 (1997) 269-292.

[53] H.L. Castricum, A. Sah, J.A.J. Geenevasen, R. Kreiter, D.H.A. Blank, J.F. Vente, J.E. ten Elshof, Structure of hybrid organic-inorganic sols for the preparation of hydrothermally stable membranes, Journal of Sol-Gel Science and Technology, 48 (2008) 11-17.

[54] K.J. Shea, D.A. Loy, A Mechanistic Investigation of Gelation. The Sol-Gel Polymerization of Precursors to Bridged Polysilsesquioxanes, Accounts of Chemical Research, 34 (2001) 707-716.

[55] T. van Gestel, D. Sebold, F. Hauler, W.A. Meulenberg, H.-P. Buchkremer, Potentialities of microporous membranes for $\mathrm{H} 2 / \mathrm{CO} 2$ separation in future fossil fuel power plants: Evaluation of $\mathrm{SiO} 2$, $\mathrm{ZrO} 2, \mathrm{Y} 2 \mathrm{O} 3-\mathrm{ZrO} 2$ and TiO2-ZrO2 sol-gel membranes, Journal of Membrane Science, 359 (2010) 64-79. [56] M.W.J. Luiten-Olieman, L. Winnubst, A. Nijmeijer, M. Wessling, N.E. Benes, Porous stainless steel hollow fiber membranes via dry-wet spinning, Journal of Membrane Science, 370 (2011) 124-130. 
8 Reflections and perspectives 
Chapter 8 


\subsection{Introduction}

In this thesis three objectives are discussed for the development of a hydrothermally stable gas separation membrane for a water gas shift membrane reactor (WGS-MR). These objectives are: metal doping of 1,2-bis(triethoxysilyl)ethane (BTESE) to alter the pore structure (chapter 3 and chapter 4), the assessment of the hydrothermal stability of such membranes (chapter 5 and chapter 6) and a critical review of the measurement methods used for the characterization and gas permeation of the membranes (chapter 2). These three objectives will be reflected upon and ideas for further research will be presented in the perspectives section of this chapter.

\subsection{Reflections on metal doping}

In this thesis the following metal dopants were discussed: yttrium, zirconium and niobium. Both zirconium and niobium are known to be able to modify the pore structure of silica membranes $[1,2]$. Yttrium was chosen as a third dopant due to its stable oxidation state of $3+$, while zirconium has a stable oxidation state of $4+$ and niobium a stable oxidation state of $5+$. In this way the influence of the oxidation state of a metal on membrane structure and performance could be investigated.

The most common precursors, used in sol-gel synthesis are metal-alkoxides. However, due to the high hydrolysis rates of both zirconium-alkoxide and niobium-alkoxide a one-step synthesis with BTESE is impossible. Therefore, a two-step synthesis procedure is needed, where BTESE is first prehydrolyzed before the addition of the metal-precursor. For niobium it is shown that by using this two-step method a BTESE matrix with embedded niobia clusters is obtained [3]. The reaction time for the prehydrolysis is therefore crucial; too short results in homopolymerization of the metal dopant, while a too long prehydrolysis results in the formation of too large BTESE particles, which will govern the gas permeation properties of the finished membrane. The difficulty of prehydrolysis control is reflected in chapter 4, where zirconiumand niobium-doped membranes were prepared with a two-step synthesis. Only a marginal improvement in the $\mathrm{H}_{2} / \mathrm{CO}_{2}$ permselectivity is observed for zirconium- and niobium doped membranes as compared to undoped membranes. Moreover, differences in pre-hydrolysis conditions can result in large variations using the same dopant. This is reflected by the discussion, given in chapter 4 , where the niobium doped membranes were compared with the work of Qureshi et al. [4]. In that work it was shown that a prehydrolysis of 2 hours at $20{ }^{\circ} \mathrm{C}$ resulted in 
a lower membrane permselectivity as compared to undoped BTESE. In chapter 4 of this thesis two synthesis routes were described for the synthesis of Nb-doped BTESE sols, by using niobium $(\mathrm{V})$ n-butoxide as $\mathrm{Nb}$ precursor. In the first route a prehydrolysis step for the $\mathrm{Nb}$ precursor of 60 minutes at $60{ }^{\circ} \mathrm{C}$ was applied, while for the second route a prehydrolysis step of 90 minutes at $60^{\circ} \mathrm{C}$ was used. A membrane made by the first route did not show any improvement in permselectivity over undoped BTESE membranes, while a membrane made by the second route showed a minor improvement. Based on these observations it is wise to find methods in which a one-step synthesis can be used to increase the homogeneity of the mixed metal sol.

The use of zirconyl nitrate opened up the route for a one-step synthesis. Due to the lower hydrolysis rate of the zirconyl nitrate in comparison with the zirconium alkoxide a one-step synthesis could be performed. By lowering the reaction temperature from of the standard $60{ }^{\circ} \mathrm{C}$ to $30^{\circ} \mathrm{C}$ the reaction rates of BTESE and zirconyl nitrate were more closely matched to obtain a homogenous dispersion of zirconia in the BTESE matrix. The same method was used to produce yttrium doped BTESE, with yttrium nitrate as a precursor. However, due to a lower reaction rate of yttrium nitrate the standard synthesis temperature of $60^{\circ} \mathrm{C}$ could be used. Zirconium doping in BTESE resulted in a membrane with a slightly lower hydrogen permeance and an increased $\mathrm{H}_{2} / \mathrm{CO}_{2}$ selectivity as compared to undoped BTESE, which can be explained as densification of the porous structure. Yttrium doping resulted in an increase in permeance as compared to undoped BTESE. However, a slight decrease in $\mathrm{H}_{2} / \mathrm{CO}_{2}$ permselectivity was observed, which is indicative for a more open network as compared to BTESE. Therefore, yttrium doping is not suitable to enhance $\mathrm{H}_{2} / \mathrm{CO}_{2}$ separation of BTESE-derived membranes. The increased permeance might be useful for separations where the differences in molecule sizes are more prominent, e.g. in cyclohexane and methylcyclohexane dehydrogenation membrane reactors $[5,6]$.

It became evident that for a zirconium doped BTESE membrane the maximum coating thickness for a defect free membrane is much smaller than for an undoped BTESE membrane. Zr-BTESE did already fracture at a layer thickness of $330 \mathrm{~nm}$, as shown in Figure 8.1, while undoped BTESE with a thickness of $550 \mathrm{~nm}$ did not show defects [7]. However, Kappert et al. [8] have shown that Zr-BTESE only starts fracturing after deposition of a Zr-BTESE layer of $2150 \mathrm{~nm}$ thickness on a silicon wafer, while undoped BTESE already starts fracturing after $1250 \mathrm{~nm}$ thickness on a silicon wafer. This difference in critical thickness can be explained by 
the fact that a dense silicon wafer has a very smooth surface and does not allow infiltration of the sol in the material, while on the other hand a porous $\gamma$-alumina support has some surface roughness and allows infiltration of the hybrid silica sol in the $\gamma$-alumina pores. The sol particle size of Zr-BTESE is $7.9 \mathrm{~nm}$, while the particle size of undoped BTESE is $14.7 \mathrm{~nm}$, which is almost twice as large. Infiltration is hence more likely to happen for Zr-BTESE. Therefore it might be that the observed thickness in SEM, which was $330 \mathrm{~nm}$ in the case of Zr-BTESE, is not the actual thickness due to infiltration, which might explain the lower maximum thickness. Drying studies on smooth silicon wafer substrates can give a first indication on the maximum coating thickness, however it is important to extend these studies to porous substrates to better understand the role of surface roughness, pore size and sol particle size (and hence the extend of infiltration) on the critical thickness of membranes. Very thin layers on the other hand are desirable as these would enhance the permeance of the membrane. However, these thin layers are prone to defects due to e.g. incomplete coverage, which is more likely to happen with a higher surface roughness.

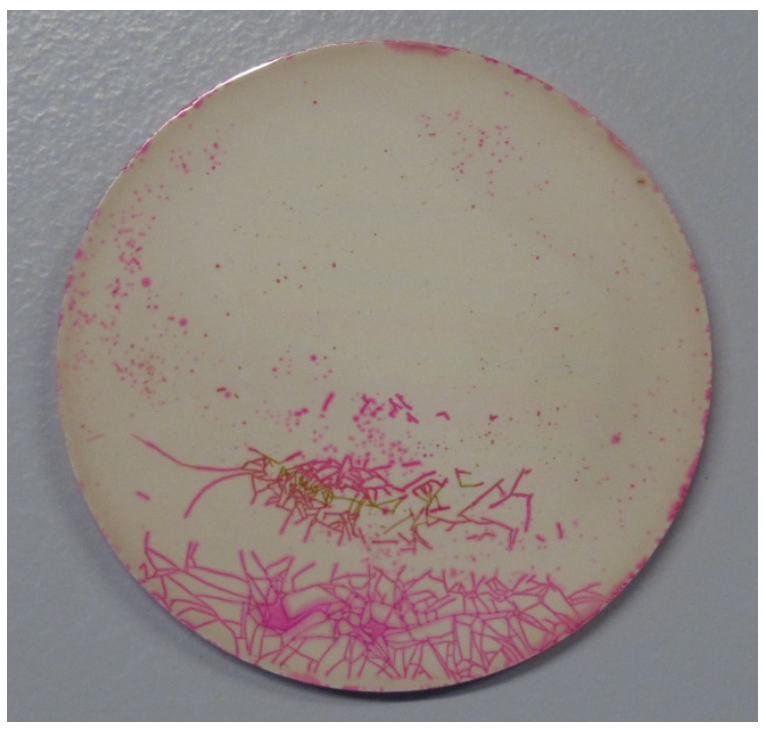

Figure 8.1: Rhodamine stained Zr-BTESE membrane with a thickness of $330 \mathrm{~nm}$ after calcination. Rhodamine is applied on the Zr-BTESE, which does not adsorb on $\mathrm{Zr-BTESE}$, but does so on alumina. It is therefore an excellent way to visualize defects in membranes 


\subsection{Reflections on hydrothermal stability}

In chapter 5 the complete membrane system is assessed on hydrothermal stability. It is shown that $\gamma$-alumina can be protected from hydrothermal degradation by applying a BTESE coating. However, such a hydrothermal treatment has a negative influence on the adherence between the several layers. Comparison of the fractured surfaces of untreated and hydrothermally treated BTESE-supported membranes show a difference at the interface between the $\gamma$-alumina and BTESE layer. Figure 5.5 clearly shows delamination of the surface layer. Further delamination was observed as well during SEM imaging, where the layers were delaminated due the electrostatic interaction caused by charge buildup in the electron microscope. Although no composition changes were observed by EDX it is still possible that partly a phase transformation of $\gamma$-alumina to boehmite or bayerite has occurred during the hydrothermal treatment. In order to confirm these phase transformations, one should extract the intermediate layer material from the multilayered membrane and perform XRD analysis, which would be very elaborate. Another method to prove these phase transformations is by performing a long-term hydrothermal treatment to confirm whether or not the $\gamma$-alumina is fully converted to boehmite or bayerite. The current hypothesis for BTESE detachment is therefore as follows: during hydrothermal treatment the $\gamma$-alumina expands due to transformations caused by the hydrolytic attack which force the BTESE layer to expand as well. The flexibility of the BTESE layer allows this expansion and hence prevents fracturing of the layer. However due to the stresses at the interface between $\gamma$-alumina and BTESE the adhesion between these layers is severely weakened.

The hydrothermal tests above boiling water, at relative low temperature $\left(100^{\circ} \mathrm{C}\right)$ and high humidity $(>95 \%)$, have shown to be a good screening tool for the study of the hydrothermal stability of the studied membranes. The tests are severe enough to deteriorate $\gamma$-alumina and silica membranes, while the test equipment is very simple. However, due to the occurrence of condensation these tests are not representative for real-world conditions, where condensation should and can be prevented by proper process control. Therefore these tests should be considered as an easy-to-use initial screening tool, after which more elaborate hydrothermal tests can be performed.

In chapter 6 the simple hydrothermal stability tests as performed in chapter 5 on BTESE membranes were extended to include pure silica (TEOS-derived) membranes and Zr-BTESE membranes. Also the stability tests were expanded to higher temperatures in a simulated syngas 
atmosphere. The higher temperature tests showed that although BTESE does not show degradation at $400{ }^{\circ} \mathrm{C}$ in TGA measurements in inert atmosphere $\left(\mathrm{N}_{2}\right)$, a prolonged exposure to $400{ }^{\circ} \mathrm{C}$ in a syngas atmosphere can result in a degradation of the BTESE and Zr-BTESE membranes. These results show the importance of testing under conditions where impurities such as oxygen are present to determine the actual temperature limit of such materials, rather than the theoretical one under perfect conditions. After a hydrothermal treatment of Zr-BTESE at $300{ }^{\circ} \mathrm{C}$ a decline in helium and hydrogen permeance is observed, while this was not the case for undoped BTESE. This decline in permeance of the small gases for Zr-BTESE is indicative for network densification. Another remarkable result obtained after this hydrothermal treatment of $\mathrm{Zr}$-BTESE is the strong increase in $\mathrm{H}_{2} / \mathrm{CO}_{2}$ permselectivity (from 12 to 35), while no change in permselectivity is found for undoped BTESE in Chapter 5 after performing this hydrothermal treatment. It is hypothesized that due to water chemisorption the acidity of the Zr-BTESE surface is altered. In zirconia doped MCM-41 catalyst is shown that Lewis sites that are present in the catalyst can be converted to Brønsted sites by steam treatment [9]. It is expected that these Lewis sites are also present in Zr-BTESE, as mixed oxides often show Lewis sites due to a charge imbalance between species [10]. Therefore it also possible in Zr-BTESE that Brønsted acid sites can be formed during hydrothermal treatment, leading to a lower affinity towards $\mathrm{CO}_{2}$, which in combination with network densification leads to a selectivity increase.

\subsection{Reflections on measurement techniques}

It became evident from the results, as described in chapter 4, that it was not possible to reproduce the results of the Nb-BTESE membranes as measured by Qi et al. [11,12]. In order to find the reason why these results could not be reproduced, a cooperation was set up between the Inorganic Membranes group of the University of Twente (Twente) and the Membrane Science and Technology Research Center of the Nanjing University of Technology (Nanjing).

In order to assess the differences in the results, two sets of Nb-BTESE membranes were prepared, one in Twente and the other in Nanjing. Both sets of membranes were measured in Twente, as well as in Nanjing. For both sets of membranes $\alpha$-alumina supports with a $\gamma$-alumina intermediate layer were prepared in Twente to rule out any differences in support quality and properties. The procedure for the preparation of Nb-BTESE membranes was exactly followed as described by Qi et al. [11]. Therefore, no differences were observed in membrane preparation. 

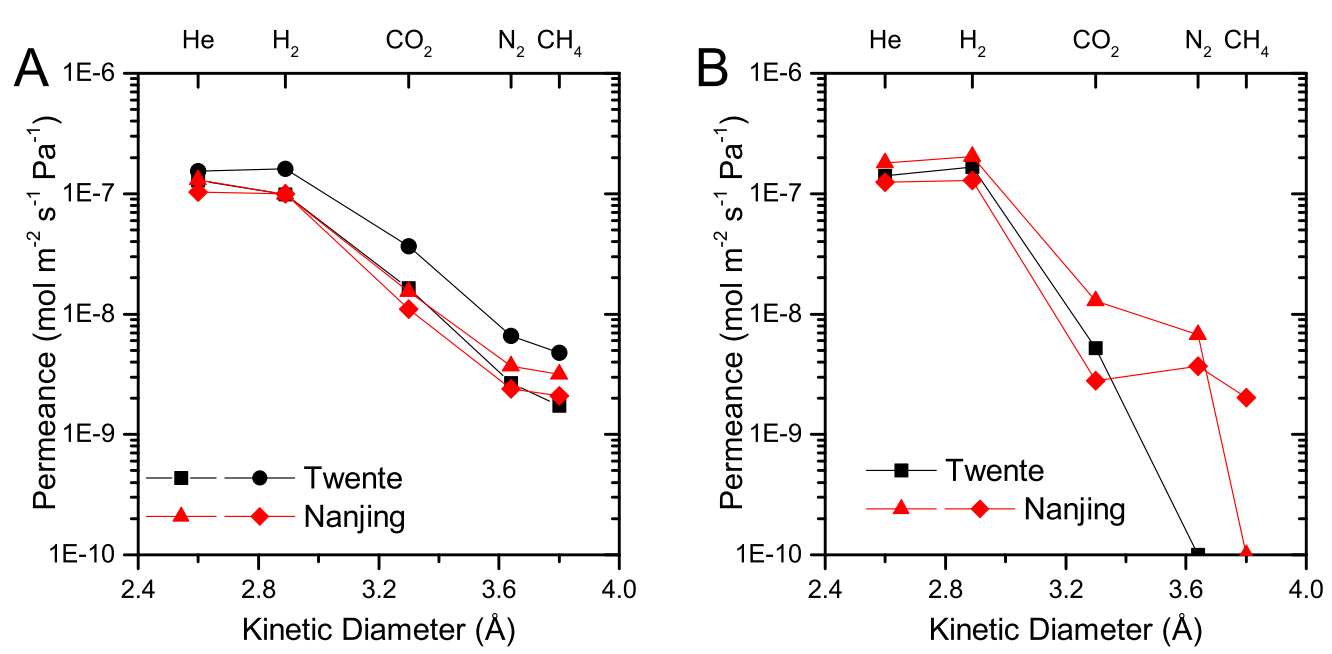

Figure 8.2: Single gas permeation measurements of Nb-BTESE-450 membranes prepared in Twente and Nanjing. A: measurements performed in Twente, B: measurements performed in Nanjing. The different symbols represent an individual membrane that is measured both in Twente and Nanjing The black symbols represent membranes prepared in Twente, the red symbols represent membranes prepared in Nanjing. Note that one of the membranes, prepared in Twente, was not measured in Nanjing

The main differences however were found in the gas permeation measurement setup. In Twente a setup is used as described in chapter 2 of this thesis which has the possibility to flush the membrane cell and has steel tubing and thermal mass flow meters that cover a broad range of flows. The setup in Nanjing used steel tubing on the feed side of the membrane, however on the permeate side flexible silicone rubber tubing is used to connect the setup to a single soap bubble meter with a volume of $50 \mathrm{~mL}$. These differences in measurement setup are reflected back in the gas permeation measurements, as shown in Figure 8.2. The permeation results of helium and hydrogen are fairly similar between the membranes and between the setups. Besides, all four membranes show an identical permeance behavior when measured on the setup in Twente (Figure 8.2A). This indicates a high degree of reproducibility for the four membranes studied. However, the measurements performed on the setup in Nanjing (Figure 8.2B) show a large spread in permeance behavior, especially for nitrogen and methane and to a lesser extend for carbon dioxide. For carbon dioxide a consistent lower permeance value is observed in Nanjing as compared to the values measured in Twente. 
The fluctuations in the results, as obtained by the equipment in Nanjing, are mainly caused by the way the permeation volume as function of time is measured, which is in this case a single soap bubble meter. In a soap bubble meter gas is passed through a soap solution to create bubbles that travel through a gas burette. The time between marks, that correspond to a gas volume, is measured to calculate the flow rate. In Nanjing a single soap bubble meter with a volume of $50 \mathrm{~mL}$ is used, which has a readout error of $0.2 \mathrm{~mL}$. Therefore, a permeation volume of $5 \mathrm{~mL}$ must be used in order to reduce the error in the flow to $4 \%$. This is viable for permeation measurements of helium and hydrogen, where the average flow was above $10 \mathrm{~mL} / \mathrm{min}$. However, this it is not recommended for the bigger gases $\left(\mathrm{CO}_{2}, \mathrm{~N}_{2}\right.$ and $\left.\mathrm{CH}_{4}\right)$, where gas flows of less than $1 \mathrm{~mL} / \mathrm{min}$ were observed. For these small flows a measurement time of more than 5 minutes and up to 25 minutes are necessary for achieving a permeation volume of $5 \mathrm{~mL}$. These long measuring times can introduce several errors. One of the errors is the diffusion of gases through the soap bubble [13], especially when there is a gradient due to insufficient flushing of the soap bubble meter. This diffusion is highest for carbon dioxide because the high solubility and reactivity of carbon dioxide in water.

Besides the large fluctuations due to the soap bubble meter consistently lower permeance values for carbon dioxide were observed in Nanjing as compared to Twente. These lower permeance values are possibly caused by the silicone tubing that is used between the membrane and the soap bubble meter. It is known that silicone is highly permeable for carbon dioxide [14] and therefore it is possible that part of the carbon dioxide that has passed the membrane is permeated through the silicone tubing, resulting in a lower measured permeate flow.

Therefore, it is questionable whether the setup as used in Nanjing is suitable for measuring gas permeation properties of highly selective membrane materials, especially when a single flow meter for a wide range of flows is used. Also it is questionable, whether in general the use of a soap bubble meter is accurate enough for measuring $\mathrm{CO}_{2}$ permeance.

\subsection{Perspectives}

Zirconium doped BTESE, prepared by a one-step synthesis with zirconyl nitrate as a precursor, is shown to be an interesting platform for further development of a WGS-MR. However, to fully unlock the potential of this membrane, a better understanding of the influence of zirconia on the permeability behavior should be obtained. Two questions remain yet unanswered: first of all 
it is unknown how is the zirconia incorporated in the hybrid silica matrix. Secondly, it is unclear how the reduced carbon dioxide permeance, observed after hydrothermal treatment for Zr-BTESE, occurs and what the role of water under hydrothermal conditions is on this reduction in $\mathrm{CO}_{2}$ permeance.

The incorporation of zirconia in the hybrid silica matrix is still not known. No crystalline phase was observed with XRD, even after calcination at $600{ }^{\circ} \mathrm{C}$. XPS measurements were performed, however no conclusive results were obtained. Transmission electron microscopy (TEM) and small angle $\mathrm{x}$-ray scattering (SAXS) can give further insight for the case whether or not small clusters are present. In literature it was shown that TEM and SAXS revealed small niobia clusters in Nb-BTESE, which acted as nucleation points for gel formation [3]. Also FTIR and EXAFS measurements are able to provide more insight in the incorporation of zirconia in the hybrid silica matrix.

The synthesis of the Zr-BTESE membranes can be optimized as well. For undoped BTESE it was shown by Castricum et al. [15] that by lowering the acid concentration a more dense structure can be obtained with a decreased nitrogen and methane permeation, while the helium, hydrogen and carbon dioxide permeation remained unaltered. However, Zr-BTESE shows already a higher $\mathrm{H}_{2} / \mathrm{CO}_{2}$ selectivity as compared to undoped BTESE. The expectation is that lowering the acid ratio during the Zr-BTESE sol-gel synthesis will lead to a further increase in $\mathrm{H}_{2} / \mathrm{CO}_{2}$ selectivity. With these alterations the goal of a $\mathrm{H}_{2} / \mathrm{CO}_{2}$ selectivity of 50 , as set in the introduction of this thesis, could be within reach.

The most important result of the hydrothermal treatment of Zr-BTESE is the relative strong reduction in carbon dioxide permeance after hydrothermal treatment. Especially the increase in $\mathrm{H}_{2} / \mathrm{CO}_{2}$ selectivity of 12 to 32 is very interesting. It is assumed that a change in affinity takes place toward $\mathrm{CO}_{2}$ due to the chemisorption of water on zirconia. The chemisorption of water results in an increase in the number of zirconia hydroxyl groups, which might change the acidity of the material. In order to fully confirm this hypothesis, the amount and nature of acidic sites need to be analyzed. Temperature programmed desorption of ammonia $\left(\mathrm{NH}_{3}\right.$-TPD) can be used to assess the concentration of acidic sites [9, 12], while FTIR and Raman with a base probe molecule like pyridine can provide knowledge on whether it is Brønsted or Lewis acidity [16].

During a step-wise hydrothermal treatment of Zr-BTESE an initial drop in hydrogen permeance was observed, which was stabilized within two hours. The drop is hydrogen permeance was from 144 
$1.4 \times 10^{-7} \mathrm{~mol} \mathrm{~m}^{-2} \mathrm{~s}^{-1} \mathrm{~Pa}^{-1}$ to $0.9 \times 10^{-7} \mathrm{~mol} \mathrm{~m}^{-2} \mathrm{~s}^{-1} \mathrm{~Pa}^{-1}$, which is a hydrogen permeance reduction of $35 \%$. Instead of firing the membranes in a dry atmosphere one could use steam-firing. Steam firing would densify the material during firing, which would decrease the permeance drop observed during hydrothermal treatment. Furthermore, steam-firing would already convert the Lewis acid sites to Brønsted ones, which would increase the $\mathrm{H}_{2} / \mathrm{CO}_{2}$ selectivity.

In this thesis only single-gas permeation measurements are discussed. However, to get a better understanding of the performance of the membranes under WGS conditions, it is of great importance to understand the influence of a mixture of hydrogen, carbon dioxide and water on their respective permeances. For example, it is shown for mixed gas measurements of cobaltdoped silica that a lower hydrogen permeance and lower $\mathrm{H}_{2} / \mathrm{CO}_{2}$ selectivity are observed for mixed gas conditions in comparison with single gas conditions [17]. However, the measurement of mixed gas permeation is not trivial, as a number of parameters like feed composition, flow rate, recovery and pressure have influence on the outcome of the results [18]. Besides, the flow patterns in measurement cells for planar membranes are complex. The flow patterns in measurement cells for tubular membranes are better known. Therefore it is preferred to use tubular membranes for mixed gas permeation measurements. Furthermore, when no sweep is used for gas separation it can be difficult to measure the selectivity of the membrane since the separation is often governed by the feed/permeate pressure ratio, rather than by the actual membrane performance [19], because of the low operating pressure used in experimental setups.

Although the microporous separation layer is of great importance for the actual separation, the underlying support and intermediate layers are of equal importance, as these will ensure a proper functioning of the membrane system under operating conditions. In chapter 5, phosphate modification of $\gamma$-alumina is discussed which increases the hydrothermal stability of the intermediate layer at low temperatures. Here mono aluminum phosphate (MAP) was applied as a separate coating on the $\alpha$-alumina before applying a $\gamma$-alumina layer. In that case the phosphate migrated into the $\gamma$-alumina intermediate layer during the calcination step. This method is suboptimal as a gradient in phosphate concentration was observed. It would be more beneficial to introduce the phosphorus into the boehmite sol prior to coating, to obtain a well dispersed phosphorus doping in $\gamma$-alumina.

The targets, set in the introductory chapter (Chapter 1) of this thesis, were a hydrothermally stable membrane with hydrogen permeance of $1.5 \times 10^{-6} \mathrm{~mol} \mathrm{~m}^{-2} \mathrm{~Pa}^{-1} \mathrm{~s}^{-1}$ and a $\mathrm{H}_{2} / \mathrm{CO}_{2}$ 
selectivity of 60 . It is shown that a phosphorus doped $\gamma$-alumina intermediate layer and a Zr-BTESE separation layer is hydrothermally stable. Although the permeance and selectivity targets were not reached, it is shown that zirconia doping is a successful method to increase the $\mathrm{H}_{2} / \mathrm{CO}_{2}$ selectivity of hybrid silica. By further optimization of the sol-gel synthesis and coating conditions of a Zr-BTESE membrane on phosphorus doped $\gamma$-alumina intermediate layer the set targets may be reached.

\subsection{References}

[1] K. Yoshida, Y. Hirano, H. Fujii, T. Tsuru, M. Asaeda, Hydrothermal stability and performance of silicazirconia membranes for hydrogen separation in hydrothermal conditions, Journal of Chemical Engineering of Japan, 34 (2001) 523-530.

[2] V. Boffa, J.E. ten Elshof, A.V. Petukhov, D.H. Blank, Microporous niobia-silica membrane with very low CO2 permeability, ChemSusChem, 1 (2008) 437-443.

[3] R. Besselink, T.M. Stawski, H.L. Castricum, J.E. Ten Elshof, Evolution of microstructure in mixed niobia-hybrid silica thin films from sol-gel precursors, J Colloid Interface Sci, 404 (2013) 24-35.

[4] H.F. Qureshi, R. Besselink, J.E. ten Elshof, A. Nijmeijer, L. Winnubst, Doped microporous hybrid silica membranes for gas separation, Journal of Sol-Gel Science and Technology, 75 (2015) 180-188.

[5] N. Itoh, S. Watanabe, K. Kawasoe, T. Sato, T. Tsuji, A membrane reactor for hydrogen storage and transport system using cyclohexane-methylcyclohexane mixtures, Desalination, 234 (2008) 261-269.

[6] T. Niimi, H. Nagasawa, M. Kanezashi, T. Yoshioka, K. Ito, T. Tsuru, Preparation of BTESE-derived organosilica membranes for catalytic membrane reactors of methylcyclohexane dehydrogenation, Journal of Membrane Science, 455 (2014) 375-383.

[7] H.F. Qureshi, A. Nijmeijer, L. Winnubst, Influence of sol-gel process parameters on the micro-structure and performance of hybrid silica membranes, Journal of Membrane Science, 446 (2013) 19-25.

[8] E.J. Kappert, D. Pavlenko, J. Malzbender, A. Nijmeijer, N.E. Benes, P.A. Tsai, Formation and prevention of fractures in sol-gel-derived thin films, Soft Matter, 11 (2015) 882-888.

[9] C. García-Sancho, R. Moreno-Tost, J. Mérida-Robles, J. Santamaría-González, A. Jiménez-López, P. Maireles-Torres, Zirconium doped mesoporous silica catalysts for dehydration of glycerol to high addedvalue products, Applied Catalysis A: General, 433-434 (2012) 179-187.

[10] J.A. Anderson, C.A. Fergusson, Surface and bulk properties of silica-zirconia mixed-oxides: acid vs base catalysed condensation, Journal of Non-Crystalline Solids, 246 (1999) 177-188.

[11] H. Qi, J. Han, N. Xu, H.J. Bouwmeester, Hybrid organic-inorganic microporous membranes with high hydrothermal stability for the separation of carbon dioxide, ChemSusChem, 3 (2010) 1375-1378.

[12] H. Qi, J. Han, N.P. Xu, Effect of calcination temperature on carbon dioxide separation properties of a novel microporous hybrid silica membrane, Journal of Membrane Science, 382 (2011) 231-237.

[13] H.M. Princen, S.G. Mason, The permeability of soap films to gases, Journal of Colloid Science, 20 (1965) 353-375.

[14] S.M. Jordan, W.J. Koros, G.K. Fleming, The effects of CO2 exposure on pure and mixed gas permeation behavior: comparison of glassy polycarbonate and silicone rubber, Journal of Membrane Science, 30 (1987) 191-212.

[15] H.L. Castricum, H.F. Qureshi, A. Nijmeijer, L. Winnubst, Hybrid silica membranes with enhanced hydrogen and CO2 separation properties, Journal of Membrane Science, 488 (2015) 121-128.

[16] G. Busca, Spectroscopic characterization of the acid properties of metal oxide catalysts, Catalysis Today, 41 (1998) 191-206.

[17] S. Battersby, S. Smart, B. Ladewig, S. Liu, M.C. Duke, V. Rudolph, J.C.D.d. Costa, Hydrothermal stability of cobalt silica membranes in a water gas shift membrane reactor, Separation and Purification Technology, 66 (2009) 299-305. 
[18] S. Battersby, T. Tasaki, S. Smart, B. Ladewig, S. Liu, M.C. Duke, V. Rudolph, J.C. Diniz da Costa, Performance of cobalt silica membranes in gas mixture separation, Journal of Membrane Science, 329 (2009) 91-98.

[19] Y. Huang, T.C. Merkel, R.W. Baker, Pressure ratio and its impact on membrane gas separation processes, Journal of Membrane Science, 463 (2014) 33-40. 



\section{Summary}

The research, as described in this thesis, is carried out within the cluster "Catalysis, Membranes and Separations" (CMS) of ADEM (A green Deal in Energy Materials), which is funded by the Dutch ministry of economic affairs. The ADEM program aims to materialize innovations in energy technologies in close collaboration with industry. In the CMS cluster the focus is on material development for technologies that can mitigate the effects of carbon dioxide. By understanding the structure-property relationship of the materials it is possible to gain insight in the performance of such materials under process conditions. The focus of this thesis is on the development of a hydrothermally stable microporous membrane that can be used in a water gas shift membrane reactor concept for pre-combustion carbon capture.

In the introductory Chapter $\mathbf{1}$ a brief overview on the different strategies for carbon capture is presented. A more detailed description is given on pre-combustion carbon capture and the water gas shift membrane reactor is described more in detail as the subject of interest. In order to provide a rationale for the choice of hydrogen separation membranes as investigated in the work described in this thesis, a brief overview on hydrogen separation membranes for a water gas shift membrane reactor is provided. The chapter is concluded with the aim and outline of the thesis.

The theoretical background on the preparation and characterization of sol-gel derived microporous membranes is discussed in Chapter 2. The preparation of the multi-layered structure and critical manufacturing parameters for gas separation membranes are discussed in detail. Furthermore, critical assessments are performed on the characterization techniques used throughout the different preparation steps of a multi-layered sol-gel derived gas separation membrane as well as on the gas permeation measurements on these membranes.

A sol-gel synthesis method for zirconium doped 1,2-bis(triethoxysilyl)ethane (Zr-BTESE) using zirconyl nitrate as a zirconium precursor is reported in Chapter 3. By using zirconyl nitrate, a one-step synthesis could be performed, with which a homogenous sol could be obtained by careful control of the sol-gel processing parameters. By tuning the concentration for the dipcoating sol defect free membranes could be obtained. These defect free membranes showed in comparison to undoped BTESE a reduction in hydrogen permeance from $4.4 \times 10^{-7}$ to $1.8 \times 10^{-7}$ 
mol m $\mathrm{m}^{-2} \mathrm{~s}^{-1} \mathrm{~Pa}^{-1}$. However, a large increase in $\mathrm{H}_{2} / \mathrm{CO}_{2}$ permselectivity is obtained, which went from 4 till 16. This shows that zirconia doping is effective for pore size reduction in BTESE.

In order to obtain a better insight on the parameters and the type of metal doping that define the influence of metal doping in BTESE on the gas permeation properties, a one-step synthesis method for yttrium and zirconium doping and a two-step synthesis method for zirconium and niobium doping are discussed in Chapter 4. A two-step synthesis method using zirconium and niobium alkoxides does not lead to a significant improvement in $\mathrm{H}_{2} / \mathrm{CO}_{2}$ permselectivity, which is caused by the difficulty to control the prehydrolysis step of BTESE. A one-step nitrate based approach is able to produce a membrane with an increased $\mathrm{H}_{2} / \mathrm{CO}_{2}$ permselectivity for zirconium, while for yttria a lower selectivity but higher hydrogen permeance is obtained.

In order to assess the hydrothermal stability of the multilayered membrane a systematic approach was used in Chapter 5. A $\gamma$-alumina and a phosphorus doped $\gamma$-alumina intermediate layer were used in hydrothermal testing to confirm their stability. It was shown that by using relative mild conditions of $100{ }^{\circ} \mathrm{C}$ and a saturated water vapor $\gamma$-alumina was destroyed by this hydrothermal treatment within 72 hours, while phosphorus doped $\gamma$-alumina remained intact. The $\gamma$-alumina intermediate layers were tested with a BTESE coating on top as well. Detachment between the $\gamma$-alumina intermediate layer and BTESE was observed, but the gas permeation/permselectivity did not show any sign of degradation.

The hydrothermal stability tests as mentioned in the previous chapter were expanded in Chapter 6 to silica membranes and Zr-BTESE membranes, where a degradation of the silica membrane was confirmed. Zr-BTESE on the other hand showed a further increase in $\mathrm{H}_{2} / \mathrm{CO}_{2}$ permselectivity after hydrothermal treatment, which is not observed for BTESE. Further hydrothermal treatment tests were performed at higher temperatures under a gas atmosphere that mimics water gas shift conditions, which showed that the maximum operating temperature of BTESE and Zr-BTESE membranes is below $400{ }^{\circ} \mathrm{C}$. A step-wise hydrothermal treatment on Zr-BTESE at $200{ }^{\circ} \mathrm{C}$ shows that the permeance values stabilize within two hours of hydrothermal treatment and are comparable with the ex-situ tests that were performed for 72 hours.

The field of sol-gel derived membranes for gas separation is not new. In Chapter 7 the current status and limitations of silica and hybrid silica membranes are discussed in terms of gas permeation properties and hydrothermal stability to analyze the limited commercial 150 
development. Furthermore the areas that require attention for further commercialization are discussed.

Finally, in Chapter $\mathbf{8}$ the results, described in this thesis are reflected and a perspective is given with suggestions for further research. 



\section{Samenvatting}

Het onderzoek, zoals beschreven in dit proefschrift, is uitgevoerd binnen het cluster "Catalysis, Membranes and Separations" (CMS) van ADEM (A green Deal in Energy Materials), gefinancierd door het Ministerie van economische zaken. Het doel van het ADEM programma is om, in nauwe samenwerking met de industrie, innovaties in energie technologieën te bewerkstelligen. De focus binnen het CMS cluster ligt op materiaalonderzoek om de gevolgen van $\mathrm{CO}_{2}$ te beperken. Door begrip te krijgen van de relaties tussen structuur en eigenschappen van materialen is het mogelijk om inzicht te krijgen in de werking van deze materialen onder proces condities. De nadruk van dit proefschrift ligt op de ontwikkeling van hydrothermaal stabiele microporeuze membranen die gebruikt kunnen worden in een water-gas-shift membraan reactor concept voor de afvang van $\mathrm{CO}_{2}$ voor verbranding.

In het inleidende Hoofdstuk 1 wordt een kort overzicht gegeven van de verschillende methoden voor $\mathrm{CO}_{2}$ afvang. Er wordt in meer detail gekeken naar $\mathrm{CO}_{2}$ afvang voor verbranding en specifiek naar een water-gas-shift membraan reactor. Een kort overzicht van verschillende membranen voor waterstof scheiding in een water-gas-shift membraan reactor is gegeven om de keuze van het type membraan voor waterstof scheiding dat onderzocht is in deze thesis te onderbouwen. Het hoofdstuk wordt afgesloten met het doel en de hoofdlijnen voor dit proefschrift.

De theoretische achtergrond voor de bereiding en karakterisering van op sol-gel gebaseerde microporeuze membranen wordt bediscussieerd in Hoofdstuk 2. De bereiding van een multilaag structuur en kritieke productie parameters voor gasscheiding membranen worden in detail bediscussieerd. Verder wordt er met een kritische blik gekeken naar de karakteriseringtechnieken die worden gebruikt in de verschillende bereidingsstappen van een multilaags sol-gel gebaseerd gasscheidingsmembraan, alsmede de gaspermeatiemetingen van zulke membranen.

In Hoofdstuk 3 wordt een synthese methode voor zirkoon gedoteerd 1,2-bis(triethoxysilyl)ethaan (Zr-BTESE) gerapporteerd, waarbij gebruik wordt gemaakt van zirconyl nitraat als zirkoon precursor. Door gebruik te maken van zirconyl nitraat kan een eenstapsynthese worden gebruikt, waarmee een homogene sol kan worden verkregen door goed 
de sol-gel bereiding te controleren. Door de dip-sol concentratie te optimaliseren kan een defectvrij membraan verkregen worden. Deze defect vrije membranen laten in vergelijking met ongedoteerd BTESE een reductie zien in waterstof permeatie van $4.4 \times 10^{-7}$ naar $1.8 \times 10^{-7}$ mol $\mathrm{m}^{-2} \mathrm{~s}^{-1} \mathrm{~Pa}^{-1}$. Echter is er een grote toename in $\mathrm{H}_{2} / \mathrm{CO}_{2}$ permselectiviteit verkregen, welke van 4 naar 16 is gegaan. Dit laat zien dat het doteren met zirkoon een positief effect heeft op de reductie van de porie grootte in BTESE.

Om een beter inzicht te krijgen in welke parameters en welke typen metalen van belang zijn voor het beïnvloeden van het gaspermeatie gedrag van BTESE membranen is er een eenstapsynthese met yttrium en zirkoon dotering en een tweestapsynthese met zirkoon en niobium dotering beschreven in Hoofdstuk 4. Het gebruik van een tweestapsynthese leidt niet tot een significante verbetering in $\mathrm{H}_{2} / \mathrm{CO}_{2}$ permselectiviteit, wat te herleiden is tot de prehydrolyse stap die moeilijk te controleren is. Een eenstapsynthese met een metaal nitraat leidt tot een membraan met een hogere $\mathrm{H}_{2} / \mathrm{CO}_{2}$ permselectiviteit in het geval van zirkoon dotering, maar tot een lagere permselectiviteit maar hogere waterstof permeatie in het geval van yttria dotering.

Om de hydrothermale stabiliteit van het multilaags systeem te beoordelen is een systematische aanpak gebruikt in Hoofdstuk 5. Een $\gamma$-alumina en fosfor gedoteerd $\gamma$-alumina membraan werden onderworpen aan een hydothermale test om de stabiliteit de bevestigen. Met het gebruik van relatief milde omstandigheden van $100{ }^{\circ} \mathrm{C}$ en verzadigde waterdamp werd aangetoond dat $\gamma$-alumina kapot gaat na 72 uur, terwijl fosfor gedoteerd $\gamma$-alumina intact blijft. Beide tussenlagen werden ook hydrothermaal getest met een BTESE toplaag. Er werd aangetoond dat de BTESE losliet van de $\gamma$-alumina laag, maar dat er geen tekenen waren van degradatie op het gebied van permeatie en permselectiviteit.

De hydrothermale tests als beschreven in het vorige hoofdstuk werden verder uitgebreid in Hoofdstuk 6 met silica en Zr-BTESE membranen, waarmee degradatie van de silica membranen werd bevestigd. Zr-BTESE laat anderzijds zien dat er een toename is van $\mathrm{H}_{2} / \mathrm{CO}_{2}$ selectiviteit na de hydrothermale test, wat niet wordt gezien in BTESE. Verdere testen werden uitgevoerd op hogere temperaturen met een gasmengsel dat gelijkend is aan water-gas-shift condities, waarmee werd aangetoond dat de maximale temperatuur waarop BTESE en Zr-BTESE membranen kunnen werken onder de $400{ }^{\circ} \mathrm{C}$ ligt. Een stapsgewijze hydrothermale test van Zr-BTESE op $200{ }^{\circ} \mathrm{C}$ laat zien dat de permeatiewaarden binnen twee uur van 
hydrothermale behandeling stabiliseren op dezelfde waarden die gemeten werden met ex-situ testen van 72 uur.

Sol-gel gebaseerde membranen voor gasscheiding zijn niet nieuw. In Hoofdstuk 7 wordt de huidige status en limiteringen van silica en hybride silica membranen besproken op het gebied van gaspermeatie en hydrothermale stabiliteit. Dit om te analyseren waarom er weinig commerciële ontwikkeling is op dit gebied. De gebieden die zorg nodig hebben voor het verder commercialiseren van dit soort membranen wordt bediscussieerd.

Als laatste wordt er in Hoofdstuk $\mathbf{8}$ teruggeblikt op de resultaten die beschreven zijn in dit proefschrift. Er wordt vooruitgekeken met suggesties voor vervolgonderzoek. 



\section{Dankwoord}

Uiteindelijk is het er toch van gekomen dat mijn proefschrift af is. Allereerst wil ik Louis bedanken voor de prettige samenwerking tijdens het onderzoek en tijdens het schrijven. Ik heb altijd erg genoten van jouw enthousiasme voor het onderzoek, waar we vaak lang over konden brainstormen tijdens de meetings. Je hebt mij voldoende vrijheden gegeven in het doen van het onderzoek, maar er wel voor gezorgd dat het een consistent verhaal is geworden. Ik waardeer vooral jouw hulp en geduld met het schrijven van het proefschrift. Het is wel gebleken dat schrijven niet mijn sterkste punt is, maar met jouw hulp is het toch nog een mooi proefschrift geworden.

Als tweede wil ik Arian bedanken voor het aanbieden van de promotieplek in Inorganic Membranes binnen het ADEM project. Het onderzoek was echt gericht op een toepassing, wat mij zeer aansprak. Jouw input en ervaring hebben mij enorm geholpen. Ik ben erg blij dat je me de mogelijkheid hebt gegeven om onderzoek te doen in Nanjing, wat een zeer interessante ervaring was op persoonlijk vlak. Het is echter jammer dat de resultaten daarvan niet in hoge mate zijn teruggekomen in het proefschrift, al heeft het ons wel geholpen om richting te kiezen in het vervolgonderzoek. Ik waardeer jouw input in het onderzoek en ben ook zeer blij met de snelle respons die ik kreeg als ik jou wat toestuurde.

Henny, bedankt voor de constructieve feedback en de connecties met Helmholtz Alliance MEM-BRAIN, waardoor ik waardevolle input en testresultaten heb kunnen verkrijgen. Nieck, bedankt voor de wetenschappelijke discussies. Ook had er zonder jouw hulp niet een goede setup gestaan voor het meten van de gaspermeatie.

Susanne, bedankt voor al het regelwerk en het plannen van de afspraken, wat vaak al een behoorlijke uitdaging is. Mieke, bedankt je inzet als AMC voor de veiligheid op het lab en voor het toevertrouwen van de boehmiet synthese aan mij. Cindy, bedankt dat je mij de fijne kneepjes van de sol-synthese en het membraan coaten hebt geleerd. Frank, bedankt voor het helpen met het bouwen en aansluiten van opstellingen. Ik ben blij dat je er vertrouwen in had om mij te laten bouwen. Ik heb er een hoop van geleerd en heeft mij een hoop praktische ervaring opgeleverd. 
Ik had het plezier om een aantal studenten te begeleiden tijdens mijn promotie. Mark, heel erg bedankt voor jouw nieuwsgierigheid en inzet, wat ervoor gezorgd heeft dat we een mooie stap konden maken met Zr-BTESE. Leon en Rik, ondanks dat jullie werk niet is opgenomen in deze thesis wil ik jullie heel erg bedanken voor de inzet en het enthousiasme. Dion, jouw werk is grotendeels terecht gekomen in hoofdstuk 5 en wil je bedanken voor al het werk dat je daarvoor hebt gedaan. Annie, thanks for all the hard work that you have put in making some nice membranes during your internship.

To avoid missing a name I would like to thank all former and present members of IM for the nice work environment. I really liked the jokes that were pulled off, even if I was the victim. I also liked the scientific discussions in the office, which is in my opinion a huge plus for having an open plan office. Also the coffee breaks were fun and therefore I would also like to thank all former and present members of SFI and MST.

Emiel, ik heb heel veel plezier gehad in samenwerken met jou. Jouw enthousiasme voor onderzoek werkt zeer aanstekelijk. We zijn samen tot genoeg wilde ideeën gekomen voor onderzoek, al zijn de meeste ook bij ideeën gebleven. Ook hebben we veel plezier samen beleefd op de verschillende winter- en summerschools. Bas, ik heb veel bewondering voor jouw doorzettingsvermogen. Ik heb ook veel plezier beleeft aan de koffiepauzes waarbij de serieuze gesprekken net zo makkelijk overgingen in luchtige gesprekken. Bas en Emiel, ik ben blij dat jullie beiden mijn paranimf willen zijn.

Furthermore I would like to thank my colleagues at Eurekite. Gerard, thanks for giving me the opportunity to work in a startup. Bahruz, Bas, Pavel, Roger, Ruta, Max, Umit and Ties, thanks for the enjoyable work atmosphere and the foosball matches.

Verder wil ik Peter en Maartje bedanken voor de gezellige avondjes, waardoor ik mijn gedachten even niet bij het promoveren of schrijven hoefde te hebben. Peter, vooral het squashen is vaak een goede afleiding geweest om even lekker het hoofd leeg te maken.

Ik wil mijn familie bedanken voor de ondersteuning in de afgelopen tijd. Het is niet altijd makkelijk om te begrijpen wat promoveren inhoudt en ben daarom blij dat jullie begrip en interesse hebben getoond. Met het afronden van dit proefschrift kan ik een lange, maar ook mooie tijd op de universiteit afronden. 
Als laatste wil ik mijn vrouw Milou bedanken. Bedankt voor alle ondersteuning die je mij hebt gegeven, wat niet altijd makkelijk was, ook omdat je zelf druk bezig was met schrijven. Uiteindelijk is 2016 is een goed jaar geworden: een bruiloft, twee promoties en allebei een fantastische baan bij een startup. Ik hou van je en hoop dat we samen een rooskleurige toekomst tegemoet gaan. 